\title{
Geld- und Vermögensanlage
}

\section{Anleihen}

\subsection{Ausstattung von Anleihen}

\begin{tabular}{|c|c|}
\hline Laufzeit & $\begin{array}{l}\text { Es ist der Zeitraum zwischen den in den Anleihebedingungen genannten } \\
\text { Verzinsungsbeginn und der Fälligkeit der Anleihe. } \\
\text { Kurzfristige Laufzeit: bis zu } 4 \text { Jahre } \\
\text { Mittelfristige Laufzeit: } 4 \text { bis } 8 \text { Jahre } \\
\text { Langfristige Laufzeit: mehr als } 8 \text { Jahre } \\
\text { Ewige Anleihen: keine festgelegte Laufzeit }\end{array}$ \\
\hline Verzinsung & $\begin{array}{l}\text { Festzinsanleihen: fester Nominalzins über die gesamte Laufzeit } \\
\text { Variabel verzinsliche Anleihen: Sie gewähren einen variablen Zinser- } \\
\text { trag, der für jede Zinsperiode gültige Zinssatz wird auf der Grundlage } \\
\text { eines Referenzzinssatzes, z. B. EURIBOR jeweils neu festgesetzt. } \\
\text { Zerobonds: Keine Zinszahlung während der Laufzeit. Der Zinsertrag } \\
\text { ergibt sich aus der Differenz zwischen Rückzahlungskurs und Emissions- } \\
\text { kurs, einmalige Zinszahlung bei Fälligkeit der Schuldverschreibung. }\end{array}$ \\
\hline Zinszahlung & Zinszahlung kann jährlich oder halbjährlich erfolgen. \\
\hline $\begin{array}{l}\text { Rückzahlungs } \\
\text { modalitäten }\end{array}$ & $\begin{array}{l}\text { Tilgungsanleihen: } \\
\text { Der Anleihebetrag wird über die Laufzeit der Anleihe verteilt in Teilbeträ- } \\
\text { gen zurückgezahlt. Die Tilgung erfolgt durch Auslosung von Serien bzw. } \\
\text { Endziffern oder Rückkauf an der Börse. } \\
\text { Gesamtfällige Anleihen: } \\
\text { Der gesamte Anleihebetrag wird am Ende der Laufzeit in einer Summe } \\
\text { zurückgezahlt. } \\
\text { Ewige Anleihen: } \\
\text { Diese Anleihen müssen nicht zurückgezahlt werden. Emittent kann die } \\
\text { Anleihe nach Ablauf einer Festzinsperiode durch Kündigung zur Rück- } \\
\text { zahlung fällig stellen. } \\
\text { Rückzahlung durch Kündigung der Anleihegläubiger (Anleger): } \\
\text { Eine Kündigung durch den Anleihegläubiger wird in den Anleihebedin- } \\
\text { gungen i. d. R. ausgeschlossen. Die Anleihegläubiger können die Anlei- } \\
\text { hen allerdings über die Börse verkaufen. } \\
\text { Kündigung durch den Emittenten: } \\
\text { Das Kündigungsrecht kann in den Anleihebedingungen vereinbart wer- } \\
\text { den. Eine Kündigung kann dann zweckmäßig sein, wenn der Nominalzins } \\
\text { der Anleihe höher ist als der aktuelle Marktzins. }\end{array}$ \\
\hline Sicherh & $\begin{array}{l}\text { Sie hängt von der Bonität des Emittenten ab. } \\
\text { Mündelsichere und deckungsstockfähige Wertpapiere sprechen für eine } \\
\text { gute Bonität des Emittenten. }\end{array}$ \\
\hline
\end{tabular}




\subsection{Bundeswertpapiere - Übersicht}

\begin{tabular}{|c|c|c|}
\hline Merkmale & Bundesanleihen & Bundesobligationen \\
\hline Emissionsrhythmus & Einmalemission & Daueremission \\
\hline Emissionsverfahren & \multicolumn{2}{|c|}{$\begin{array}{l}\text { Tenderverfahren } \\
\text { (nur Mitglieder der Bietergruppe Bundesemissionen) }\end{array}$} \\
\hline Börsenhandel & \multicolumn{2}{|c|}{ Handel an allen deutschen Wertpapierbörsen } \\
\hline $\begin{array}{l}\text { Mindestauftrags- } \\
\text { größe }\end{array}$ & \multicolumn{2}{|c|}{ Mindestauftragswert der Kreditinstitute } \\
\hline Anlagehöchstbetrag & \multicolumn{2}{|l|}{ unbeschränkt } \\
\hline Zinszahlung & \multicolumn{2}{|l|}{ jährlich nachträglich } \\
\hline Zinsmethode & \multicolumn{2}{|l|}{ taggenau (actual/actual) } \\
\hline Laufzeit & $\begin{array}{l}\text { - Neuemissionen: } \\
\text { überwiegend } 10 \text { Jahre } \\
\text { - börsennotierte Titel: } \\
\text { ca. } 1 \text { Monat bis unter } 30 \text { Jahre }\end{array}$ & $\begin{array}{l}\text { - Neuemissionen: } \\
5 \text { Jahre } \\
\text { - börsennotierte Titel: } \\
\text { ca. } 1 \text { Monat bis unter } \\
\text { 5 Jahre }\end{array}$ \\
\hline Rückzahlung & \multicolumn{2}{|l|}{ zum Nennwert } \\
\hline Erwerber & \multicolumn{2}{|l|}{ jedermann } \\
\hline $\begin{array}{l}\text { Verkauf bzw. } \\
\text { vorzeitige Rückgabe }\end{array}$ & \multicolumn{2}{|c|}{$\begin{array}{l}\text { nach Börseneinführung täglicher Verkauf zum Börsenkurs; bei au- } \\
\text { Berbörslichem Verkauf über die Deutsche Finanzagentur unter Ab } \\
\text { zug einer Gebühr von } 0,4 \text { \% vom Kurswert }\end{array}$} \\
\hline Verkaufsstellen & \multicolumn{2}{|l|}{ Kreditinstitute } \\
\hline $\begin{array}{l}\text { Verwahrung/ } \\
\text { Verwaltung }\end{array}$ & \multicolumn{2}{|l|}{ Kreditinstitute } \\
\hline $\begin{array}{l}\text { Kosten } \\
\text { Erwerb ex Emission: } \\
\text { Einlösung bei } \\
\text { Fälligkeit: } \\
\text { Verwaltung: }\end{array}$ & \multicolumn{2}{|c|}{$\begin{array}{l}\text { übliche Provision } \\
\text { gebührenfrei bei der Deutschen Finanzagentur } \\
\text { - Depotgebühren bei Kreditinstituten } \\
\text { - gebührenfrei bei der Deutschen Finanzagentur }\end{array}$} \\
\hline
\end{tabular}




\subsection{Pfandbriefe}

\begin{tabular}{|l|l|}
\hline Wesen & $\begin{array}{l}\text { Pfandbriefe sind von Pfandbriefbanken ausgegebene, gedeckte } \\
\text { Schuldverschreibungen. }\end{array}$ \\
\hline Arten & $\begin{array}{l}\text { - Hypothekenpfandbriefe } \\
\text { - Öffentliche Pfandbriefe } \\
\text { - Schiffspfandbriefe }\end{array}$ \\
\hline $\begin{array}{l}\text { Voraussetzungen } \\
\text { für die Erlaubnis } \\
\text { zur Emission von } \\
\text { Pfandbriefen }\end{array}$ & $\begin{array}{l}\text { - Mindestkernkapital des Kreditinstituts beträgt } 25 \text { Millionen EUR. } \\
\text { - Verfügung über geeignete Risikomanagementsysteme für die De- } \\
\text { ckungsmassen und das Emissionsgeschäft } \\
\text { - regelmäßige und nachhaltige Betreibung des Pfandbriefgeschäfts } \\
\text { - Bestehen eines organisatorischen Rahmens }\end{array}$ \\
\hline Rechte des & $\begin{array}{l}\text { - Zinsertrag } \\
\text { Anlegers }\end{array}$ \\
\hline Rückzahlung \\
- Insolvenzvorrecht \\
- Deckungsregister: Die zur Deckung der Pfandbriefe verwendeten \\
merkmale
\end{tabular}


1.4 Risiken bei festverzinslichen Wertpapieren

\begin{tabular}{|c|c|c|}
\hline Bonitätsrisiko & $\begin{array}{l}\text { Zinsänderungs- und Wäh- } \\
\text { rungsrisiko }\end{array}$ & $\begin{array}{l}\text { Kündigungs- und Auslo- } \\
\text { sungsrisiko }\end{array}$ \\
\hline $\begin{array}{l}\text { - Gefahr der Zahlungsunfä- } \\
\text { higkeit des Anleiheschuld- } \\
\text { ners } \\
\text { - Das Bonitätsrisiko ist abhän- } \\
\text { gig von der Laufzeit der An- } \\
\text { leihe und der Anleihewäh- } \\
\text { rung. } \\
\text { - Das Bonitätsrisiko schlägt } \\
\text { sich im Kurs und in der Ren- } \\
\text { dite der Anleihe nieder. Erst- } \\
\text { klassige Schuldner begeben } \\
\text { ihre Anleihen mit niedrige- } \\
\text { rem Nominalzins. Emittenten } \\
\text { mit niedriger Bonitätsein- } \\
\text { schätzung begeben ihre An- } \\
\text { leihen mit höheren Renditen, } \\
\text { die aber auch höhere Risi- } \\
\text { ken bergen. }\end{array}$ & $\begin{array}{l}\text { - Das Zinsänderungsrisiko } \\
\text { ergibt sich aus der unge- } \\
\text { wissen zukünftigen Zins- } \\
\text { entwicklung. Steigt der } \\
\text { Marktzins, wirkt sich das } \\
\text { Zinsänderungsrisiko } \\
\text { durch Kursverluste aus. } \\
\text { Die Zinsreagibilität ist um- } \\
\text { so höher, je niedriger der } \\
\text { Zinssatz und je länger die } \\
\text { Restlaufzeit ist. } \\
\text { - Fremdwährungsanleihen } \\
\text { haben ein zusätzliches } \\
\text { Währungsrisiko. }\end{array}$ & $\begin{array}{l}\text { - Das Kündigungsrisiko be- } \\
\text { steht in der Gefahr, dass der } \\
\text { Anleihegläubiger bei sinken- } \\
\text { den Marktzinsen mit einer } \\
\text { Kündigung der Emission } \\
\text { durch den Anleiheschuldner } \\
\text { rechnen muss. Durch die } \\
\text { Kündigung kann der Anlei- } \\
\text { heschuldner seine Zinslast } \\
\text { senken. Voraussetzung ist } \\
\text { eine Kündigungsklausel in } \\
\text { den Anleihebedingungen. } \\
\text { - Das Auslosungsrisiko ist die } \\
\text { Gefahr bei Auslosungsanlei- } \\
\text { hen, dass eine frühzeitige } \\
\text { Auslosung bei vorgegebener } \\
\text { Renditeerwartung zu einem } \\
\text { Renditeverlust führen kann. }\end{array}$ \\
\hline
\end{tabular}

1.5 Nominalverzinsung und Rendite bei festverzinslichen Wertpapieren

\begin{tabular}{|c|c|}
\hline Nominalverzinsung & Rendite \\
\hline $\begin{array}{l}\text { Die Nominalverzinsung stellt } \\
\text { den verbrieften jährlichen } \\
\text { Zinsanspruch, bezogen auf } \\
\text { den Nennwert, dar. }\end{array}$ & $\begin{array}{l}\text { Die Rendite drückt den durchschnittlichen jährlichen Kapi- } \\
\text { talertrag einer Kapitalanlage, unter Berücksichtigung der } \\
\text { Rückzahlungsgewinne bzw. Rückzahlungsverluste, im Ver- } \\
\text { hältnis zum tatsächlich eingesetzten Kapital aus. }\end{array}$ \\
\hline $\begin{array}{l}\text { Beispiel für eine Nominal- } \\
\text { verzinsung der Unterneh- } \\
\text { mensanleihe der Stahlwerke } \\
\text { Witten AG } \\
\text { - Nominalverzinsung: } 7 \% \\
\text { - } \% \text {. a. } \\
\text { - } \quad \text { Zällig: } 03.11 .2023 \\
\text { - } \quad \text { Aktueller Kurs: } 108,9 \% \\
\text { - Jährliche Zinszahlung bei } \\
\text { einem Anlagebetrag von } \\
\text { 5.000,00 EUR, Nennwert: } \\
\text { 350,00 EUR }\end{array}$ & $\begin{array}{l}\text { Beispiel für eine Renditeberechnung bei der Unterneh- } \\
\text { mensanleihe der Stahlwerke Witten AG } \\
\text { - Nominalverzinsung: } 7 \% \text { p. a. } \\
\text { - } \quad \text { Fällig: } 03.11 .2023 \\
\text { - Zinstermin: } 03.11 . \text { gzj. } \\
\text { - } \quad \text { Aktueller Erwerbskurs: } 108,9 \% \\
\text { - Restlaufzeit: } 3 \text { Jahre } \\
\text { - Rückzahlungswert: } 100 \% \text { Nennwert } \\
\text { Berechnung der Rendite: } \\
\qquad P_{\text {eff }}=\frac{\left[P_{n o m+}\left(\frac{R_{k}-E_{k}}{J}\right)\right]}{E_{k}} * 100 \\
\text { Formel: } \\
(7+((100-108,9): 3): 108,9) \times 100=(7-2,97): \\
108,9 \times 100=4,03: 108,9 \times 100=3,7 \%\end{array}$ \\
\hline
\end{tabular}




\subsection{Stückzinsberechnung}

\section{Stückzinsberechnung}

Beim Erwerb einer Anleihe zahlt der Käufer neben dem Kurswert auch die aufgelaufenen Stückzinsen an den Veräußerer. Bei einem Erwerb muss der Käufer dem Verkäufer die anteiligen Stückzinsen vom Beginn des Zinslaufs bis zum Kauf erstatten.

Geldvaluta: Börsengeschäfte werden zwei Börsentage nach dem Abschluss des Kaufvertrages abgerechnet.

Stückzinsvaluta: Der Stückzinsvalutatag ist der Kalendertag vor dem Geldvalutatag.

\section{Beispiel 1: Ermittlung der Geld- und Zinsvaluta}

Handelstag: Mittwoch, 14.10.2020

+2 Börsentage $=$ Freitag, 16.10.2020 (= Geldvaluta $)$

- 1 Kalendertag = Donnerstag, 15.10.2020 (= Zinsvaluta)

\section{Beispiel 2: Ermittlung der Geld- und Zinsvaluta}

Handelstag: Donnerstag, 15.10.2020

+2 Börsentage $=$ Montag, 19.10.2020 (= Geldvaluta)

- 1 Kalendertag = Sonntag, 18.10.2020 (= Zinsvaluta)

\section{Beispiel 3: Stückzinsberechnung beim Verkauf einer Anleihe}

Handelstag: Freitag, 16.10.2020

Nominal $10.000,00$ EUR

Zinssatz: $4,25 \%$

Zinstermine: 10.10. gzj.

Laufzeit: bis 2023

\begin{tabular}{|l|r|}
\hline Geldvaluta & 20.10 .2020 \\
\hline Zinsvaluta & 19.10 .2020 \\
\hline Zinsen für 10 Tage vom 10.10 .2020 & \\
einschließlich bis 19.10 .2020 einschließlich & \\
$10.000,00 \times 10 \times 4,25:(365 \times 100)=$ & $\mathbf{1 1 , 6 4}$ EUR \\
\hline
\end{tabular}

\subsection{Effektivzinsberechnung}

\section{Rendite}

Die Effektivverzinsung (Rendite) ist der Anlageertrag bezogen auf eine Anlagedauer von einem Jahr und einem Kapitaleinsatz von 100,00 EUR.

Formel: $\quad P_{\text {eff }}=\frac{\left[P_{\text {nom }}+\left(\frac{R_{k}-E_{k}}{J}\right)\right]}{E_{k}} * 100$

$\mathrm{P}_{\text {eff }}=$ Effektivverzinsung

$\mathrm{P}_{\text {nom }}=$ Nominalverzinsung

$\mathrm{J}=$ Anlagedauer in Jahren

$E_{k}=$ Erwerbskurs

$R_{k}=$ Rückzahlungskurs

Beispiel einer Renditeberechnung für eine Industrieanleihe

Nennwert: 10.000,00 EUR

Restlaufzeit: 10 Jahre 
Nominalverzinsung: $5,5 \%$

Erwerb bei einem Kapitalmarktzinsniveau von $6 \%$

Erwerbskurs: $104,56 \%$

Jahreskupon, Zinsen sind jährlich zahlbar

$P_{\text {eff }}=(5,5+(100-104,56): 10): 104,56 \times 100=4,824 \%$

\subsection{Floating Rate Notes}

\begin{tabular}{|c|c|}
\hline Wesen & $\begin{array}{l}\text { Floating Rate Notes (Floater) sind eine Anleihe, bei der der Zinssatz } \\
\text { viertel- oder halbjährlich im Voraus unter Bezug auf einen Referenz- } \\
\text { zinssatz des Geldmarktes (z. B. EURIBOR) zuzüglich eines Aufschlags } \\
\text { oder abzüglich eines Abschlags festgelegt wird. Die Höhe des Auf- oder } \\
\text { Abschlags richtet sich nach der Bonität des Emittenten, der Laufzeit der } \\
\text { Anleihe sowie der Marktlage. Sie wird bei Emission für die gesamte } \\
\text { Laufzeit festgelegt. Floater werden am Euro-Kapitalmarkt und mit Bin- } \\
\text { dung an den EURIBOR am deutschen Kapitalmarkt emittiert. Da der } \\
\text { Zinssatz variabel ist, wird eine Verbindung zwischen Geld- und Kapi- } \\
\text { talmarkt hergestellt. }\end{array}$ \\
\hline Laufzeit & i. d. R. 5 bis 10 Jahre \\
\hline $\begin{array}{l}\text { Kündigungs- } \\
\text { möglichkeit }\end{array}$ & $\begin{array}{l}\text { Ein Kündigungsrecht des Schuldners während der Laufzeit ist üblich, z. } \\
\text { B. Kündigung zu Zinszahlungsterminen oder zu jedem Termin. }\end{array}$ \\
\hline $\begin{array}{l}\text { Unterschiede zu } \\
\text { den } \\
\text { festverzinslichen } \\
\text { Wertpapieren }\end{array}$ & $\begin{array}{l}\text { - variabler Zinssatz } \\
\text { - Geldmarktausrichtung des Zinssatzes } \\
\text { - größere Häufigkeit der Zinszahlung }\end{array}$ \\
\hline Emittenten & $\begin{array}{l}\text { Kreditinstitute, Unternehmen, Regierungen und supranationale Organi- } \\
\text { sationen }\end{array}$ \\
\hline Zinssatz & $\begin{array}{l}\text { Der Zinssatz ist variabel und liegt meist unter dem Kapitalmarktzins- } \\
\text { satz. }\end{array}$ \\
\hline Vorteile & $\begin{array}{l}\text { - Der Schuldner profitiert von einem evtl. fallenden Zinsniveau. Der } \\
\text { Schuldner trägt das aber Zinsänderungsrisiko. } \\
\text { - Werden Floater von Kreditinstituten emittiert, so können diese hiermit } \\
\text { langfristig zugesagte, zinsvariable Darlehen refinanzieren und damit } \\
\text { eine entsprechende Konditionengestaltung vornehmen. } \\
\text { - Ein Anleger kann aufgrund der unterjährigen Zinszahlungen bei einer } \\
\text { Wiederanlage der Zinserträge einen Zinseszinseffekt erzielen. }\end{array}$ \\
\hline Anleger & überwiegend Banken \\
\hline Liquidität & $\begin{array}{l}\text { Erstklassige Floater sind sehr liquide, soweit ein funktionsfähiger Se- } \\
\text { kundärmarkt existiert. }\end{array}$ \\
\hline Risiken & $\begin{array}{l}\text { - Das Kursrisiko ist begrenzt. Es kommt bei einwandfreier Bonität des } \\
\text { Schuldners nur zu geringen Abweichungen vom Nennwert, da die } \\
\text { Zinssätze in relativ kurzen Zeitabständen den aktuellen Geldmarkt- } \\
\text { konditionen angepasst werden. } \\
\text { - Ist der Schuldner nicht in der Lage, steigende Zinsen zu zahlen, so } \\
\text { erhöht sich das Bonitätsrisiko für den Anleger. }\end{array}$ \\
\hline
\end{tabular}




\section{Beispiel für einen Floater}

Ein Kunde erteilt der Nordbank AG am 27. November (Mittwoch) die Order zum Kauf von nominal 20.000,00 EUR der folgenden Anleihe:

Nordhypothekenbank AG variabel verzinster öffentlicher Pfandbrief Serie 03/20..

Zinstermine: vierteljährlich 10. März/Juni/September/Dezember (act/360)

Zinssatz: 3-Monats-Euribor am 5. des Monats der Zinszahlung + 0,5 Prozentpunkte

Fälligkeit: Dezember 20..

Aktueller Börsenpreis: 98,2 \%

Am 5. September des Jahres betrug der 3-Monats-Euribor 0,9\%.

Ermittlung des ausmachenden Betrags, den der Kunde zu zahlen hat:

\begin{tabular}{|l|r|}
\hline Kurswert 98,2 \% von 20.000,00 EUR & $19.640,00$ EUR \\
\hline $\begin{array}{l}\text { + Stückzinsen für } 80 \text { Tage } \\
(20.000 \times 80 \times 1,4):(360 \times 100)\end{array}$ & 62,22 EUR \\
\hline$=$ ausmachender Betrag & $\mathbf{1 9 . 7 0 2 , 2 2 ~ E U R ~}$ \\
\hline
\end{tabular}

Ermittlung der Zinszahlung am 10. Dezember des Jahres:

Zinsen für 91 Tage bei einem Anlagebetrag von 20.000,00 EUR

$(20.000 \times 91 \times 1,4):(360 \times 100)$

70,78 EUR 


\section{Aktien}

\subsection{Aktionärsrechte, Aktienarten, Aktienregister und Aktienrückkauf}

\begin{tabular}{|c|c|}
\hline Aktionärsrechte & $\begin{array}{l}\text { - Teilnahme an der Hauptversammlung } \\
\text { - Stimmrecht in der Hauptversammlung } \\
\text { - Recht auf Gewinnbeteiligung } \\
\text { - Anspruch auf Auskunft durch den Vorstand } \\
\text { - Angabe der Bezüge des Vorstands } \\
\text { - Bezugsrecht zum Bezug z. B. junger Aktien bei einer Kapitalerhöhung } \\
\text { - Anspruch auf Teilnahme am Liquidationserlös }\end{array}$ \\
\hline Stammaktie & $\begin{array}{l}\text { Aktie, die dem Inhaber die normalen Aktionärsrechte laut Aktiengesetz } \\
\text { gewährt }\end{array}$ \\
\hline Namensaktie & $\begin{array}{l}\text { Auf den Namen des Inhabers ausgestellte Aktien. Name, Wohnort und Be- } \\
\text { ruf des Inhabers müssen im Aktienregister der Gesellschaft eingetragen } \\
\text { werden. Namensaktien sind kraft Gesetzes Orderpapiere und können da- } \\
\text { her nur durch Indossament übertragen werden. Namensaktien bieten Ge- } \\
\text { sellschaften die Möglichkeit, ihren Aktionärskreis besser zu kennen und } \\
\text { einfacher mit den Aktionären direkt in Kontakt zu treten. }\end{array}$ \\
\hline \begin{tabular}{|l|} 
Vinkulierte \\
Namensaktie
\end{tabular} & $\begin{array}{l}\text { Sonderform der Namensaktie. Eine vinkulierte Namensaktie kann nur mit } \\
\text { Zustimmung der AG an einen neuen Eigentümer übertragen werden. Die } \\
\text { Vinkulierung von Namensaktien ist möglich, wenn die Satzung der Ge- } \\
\text { sellschaft dieses vorsieht, so z. B. bei Versicherungsgesellschaften, de- } \\
\text { ren Grundkapital nicht voll eingezahlt ist, oder bei Gesellschaften, die } \\
\text { sich vor Überfremdung schützen wollen. }\end{array}$ \\
\hline Vorzugsaktie & $\begin{array}{l}\text { Aktiengattung, der im Gegensatz zur Stammaktie das Stimmrecht fehlt. } \\
\text { Als Ausgleich dafür sind i. d. R. Vorrechte bei der Gewinnverteilung und } \\
\text { Abwicklung einer AG verbrieft. Eine AG kann neben Stammaktien auch } \\
\text { Vorzugsaktien emittieren, allerdings darf deren Anteil am Grundkapital } \\
\text { nicht höher sein als der Anteil der Stammaktien. Zu den Sonderrechten } \\
\text { von Vorzugsaktionären gehört meist eine höhere Dividende. }\end{array}$ \\
\hline $\begin{array}{l}\text { Berichtigungs- } \\
\text { aktie } \\
\text { (Gratisaktie) }\end{array}$ & $\begin{array}{l}\text { Aktie, die durch die Umwandlung von offenen Rücklagen in Grundkapital } \\
\text { entsteht und an die Aktionäre ohne Gegenleistung ausgegeben wird (§§ } \\
207 \text { bis } 220 \text { AktG). Die Bezeichnung „Gratisaktien“ ist irreführend, weil } \\
\text { der Aktionär bereits vor dem reinen Passivtausch an den Rücklagen } \\
\text { durch seinen Aktienbesitz beteiligt war. Für den Aktionär ändert sich da- } \\
\text { her der Wert seiner Beteiligung nicht, obwohl die Aktie um den Berichti- } \\
\text { gungsabschlag leichter wird. }\end{array}$ \\
\hline Aktienanleihe & $\begin{array}{l}\text { Die Aktienanleihe wird auch Reverse Convertible Bond genannt. Sie ist } \\
\text { eine Anleihe mit i. d. R. relativ kurzer Laufzeit. Der Schuldner hat bei diesem } \\
\text { Wertpapier das Recht, die Anleihe am Ende der Laufzeit wahlweise zu } \\
100 \% \text { oder durch Lieferung einer vorher festgelegten Zahl einer bestimm- } \\
\text { ten Aktie zurückzahlen zu können. Da der Anleger bei einer Aktienanleihe } \\
\text { dabei das Risiko übernimmt, dass die Aktien zum Rückzahlungszeitpunkt } \\
\text { der Anleihe insgesamt einen Wert ergeben, der unter dem Anleihewert } \\
\text { liegt, wird eine Aktienanleihe höher verzinst als eine „normale“ Anleihe. }\end{array}$ \\
\hline
\end{tabular}




\begin{tabular}{|c|c|}
\hline Aktienregister & $\begin{array}{l}\text { Das Aktienregister ist ein Register, das von Aktiengesellschaften geführt } \\
\text { wird, die Namensaktien oder Zwischenscheine emittieren. Während Inha- } \\
\text { beraktien formlos durch bloße Einigung und Übergabe übertragen werden } \\
\text { können (§§ } 929 \text { ff. BGB), gehören Namensaktien und Zwischenscheine } \\
\text { zu den geborenen Orderpapieren, die zwecks Übertragung noch eines } \\
\text { Indossaments bedürfen. Die Sonderform der vinkulierten Namensaktien } \\
\text { macht deren Übertragung von der Zustimmung der Aktiengesellschaft ab- } \\
\text { hängig, wodurch zur Übertragung eine Zession erforderlich wird. } \\
\text { Namensaktien und Zwischenscheine erfordern die Führung eines Aktien- } \\
\text { registers durch die Aktiengesellschaft, sodass neben Indossament/Zession } \\
\text { auch das Aktienregister die Verkehrsfähigkeit dieser Aktienarten behindert. } \\
\text { In § } 67 \text { Abs. } 1 \text { AktG wird bestimmt, dass die Inhaber von Namensaktien zur } \\
\text { Eintragung ins Aktienregister Namen, Geburtsdatum, Beruf und Adresse } \\
\text { sowie die Stückzahl oder die Aktiennummer (bei Nennbetragsaktien den } \\
\text { Betrag) mitzuteilen haben. Die Eintragung ins Aktienregister ist für den kon- } \\
\text { stitutiven Rechtserwerb der Aktionärsrechte jedoch nicht notwendig, son- } \\
\text { dern dient lediglich der Legitimation gegenüber der Gesellschaft. } \\
\text { Das Aktienregister dient der Gesellschaft zur sicheren Identifikation des } \\
\text { Aktionärs und dazu, den Mitteilungspflichten gegenüber den Aktionären } \\
\text { nachkommen zu können. Das Aktienregister gibt die aktuelle Aktionärs- } \\
\text { struktur und deren Veränderungen wieder. Aktienregisterführer kann so- } \\
\text { wohl die Gesellschaft sein oder eine von ihr hiermit beauftragte Registrar- } \\
\text { gesellschaft. Diese führt dann das Aktienregister. Der Inhalt eines Aktien- } \\
\text { registers ist in § } 67 \text { Abs. } 1 \text { AktG abschließend aufgezählt. } \\
\text { Nach internationalem Recht sind ausländische Aktionäre überwiegend in } \\
\text { Nomineebeständen als Fremdbesitz ins Aktienregister eingetragen. Wäh- } \\
\text { rend inländische Namensaktionäre direkt durch die Depotbanken über das } \\
\text { zentrale System der Clearstream Banking an die Aktienregister gemeldet } \\
\text { werden, werden ausländische Aktionäre häufig über eine Bank als Inhabe- } \\
\text { rin eines sog. Omnibuskontos registriert. Damit wird in diesem Fall nur die } \\
\text { Bank als Aktionärin im Aktienregister eingetragen. }\end{array}$ \\
\hline Aktienrückkauf & $\begin{array}{l}\text { Es ist die Möglichkeit einer Aktiengesellschaft, eigene Aktien erwerben zu } \\
\text { können. Ein Aktienrückkauf kann z. B. sinnvoll sein, wenn er aus Grün- } \\
\text { den der Kurspflege notwendig erscheint, der Erschwerung einer Unter- } \\
\text { nehmensübernahme dient oder wenn die eigenen Aktien als Zahlungs- } \\
\text { mittel bei der Übernahme eines anderen Unternehmens verwendet wer- } \\
\text { den sollen. Auf der anderen Seite kann sich das Unternehmen dadurch, } \\
\text { dass es eigene Anteile erwirbt, teilweise der Kontrolle durch die Aktionäre } \\
\text { entziehen. Für den Aktienrückkauf gilt gemäß Aktiengesetz eine Ober- } \\
\text { grenze von } 10 \% \text { des Grundkapitals. }\end{array}$ \\
\hline
\end{tabular}




\subsection{Beispiel einer Tagesordnung der ordentlichen Hauptversammlung der Siemens AG Aktiengesellschaft am 5. Februar 2020}

1. Vorlage des festgestellten Jahresabschlusses und des gebilligten Konzernabschlusses ...

2. Beschlussfassung über die Verwendung des Bilanzgewinns der Siemens AG

3. Beschlussfassung über die Entlastung der Mitglieder des Vorstandes

4. Beschlussfassung über die Entlastung der Mitglieder des Aufsichtsrats

5. Beschlussfassung über die Bestellung des Abschlussprüfers und Konzernabschlussprüfers

6. Beschlussfassung über die Billigung des Vergütungssystems für die Vorstandsmitglieder

7. Beschlussfassung über die Ermächtigung zum Erwerb und zur Verwendung eigener Aktien gemäß § 71 Abs. 1 Aktiengesetz sowie zum Ausschluss des Bezugs- und des Andienungsrechts

8. Beschlussfassung über die Ermächtigung zum Einsatz von Derivaten im Rahmen des Erwerbs eigener Aktien nach $\S 71$ Abs. 1 Aktiengesetz sowie zum Ausschluss des Bezugsund des Andienungsrechts

9. Beschlussfassung über die Erteilung einer neuen Ermächtigung des Vorstands zur Begebung von Wandel- /Optionsschuldverschreibungen, zum Ausschluss des Bezugsrechts sowie über die Schaffung eines bedingten Kapitals 2020, die Aufhebung des Bedingten Kapitals 2015 und des Bedingten Kapitals 2010 und entsprechende Satzungsänderungen

10.Beschlussfassung über die Zustimmung zu einem Beherrschungs- und Gewinnabführungsvertrag zwischen der Siemens AG und einer Tochtergesellschaft

Auskunftsrecht gemäß $\S 131$ Abs. 1, § 293 Abs. 3 Aktiengesetz: In der Hauptversammlung kann jeder Aktionär oder Aktionärsvertreter vom Vorstand Auskunft verlangen über Angelegenheiten der Gesellschaft, die rechtlichen und geschäftlichen Beziehungen der Gesellschaft zu verbundenen Unternehmen sowie über die Lage des Konzerns und der in den Konzernabschluss einbezogenen Unternehmen, sowie die Auskunft zur sachgemäßen Beurteilung eines Gegenstands der Tagesordnung erforderlich ist. ...

\subsection{Allgemeines zu virtuellen Hauptversammlungen}

Der Gesetzgeber hat 2020 eine neue Regelung für die Teilnahme an Hauptversammlungen von Aktiengesellschaften erlassen. Das Aktiengesetz wurde von der Bundesregierung geändert. Es sind jetzt also virtuelle, beschlussfähige Hauptversammlungen möglich, auf denen Beschlüsse gefasst werden können. Die Präsenzpflicht bei Hauptversammlungen wurde aufgeweicht. Die Aktiengesellschaften brauchen dafür nicht ihre Satzung ändern. Die Einberufungsfrist wird von 30 auf 21 Tage verkürzt. Der Vorstand ist ermächtigt worden, auch ohne Satzungsregelung Abschlagszahlungen auf den Bilanzgewinn vorzunehmen. Zudem wurde die Möglichkeit eröffnet, eine Hauptversammlung innerhalb des Geschäftsjahres durchzuführen. Mit dieser Änderung des Aktienrechts will die Bundesregierung dem Unternehmen es ermöglichen, trotz des "Lockdowns“ in jeder Situation handlungsfähig zu bleiben. Zuletzt hatten mehrere deutsche große Konzerne wie Daimler oder die Deutsche Telekom ihr Aktionärstreffen auf einen späteren Zeitpunkt verschoben. Nach dem bisher geltenden Aktienrecht mussten sie aber bis spätestens acht Monate nach Ende des Geschäftsjahrs, also bis August eine Hauptversammlung durchführen. Nur dann konnten auch die Dividenden ausgezahlt werden. 


\subsection{Beispiel einer Einladung zu einer virtuellen Hauptversammlung der Krones AG vom 18.05.2020}

Angaben zur Einberufung der virtuellen Hauptversammlung (HV)

1. Gesamtzahl der Aktien und Stimmrechte

Das Grundkapital der Gesellschaft beträgt zum Zeitpunkt der Einberufung der HV EUR 40.000.000,00. Es ist eingeteilt in 31.593.072 Stückaktien. Jede Stückaktie gewährt in der HV eine Stimme. Die Gesellschaft hält keine eigenen Aktien.

2. Durchführung der HV als virtuelle HV ohne physische Präsenz der Aktionäre und ihrer Bevollmächtigten; Online-Service

Die ordentliche HV wird mit Zustimmung des Aufsichtsrats der Gesellschaft als virtuelle HV ohne physische Präsenz der Aktionäre und ihrer Bevollmächtigten (mit Ausnahme der von der Gesellschaft benannten Stimmrechtsvertreter) gemäß $\S 1$ Abs. 1 und Abs. 2 des Gesetzes über Maßnahmen im Gesellschafts-, Genossenschafts-, Vereins-, Stiftungs- und Wohnungseigentumsrecht zur Bekämpfung der Auswirkungen der COVID-19-Pandemie (Art. 2 des Gesetzes zur Abmilderung der Folgen der COVID-19-Pandemie im Zivil-, Insolvenz- und Strafverfahrensrecht ...) abgehalten. Die gesamte, in den Geschäftsräumen der Gesellschaft stattfindende, HV wird zu diesem Zweck ... über den Online-Service der Gesellschaft unter der Internetadresse www.krones.com/de über den Link „Unternehmen/Investor Relation/Hauptversammlung/2020" live in Bild und Ton übertragen. Es können nur diejenigen Aktionäre, die sich ... ordnungsgemäß angemeldet haben, die Bild- und Tonübertragung der gesamten HV über den Online-Service der Gesellschaft verfolgen. Darüber hinaus können Aktionäre persönlich ... ihr Stimmrecht per Briefwahl oder durch die Bevollmächtigung eines von der Gesellschaft benannten Stimmrechtsvertreters ausüben sowie über den Online-Service der Gesellschaft Fragen stellen und einen Widerspruch gegen Beschlüsse der HV erklären.

Eine darüber hinausgehende Ausübung von Aktionärsrechten ist in der virtuellen HV nicht möglich. Insbesondere ist eine Teilnahme der Aktionäre ..., mit Ausnahme der von der Gesellschaft benannten weisungsgebundenen Stimmrechtsvertreter, vor Ort ausgeschlossen. Die Übertragung der HV in Bild und Ton sowie die Einräumung des Stimmrechts sowie der Fragemöglichkeit und der Möglichkeit zum Widerspruch berechtigen die Aktionäre und Aktionärsvertreter auch nicht zur Teilnahme an der HV im Wege elektronischer Kommunikation im Sinne von § 18 Abs. Satz 2 AktG (keine elektronische Teilnahme).

3. ... Nach ordnungsgemäßen Anmeldung und des besonderen Nachweises des Anteilbesitzes bei der Gesellschaft werden den Aktionären - anstelle der herkömmlichen Eintrittskarten - Zugangskarten für den Online-Service der Gesellschaft mit persönlichen Zugangsdaten (Zugangskartennummer und Zugangscode) für die Ausübung der Aktionärsrechte in Bezug auf die virtuelle HV übermittelt.

4. Bedeutung des Nachweisstichtags

Der Nachweisstichtag (auch Record Date genannt) ist das entscheidende Datum für die Ausübung der Aktionärsrechte in Bezug auf die virtuelle HV. Im Verhältnis zur Gesellschaft gilt für die Ausübung der Aktionärsrechte insbesondere des Stimmrechts, in Bezug auf die virtuelle HV als Aktionär nur, wenn zum Nachweisstichtag Aktionär der Gesellschaft war und den Nachweis hierüber fristgerecht erbracht hat. Veränderungen im Aktienbestand nach diesem Zeitpunkt haben hierfür keine Bedeutung. ... Aktionäre, die sich ordnungsgemäß angemeldet und den Nachweis erbracht haben, sind auch dann zur Ausübung ihrer Aktionärsrechte in Bezug auf die virtuelle HV berechtigt, wenn sie die Aktien nach dem 
Nachweisstichtag veräußern. Der Nachweisstichtag hat keine Auswirkungen auf die Veräußerbarkeit der Aktien und ist kein relevantes Datum für eine eventuelle Dividendenberechtigung.

5. Verfahren für die Stimmabgabe durch Briefwahl

Aktionäre können ihr Stimmrecht in Textform ... oder im Wege elektronischer Kommunikation abgeben (Briefwahl). Hierzu ist eine ordnungsgemäße Anmeldung erforderlich. Das Briefwahlformular ist auf der Zugangskarte für den Online-Service der Gesellschaft, ... abgedruckt.

8. Fragemöglichkeit der Aktionäre ... Auskunftsrecht der Aktionäre ...

Ordnungsgemäß angemeldete Aktionäre haben die Möglichkeit, im Wege der elektronischen Kommunikation Fragen zu stellen ... Aus organisatorischen Gründen sind Fragen spätestens bis zum Ablauf des 16. Mai ... 24 Uhr ... einzureichen.

\subsection{Bezugsrechte}

\begin{tabular}{|c|c|}
\hline $\begin{array}{l}\text { Gesetzliches } \\
\text { Bezugsrecht }\end{array}$ & $\begin{array}{l}\text { Bei der Ausgabe junger Aktien steht den Aktionären aufgrund des Verwäs- } \\
\text { serungsschutzes ein gesetzliches Bezugsrecht zu. Das Bezugsverhältnis } \\
\text { ist das Verhältnis, in dem der Aktionär aufgrund des Bestandes an alten } \\
\text { Aktien neue Aktien beziehen kann (Anzahl alter Aktien dividiert durch die } \\
\text { Anzahl der jungen Aktien). } \\
\text { Der Bezugsrechtshandel dauert mindestens } 14 \text { Tage. Die beiden letzten } \\
\text { Tage der Bezugsfrist dienen der Erfüllung der am letzten Handelstag abge- } \\
\text { schlossenen Geschäfte. Mit Beginn des Bezugsrechtshandels notieren die } \\
\text { alten Aktien „ex Bezugsrecht“. }\end{array}$ \\
\hline \multirow[t]{7}{*}{$\begin{array}{l}\text { Ermittlung des } \\
\text { rechnerischen } \\
\text { Werts des } \\
\text { Bezugsrechts }\end{array}$} & $\begin{array}{l}\mathrm{B}=\mathrm{K}_{\mathrm{a}}-\mathrm{K}_{\mathrm{n}}:(\mathrm{m}: \mathrm{n}+1) \\
\mathrm{B}=\text { rechnerischer Wert des Bezugsrechts } \\
\mathrm{K}_{\mathrm{a}}=\text { Kurs der alten Aktien } \\
\mathrm{K}_{\mathrm{n}}=\text { Ausgabepreis der neuen Aktien } \\
\mathrm{m}: \mathrm{n}=\text { Bezugsverhältnis (= altes Kapital : Kapitalerhöhung) }\end{array}$ \\
\hline & $\begin{array}{l}\text { Beispiel für die Berechnung des rechnerischen Werts des } \\
\text { Bezugsrechts }\end{array}$ \\
\hline & $\begin{array}{l}\text { Kurs der alten Aktie: } 83 \text { EUR } \\
\text { altes Kapital: } 65 \text { Mio. EUR } \\
\text { Kapitalerhöhung: } 13 \text { Mio. EUR } \\
\text { Bezugspreis der jungen Aktie: } 50,00 \text { EUR } \\
\end{array}$ \\
\hline & $\mathrm{B}=(83-50):(5+1)=$ \\
\hline & $\begin{array}{l}\text { Wenn die neuen Aktien nicht voll dividendenberechtigt sind, muss die } \\
\text { Formel um den Dividendennachteil/Dividendenvorteil erweitert werden: } \\
\mathrm{B}=\mathrm{Ka}-(\mathrm{Kn}+/ \text { - Dividendennachteil/Dividendenvorteil }):(\mathrm{m}: \mathrm{n}+1)\end{array}$ \\
\hline & $\begin{array}{l}\text { Beispiel für die Berechnung des rechnerischen Werts des } \\
\text { Bezugsrechts mit Dividendennachteil }\end{array}$ \\
\hline & $\begin{array}{l}\text { Kurs der alten Aktie: } 83,00 \text { EUR } \\
\text { altes Kapital: } 65 \text { Mio. EUR } \\
\text { Kapitalerhöhung: } 13 \text { Mio. EUR } \\
\text { Bezugspreis der jungen Aktie: } 50,00 \text { EUR } \\
\text { Bardividende für die alten Aktien: } 0,80 \text { EUR } \\
\end{array}$ \\
\hline
\end{tabular}




\begin{tabular}{|c|c|c|}
\hline & \multicolumn{2}{|c|}{ Die jungen Aktien sind zu einem Viertel dividendenberechtigt. } \\
\hline & $B=(83,00-50-0,60):(5+1)=$ & 5,40 EUR \\
\hline $\begin{array}{l}\text { Kapital- } \\
\text { erhöhung aus } \\
\text { Gesellschafts- } \\
\text { mitteln }\end{array}$ & \multicolumn{2}{|c|}{$\begin{array}{l}\text { Bei der Kapitalerhöhung aus Gesellschaftsmitteln erhalten die Altaktionä- } \\
\text { re in einem bestimmten Verhältnis Berichtigungsaktien. Es fließen der AG } \\
\text { keine liquiden Mittel zu, da es sich hier um einen buchungstechnischen } \\
\text { Tausch auf der Passivseite der Bilanz handelt. Der Grund für die Kapital- } \\
\text { erhöhung liegt bei Aktien mit sehr hohem Börsenkurs vor allem darin, das } \\
\text { Vermögen der AG auf eine größere Zahl von Aktien zu verteilen, um so } \\
\text { den Kurs „leichter“ zu machen, womit die Aktie insbesondere für Kleinan- } \\
\text { leger interessanter wird. Durch die Ausgabe der Berichtigungsaktien än- } \\
\text { dert sich die Vermögensposition der Aktionäre trotz der Kurssenkung } \\
\text { nicht. } \\
\text { Beispiel: } \\
\text { Eine Aktiengesellschaft erhöht ihr Grundkapital von derzeit } 56 \text { Millionen } \\
\text { EUR durch die Auflösung von Rücklagen um 14 Millionen EUR auf dann } \\
70 \text { Millionen EUR im Verhältnis } 2: 1 \text {. Die alte Aktie notiert zurzeit mit } \\
\text { einem Kurs von } 120,00 \text { EUR. } \\
\text { Berechnung des Berichtigungsabschlags: } \\
\text { Berichtigungsabschlag = Kurs der alten Aktie : (Bezugsverhältnis + 1) } \\
40=120: 3 \\
\text { Der Kurs der alten Aktie wird um 40,00 EUR reduziert auf dann } 80,00 \\
\text { EUR. Der Aktionär erhält für zwei alte Aktien eine zusätzliche Berichti- } \\
\text { gungsaktie, die ihm in sein Depot gebucht wird. }\end{array}$} \\
\hline $\begin{array}{l}\text { Kapital- } \\
\text { herabsetzung }\end{array}$ & $\begin{array}{l}\text { Eine Kapitalherabsetzung ist eine V } \\
\text { ternehmens durch Gesellschafterbe } \\
\text { findet meist dann statt, wenn das Ur } \\
\text { auszugleichen. Voraussetzung ist ei } \\
\text { qualifizierter Mehrheit zu beschließe } \\
\text { nominellen Kapitalherabsetzung ist } \\
\text { durch Anpassung des festgelegten } \\
\text { reduzierte Gesellschaftsvermögen. } \\
\text { Eine Kapitalherabsetzung kann durc } \\
\text { die durch die zwangsweise Einzieh } \\
\text { werb eigener Aktien durch die Gese } \\
\text { Eintragung ins Handelsregister gilt o } \\
\text { Beispiel einer Kapitalherabsetzun } \\
\text { Der Solaranlagenbauer Solarcity AC } \\
\text { der Hälfte seines Grundkapitals von } \\
\text { Kapitalschnitt im Verhältnis von } 8: 1 \\
\text { werden. } \\
\text { Ein Depotkunde, der z. B. } 800 \text { Aktie } \\
\text { hatte, erhält nach der Kapitalherabs } \\
\text { larcity AG-Aktien } 100 \text { Stück neue Sc }\end{array}$ & $\begin{array}{l}\text { eines Un- } \\
\text { setzung } \\
\text {, Verluste } \\
\text { llung mit } \\
\text { weck einer } \\
\text { rbilanz } \\
\text { h Verluste } \\
\text { eschehen, } \\
\text { den Er- } \\
\text { mit der } \\
\text { gesetzt. } \\
\text { Verlust } \\
\text { sollte ein } \\
\text { urchgeführt } \\
\text { alten So- }\end{array}$ \\
\hline
\end{tabular}




\begin{tabular}{|l|l|}
\hline Bezugsrechts- & In der letzten Zeit waren Bezugsrechtsemissionen für deutsche Börsen- \\
unternehmen die wichtigste Möglichkeit zur Eigenkapitalzufuhr. Primär \\
wurden sie zur Refinanzierung, Verbesserung von Bilanzrelationen und \\
zur Beibehaltung von Rating-Bewertungen genutzt (z. B. Volkswagen, \\
Continental, Heidelberg Cement, Infineon, Deutsche Wohnen), daneben \\
auch, um M\&A-Transaktionen und zukünftiges Wachstum zu finanzieren \\
(z. B. Volkswagen, K+S, Klöckner \& Co., Rhön-Klinikum). \\
Für die Wahl der Bezugsrechtsemission sprechen mehrere Gründe: Bei \\
der von Unternehmen angestrebten Zufuhr neuer Liquidität kommt nur \\
eine Barkapitalerhöhung in Frage, und bei dieser kann das gesetzliche \\
Bezugsrecht der Aktionäre nur bis zu einem Emissionsvolumen von ma- \\
ximal 10\% des bestehenden Grundkapitals ausgeschlossen werden. \\
Daher bleibt in aller Regel nur die Bezugsrechtsemission, wenn der Li- \\
quiditätsbedarf diese Grenze überschreitet. \\
Darüber hinaus sind Bezugsrechtsemissionen gegenüber Kapitalerhö- \\
hungen mit Ausschluss des Bezugsrechts der Aktionäre vor allem im \\
Hinblick auf die Festlegung des Ausgabebetrages flexibler. Insbesondere \\
darf hierbei der Abschlag auf den Börsenkurs 5 \% überschreiten. Dieser \\
Umstand hilft erheblich dabei, die neuen Aktien gerade in Zeiten volatiler \\
Kapitalmärkte zu vermarkten. Die Aktionärsbasis bildet schließlich nicht \\
selten ein gutes Nachfragereservoir bei einer Kapitalerhöhung, da die \\
Altaktionäre die Equity Story des Unternehmens bereits durch ihre frühe- \\
re Investitionsentscheidung unterstützt hatten.
\end{tabular}

2.6 Kapitalerhöhungen

Kapitalerhöhungen auf der Grundlage des Aktiengesetzes

\begin{tabular}{|l|l|l|}
\hline Arten & Rechtsgrundlage & Kennzeichnung \\
\hline $\begin{array}{l}\text { Kapitalerhöhung } \\
\text { gegen Einlagen: } \\
\text { ordentliche Kapital- } \\
\text { erhöhung und } \\
\text { Genehmigtes Kapital }\end{array}$ & $\begin{array}{l}\text { Die Hauptversammlung be- } \\
\text { schließt eine konkrete Kapital- } \\
\text { erhöhung (ordentliche Kapitaler- } \\
\text { höhung) oder sie ermächtigt den } \\
\text { Vorstand, das Grundkapital in } \\
\text { einem Zeitraum von maximal fünf } \\
\text { Jahren bis zu maximal 50\% des } \\
\text { bisherigen Grundkapitals zu } \\
\text { erhöhen (Genehmigtes Kapital, } \\
\text { sog. Vorratsbeschluss). }\end{array}$ & $\begin{array}{l}\text { Die Hauptversammlung kann mit } \\
\text { dreiviertel Mehrheit des anwe- } \\
\text { senden Kapitals die Erhöhung } \\
\text { des Grundkapitals durch Ausga- } \\
\text { be neuer Aktien gegen Bezah- } \\
\text { lung des Ausgabepreises (or- } \\
\text { dentliche Kapitalerhö- } \\
\text { hung/Genehmigtes Kapital) be- } \\
\text { schließen. Mit der Eintragung } \\
\text { ihrer Durchührung in das Han- } \\
\text { delsregister ist das Grundkapital } \\
\text { erhöht. Da der Ausgabepreis der } \\
\text { neuen Aktien in der Regel niedri- } \\
\text { ger ist als der Börsenkurs der }\end{array}$ \\
& & $\begin{array}{l}\text { alten Aktien, wird deren Wert } \\
\text { nach der Aktienausgabe sinken } \\
\text { (Verwässerungseffekt). Der }\end{array}$ \\
& & $\begin{array}{l}\text { Kursverlust der alten Aktie (Be- } \\
\text { zugsrechtsabschlag) entspricht } \\
\text { dem Wert des Bezugsrechts. }\end{array}$ \\
\hline
\end{tabular}




\begin{tabular}{|c|c|c|}
\hline Arten & Rechtsgrundlage & Kennzeichnung \\
\hline $\begin{array}{l}\text { Bedingte } \\
\text { Kapitalerhöhung }\end{array}$ & $\begin{array}{l}\text { Die Hauptversammlung } \\
\text { beschließt eine konkrete Kapital- } \\
\text { erhöhung bzw. sie ermächtigt } \\
\text { den Vorstand, das Grundkapital } \\
\text { in einem Zeitraum von maximal } \\
\text { fünf Jahren bis zu maximal } 50 \% \\
\text { des bisherigen Grundkapitals zu } \\
\text { erhöhen. }\end{array}$ & $\begin{array}{l}\text { Die Hauptversammlung kann mit } \\
\text { dreiviertel Mehrheit des anwe- } \\
\text { senden Kapitals eine Erhöhung } \\
\text { des Grundkapitals beschließen, } \\
\text { die nur insoweit durchgeführt } \\
\text { werden soll, wie von einem Um- } \\
\text { tausch- oder Bezugsrecht } \\
\text { (Wandelanleihen, Optionsanlei- } \\
\text { hen) Gebrauch gemacht wird, das } \\
\text { die Gesellschaft auf die neuen } \\
\text { Aktien einräumt. Die bedingte } \\
\text { Kapitalerhöhung soll nur zu } \\
\text { folgenden Zwecken beschlossen } \\
\text { werden: } \\
\text { - Gewährung von Umtausch- } \\
\text { oder Bezugsrechten an die } \\
\text { Gläubiger von Wandel-/ } \\
\text { Optionsanleihen } \\
\text { - Vorbereitung des Zusammen- } \\
\text { schlusses der Gesellschaft mit } \\
\text { anderen Unternehmen } \\
\text { - Ausgabe von Belegschaftsak- } \\
\text { tien. Der Nennbetrag des be- } \\
\text { dingten Kapitals darf } 50 \% \text { des } \\
\text { bisherigen Grundkapitals nicht } \\
\text { übersteigen. }\end{array}$ \\
\hline $\begin{array}{l}\text { Kapitalerhöhung aus } \\
\text { Gesellschaftsmitteln } \\
\text { und Aktiensplit }\end{array}$ & $\begin{array}{l}\text { Die Hauptversammlung } \\
\text { beschließt eine konkrete Kapital- } \\
\text { erhöhung bzw. sie ermächtigt } \\
\text { den Vorstand, das Grundkapital } \\
\text { in einem Zeitraum von maximal } \\
\text { fünf Jahren bis zu maximal } 50 \% \\
\text { des bisherigen Grundkapitals zu } \\
\text { erhöhen. }\end{array}$ & $\begin{array}{l}\text { Die Hauptversammlung kann mit } \\
\text { Dreiviertel des anwesenden Kapi- } \\
\text { tals die Erhöhung des Grundkapi- } \\
\text { tals durch Umwandlung von Kapi- } \\
\text { tal- und Gewinnrücklagen in } \\
\text { Grundkapital beschließen. Mit der } \\
\text { Eintragung des Beschlusses über } \\
\text { die Erhöhung des Grundkapitals } \\
\text { in das Handelsregister ist das } \\
\text { Grundkapital erhöht. Die neuen } \\
\text { Aktien (Berichtigungsaktien) gel- } \\
\text { ten als voll eingezahlt. Sie stehen } \\
\text { den Aktionären im Verhältnis } \\
\text { ihrer Anteile am bisherigen } \\
\text { Grundkapital zu. } \\
\text { Die Hauptversammlung kann } \\
\text { eine Neueinteilung des Grundka- } \\
\text { pitals durch die Ausgabe neuer } \\
\text { Aktien (Aktiensplit) beschließen. } \\
\text { Der auf die einzelne Aktie entfal- }\end{array}$ \\
\hline
\end{tabular}




\begin{tabular}{|l|l|l|}
\hline Arten & Rechtsgrundlage & Kennzeichnung \\
\hline & & lende anteilige Betrag des Grund- \\
& kapitals (Nennbetrag) sinkt \\
dadurch. Die neuen Aktien ste- \\
hen den Aktionären der Gesell- \\
schaft entsprechend ihrer bishe- \\
rigen Beteiligung zu. \\
& Ziel von Aktiensplits ist die Ver- \\
& ringerung des Aktienkurses, um \\
& die Verkehrsfähigkeit der Aktie zu \\
& erhöhen. \\
\hline
\end{tabular}

\subsection{Emissionsarten}

\begin{tabular}{|l|l|}
\hline Festpreisverfahren & $\begin{array}{l}\text { Das Festpreisverfahren ist ein Emissionsverfahren, das bei Kapital- } \\
\text { erhöhungen gegen Einlagen Anwendung findet, bei denen die Aktio- } \\
\text { näre ein Bezugsrecht besitzen und die Aktien schon an der Börse } \\
\text { notieren. Der Emittent legt in Absprache mit dem Konsortium einen } \\
\text { verbindlichen Emissionspreis fest, der meist unter dem aktuellen } \\
\text { Börsenkurs der Aktie liegt, da in diesem Fall das Bezugsrecht einen } \\
\text { inneren Wert besitzt. Die Anleger haben keinen Einfluss auf den } \\
\text { Ausgabepreis. }\end{array}$ \\
\hline Bookbuilding- \\
Verfahren & $\begin{array}{l}\text { Es ist ein Verfahren, das einen marktgerechten Ausgabepreis von } \\
\text { Aktien im Zusammenhang mit der Börseneinführung einer Aktienge- } \\
\text { sellschaft ermittelt. Ausgangspunkt für die Preisfindung ist ein zwi- } \\
\text { schen Emittent und Konsortialführer abgesprochener Preisrahmen } \\
\text { (Bookbuilding-Spanne), der im Rahmen von Vorgesprächen mit } \\
\text { potenziellen Investoren ermittelt und veröffentlicht wird. Während } \\
\text { einer festgelegten Zeichnungsfrist haben Kaufinteressenten an- } \\
\text { schließend die Möglichkeit zur Abgabe verbindlicher Gebote inner- } \\
\text { halb des Preisrahmens, die in einer zentralen Datei (Orderbuch) } \\
\text { erfasst werden. Nach Schließung des Orderbuchs am Ende der } \\
\text { Zeichnungsfrist wird aus den eingegangenen Geboten der endgülti- } \\
\text { ge Ausgabepreis festgelegt. }\end{array}$ \\
\hline Greenshoe & $\begin{array}{l}\text { Es ist eine Mehrzuteilungsreserve beim Bookbuilding-Verfahren. Der } \\
\text { Greenshoe ermöglicht dem konsortialführenden Kreditinstitut eine } \\
\text { höhere Zuteilung von Aktien für die Zeichner als ursprünglich ge- } \\
\text { plant. Er dient so als Instrument zur Stabilisierung eines durch sehr } \\
\text { großes Anlegerinteresse in die Höhe getriebenen Kurses für die } \\
\text { neuen Aktien. }\end{array}$ \\
\hline
\end{tabular}




\subsection{Stimmrechtsvollmacht}

\begin{tabular}{|c|c|}
\hline $\begin{array}{l}\text { Ausübung des } \\
\text { Stimmrechts auf } \\
\text { einer Hauptver- } \\
\text { sammlung }\end{array}$ & $\begin{array}{l}\text { Banken sind nicht verpflichtet, die Ausübung von Stimmrechten aus } \\
\text { Kundendepots zu übernehmen. Sofern Banken das Stimmrecht für } \\
\text { Aktionäre ausüben wollen, müssen sie vom Kunden mit der Wahr- } \\
\text { nehmung der Stimmrechte aus den hinterlegten Aktien beauftragt } \\
\text { werden. }\end{array}$ \\
\hline $\begin{array}{l}\text { Arten von Stimm- } \\
\text { rechtsvollmachten }\end{array}$ & $\begin{array}{l}\text { - Der Kunde kann eine Einzelstimmrechtsvollmacht oder eine all- } \\
\text { gemeine Stimmrechtsvollmacht der Bank erteilen. } \\
\text { - Die Einzelstimmrechtsvollmacht gilt nur für eine Hauptversamm- } \\
\text { lung. } \\
\text { - Die allgemeine Stimmrechtsvollmacht gilt für alle Hauptversamm- } \\
\text { lungen inländischer Aktien im Depot des Kunden. Bei einer unbe- } \\
\text { fristeten Erteilung muss die Bank einmal jährlich den Kunden auf } \\
\text { die Möglichkeit des jederzeitigen Widerrufs der Vollmacht und auf } \\
\text { andere Vertretungsmöglichkeiten hinweisen. Sie ist jederzeit wi- } \\
\text { derruflich. }\end{array}$ \\
\hline $\begin{array}{l}\text { Beispiele für Vertre- } \\
\text { tungsmöglichkeiten }\end{array}$ & $\begin{array}{l}\text { - Kreditinstitute } \\
\text { - Schutzgemeinschaft der Kleinaktionäre (SdK) } \\
\text { - Deutsche Schutzvereinigung für Wertpapierbesitz e.V. (DSW) } \\
\text { - Depotkunden können sich für einzelne Hauptversammlungen Ein- } \\
\text { trittskarten von ihrer Bank besorgen lassen, um selbst das Stimm- } \\
\text { recht auszuüben oder ausüben zu lassen. }\end{array}$ \\
\hline $\begin{array}{l}\text { Vorschriften für die } \\
\text { Ausübung von Voll- } \\
\text { machten durch Kre- } \\
\text { ditinstitute }\end{array}$ & $\begin{array}{l}\text { - Das Kreditinstitut ist im Aktienregister anstelle des Depotkunden } \\
\text { eingetragen: Mitteilung eigener Vorschläge zur Ausübung des } \\
\text { Stimmrechts zu den einzelnen Tagesordnungspunkten an den } \\
\text { Depotkunden durch das Kreditinstitut. } \\
\text { - Der Aktionär ist im Aktienregister der AG eingetragen: Das Kredit- } \\
\text { institut muss dem Aktionär die eigenen Vorschläge z. B. auf der } \\
\text { Homepage zugänglich machen. } \\
\text { - Bei den eigenen Vorschlägen muss sich die Bank vom Interesse } \\
\text { des Aktionärs leiten lassen. } \\
\text { - Das Kreditinstitut verpflichtet sich zur Einhaltung der Pflichten } \\
\text { sowie zur ordnungsgemäßen Ausübung der Stimmrechte. } \\
\text { - Das Kreditinstitut muss den Depotkunden um Weisung für die } \\
\text { Erteilung der Stimmrechtsausübung bitten. } \\
\text { - Das Kreditinstitut stimmt entsprechend den eigenen Vorschlägen } \\
\text { ab, falls der Aktionär nicht andere Weisungen erteilt. } \\
\text { - Hinweis auf personelle oder kapitalmäßige Verbindungen zwi- } \\
\text { schen der Gesellschaft und dem Kreditinstitut } \\
\text { - Besondere Vorschriften bei eigenen Hauptversammlungen und } \\
\text { Hauptversammlungen bei AG, bei denen das Kreditinstitut mit } \\
\text { mehr als } 5 \text { \% beteiligt ist: Der Depotkunde muss ausdrücklich } \\
\text { Weisungen zu den einzelnen Punkten der Hauptversammlungen } \\
\text { erteilen. }\end{array}$ \\
\hline
\end{tabular}




\subsection{Aktienanalyse und Aktienindizes}

\begin{tabular}{|c|c|}
\hline $\begin{array}{l}\text { Fundamen- } \\
\text { talanalyse }\end{array}$ & $\begin{array}{l}\text { Die Fundamentalanalyse ist ein Verfahren zur Prognose zukünftiger Kurs- } \\
\text { entwicklungen einer Aktie. Bei der Fundamentalanalyse wird der innere Wert } \\
\text { einer Aktie mit Hilfe gesamtwirtschaftlicher Faktoren (z. B. Konjunktur), } \\
\text { branchenspezifischer Faktoren (z. B. Geschäftsklima bei Anbietern von In- } \\
\text { ternet-Software) und unternehmensindividueller Faktoren (z. B. Kurs- } \\
\text { Gewinn-Verhältnis) ermittelt. Diese prognostizierten zukünftigen Erträge } \\
\text { werden auf den gegenwärtigen Betrachtungszeitpunkt abgezinst. }\end{array}$ \\
\hline $\begin{array}{l}\text { Technische } \\
\text { Analyse }\end{array}$ & $\begin{array}{l}\text { Bei der technischen Analyse versucht man Aussagen über die zukünttige } \\
\text { Kursentwicklung aus der Analyse vergangener Kursentwicklungsmuster } \\
\text { abzuleiten. Börsenbezogene Daten wie Kursverlauf oder Handelsvolumen } \\
\text { werden untersucht. Als Hilfsmittel werden Charts genutzt, d. h. grafische } \\
\text { Darstellungen von Kurs- oder Umsatzentwicklungen zur Ermittlung von } \\
\text { Trends. Kauf- bzw. Verkaufssignale werden aus typischen Erscheinungsbil- } \\
\text { dern (Formationen) abgeleitet. So gilt z. B. ein Kursverlauf in „W“-Form mit } \\
\text { zunächst sinkenden, dann steigenden, erneut sinkenden und wieder anstei- } \\
\text { genden Kursen als Kaufsignal, da unterstellt wird, dass nach Erreichen des } \\
\text { oberen rechten Punktes des „W“ mit Kurssteigerungen zu rechnen ist. Um- } \\
\text { gekehrt wird eine „M“-Formation als Verkaufssignal gewertet. }\end{array}$ \\
\hline Aktie & $\begin{array}{l}\text { Hinter der Berechnung der Indexwerte steht ein Korb von Wertpapieren. } \\
\text { Beim DAX (Deutscher Aktienindex) und beim amerikanischen Dow Jones } \\
\text { handelt es sich um die Aktien der } 30 \text { größten, d. h. börsenumsatzstärksten } \\
\text { deutschen bzw. amerikanischen Unternehmen. Im Gegensatz zum Dow } \\
\text { Jones enthält der DAX jedoch eine Gewichtung: Je höher die Börsenkapita- } \\
\text { lisierung eines DAX-Wertes ist, desto höher sein Gewicht. Kursschwankun- } \\
\text { gen von hoch gewichteten DAX-Werten führen damit zu einem größeren } \\
\text { Einfluss auf die Indexentwicklung als Kursschwankungen geringer gewichte- } \\
\text { ter Aktien. } \\
\text { Wertpapierindizes erfüllen zum einen eine Informationsfunktion für den Anle- } \\
\text { ger. Sie dienen aber auch als Benchmark, d. h. als Vergleichsmaßstab für } \\
\text { Wertpapieranlagen. Ist z. B. der DAX innerhalb eines Zeitraums um 10\% ge- } \\
\text { stiegen, so ist diese Veränderung eine wichtige Vergleichsziffer für Anleger, } \\
\text { deren Aktiendepot aus Werten großer deutscher Unternehmen zusammenge- } \\
\text { setzt ist. Wertpapierindizes erfüllen aber auch eine operative Funktion, indem } \\
\text { sie als Grundlage für Optionen und Futures fungieren. } \\
\text { Ein Wertpapierindex kann auch ein Performance-Index sein. Bei dieser } \\
\text { Indexart werden Kursrückgänge aufgrund von Ausschüttungen oder Kapi- } \\
\text { taländerungsmaßnahmen in der Indexformel berücksichtigt. Schüttet z. B. } \\
\text { eine AG eine Dividende aus, so verringert sich durch den hiermit verbunde- } \\
\text { nen Liquiditätsabfluss i. d. R. der Aktienkurs des Unternehmens. Die Aktie } \\
\text { wird am Tag der Ausschüttung daher auch mit dem Kurszusatz „,ex D“ no- } \\
\text { tiert. Für den Anleger ist rechnerisch dadurch kein realer Verlust verbunden, } \\
\text { da der Kursrückgang durch die Dividendenzahlung entsprechend ausgegli- } \\
\text { chen wird. In einem Performanceindex würde daher im Gegensatz zu einem } \\
\text { Kursindex der Kursrückgang korrigiert um die diesem Rückgang gegenüber- } \\
\text { stehende Dividendenzahlung. Der DAX wird sowohl als Kurs- als auch Per- } \\
\text { formanceindex berechnet. }\end{array}$ \\
\hline
\end{tabular}


Begriffserklärungen aus der technischen Aktienanalyse

Aktienanalyse ist ein Verfahren zur Beurteilung von Unternehmen oder Aktien.

Bärenfalle Eine Bärenfalle ist ein charttechnisches Verkaufssignal, das sich im Nachhinein als Fehlsignal entpuppt. Der Kurs bricht aus einem kontinuierlichen Kursverlauf nach unten aus und lässt ein Verkaufssignal erkennen. Jedoch folgt ein scharfer Richtungswechsel und hebt das Wertpapier wieder über den Trend (vgl. Bullenfalle).

Balkenchart Ein Balkenchart ist eine charttechnische Darstellung eines Kursverlaufes. Ein vertikaler Strich (Balken) stellt den Höchst- und Tiefstkurs meist eines Tages dar. Er wird durch einen kleinen horizontalen Strich links (Eröffnung) und rechts (Schluss) ergänzt.

Benchmark ist ein Vergleichsindex, an dem der Anlageerfolg gemessen wird. Bei Aktien kann das der Aktienindex Dax sein.

Blue Chips (Standardwerte) Bezeichnung für Aktien der größten, international bekannten Unternehmen mit hohem Anteil am Börsenumsatz. Die 30 größten deutschen Unternehmen sind z. B. im Dax enthalten.

Bullenfalle Eine Bullenfalle ist ein charttechnisches Kaufsignal, welches sich im Nachhinein als Fehlsignal entpuppt. Der Kurs bricht aus einem kontinuierlichen Kursverlauf nach oben aus und kündigt ein Kaufsignal an. Danach folgt jedoch ein heftiger Kurseinbruch, der auf das alte Niveau einschwenkt.

Chart Grafische Darstellung von beobachteten Kursverläufen einzelner Wertpapiere. Dabei bilden die jeweiligen Tageskurse jeweils einen Punkt in einem Diagramm.

Durchschnittslinien Bei Durchschnittslinien werden die letzten z. B. 38 Tageskurse gemittelt (alle addiert und durch 38 dividiert). In den folgenden Tagen fällt jeweils der früheste Kurs heraus und der jüngste wird hinzugefügt. Während die 38-Tage-Linie eher kurzfristige Signale gibt, nimmt man langfristig 200 Tage an.

Signale Im engeren Sinne gibt es nur zwei Signale. Das eine ist „kaufen“ und das andere „verkaufen“. Je nach Temperament reicht/reichen für eine Entscheidung ein oder mehrere Signale aus. Ist der Markt hochgradig reagibel, hat man bei mehreren Signalen den günstigsten Zeitpunkt meist verpasst.

\section{Kursformationen:}

Wimpel Ein Wimpel ist eine Kursformation, bei der die Kursbewegungen immer geringer werden. Ein Ausbruch aus der Formation ist nahezu unausweichlich und weist auf eine neue Trendentwicklung hin.

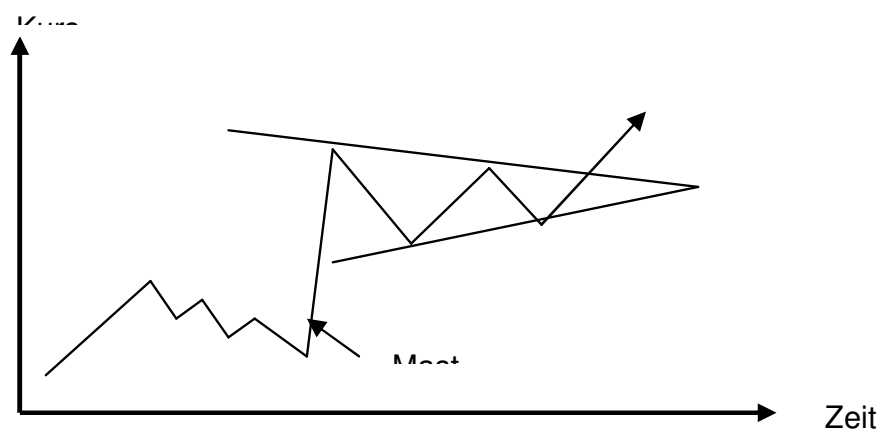


Flagge Eine Flagge verläuft oft antizyklisch zum Trend und weist auf eine Fortsetzung hin. Die obere und untere Trendlinien verlaufen weitgehend parallel. Ein deutlicher Ausbruch des Kursverlaufs deutet häufig auf eine Trendwende hin.

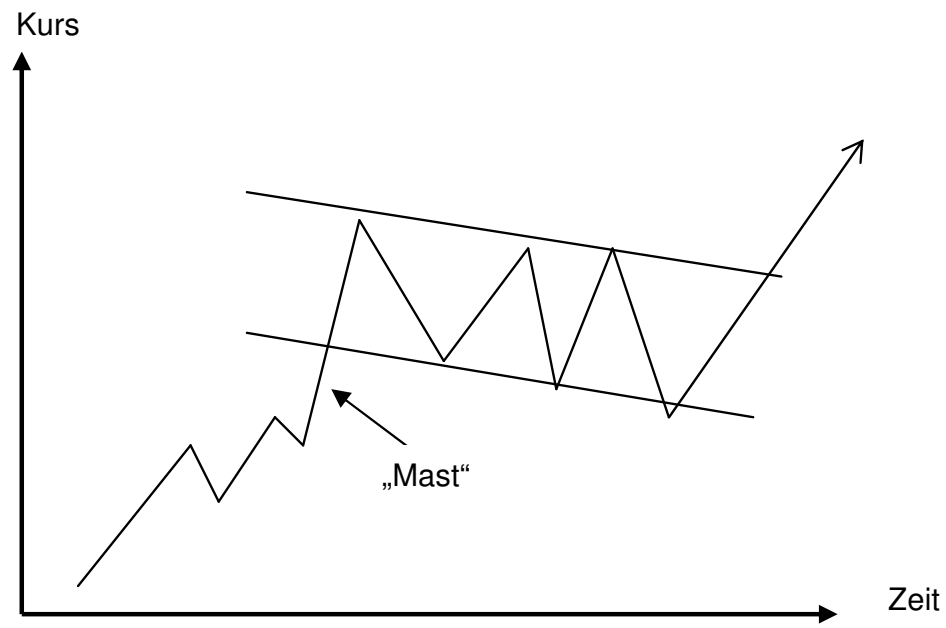

Bei einem Balkenchart werden die Kurse eines Tages in einer Senkrechten abgebildet. Liegen signifikante Kursdaten wie Schluss- oder Eröffnungskurse mehrfach am unteren oder oberen Ende der Chartlinie, lassen sich daraus Signale für einen Trendwechsel ablesen.

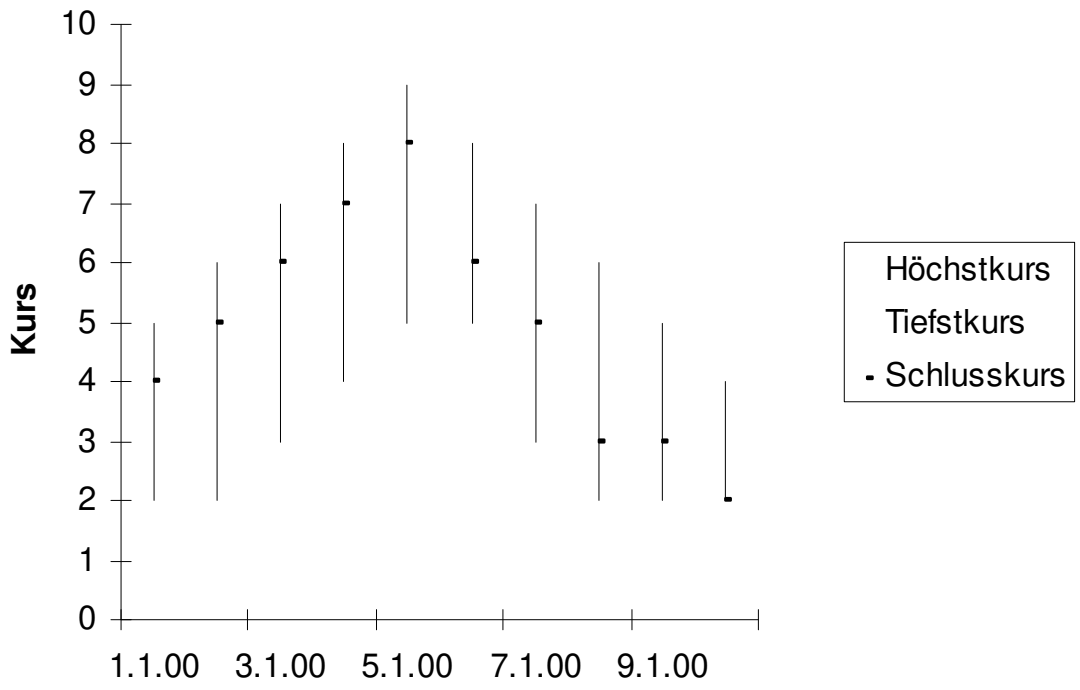

Tag(Zeit) 
Bei einem Keil verlaufen im Gegensatz zum Dreieck die Kurse stetig zusammen und es zeichnet sich erst langfristig ein Schnittpunkt der Geraden ab. Es kann manchmal Jahre dauern, bis fertige Keilmuster entstanden sind.

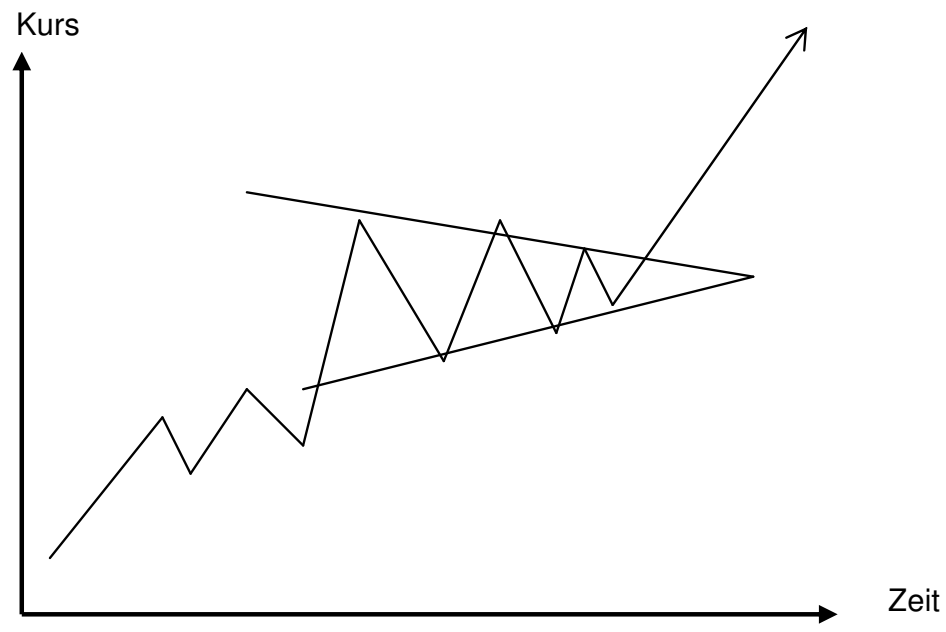

Unterstützungslinien sind analog zu den Widerstandslinien Parallelen zur x-Achse. Fällt der Kurs eines Wertpapiers mehrmals bis auf einen bestimmten Kurs zurück, um im Anschluss daran wieder zu steigen, so spricht man von einer Unterstützung. Wird eine Unterstützung jedoch nach unten durchbrochen lassen sich Schlüsse auf die weitere Kursentwicklung ziehen.

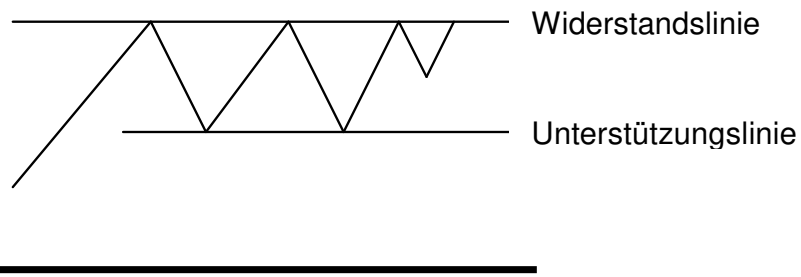

Widerstand Steigt der Kurs eines Wertpapiers mehrmals hintereinander bis auf ein bestimmtes Niveau an, um im Anschluss daran wieder zurückzufallen, so spricht man von einer Widerstandslinie. Das Durchbrechen einer Widerstandslinie lässt eine weitere Kurssteigerung erwarten. 


\subsection{Ertragskennziffern}

\begin{tabular}{|l|l|}
\hline $\begin{array}{l}\text { Kurs-Gewinn- } \\
\text { Verhältnis } \\
\text { (KGV) }\end{array}$ & $\begin{array}{l}\text { Diese Kennziffer gibt die Anzahl der Jahre an, nach denen bei einem } \\
\text { gleich bleibenden Gewinn des Unternehmens der Aktienkurs verdient ist. } \\
\text { Das KGV errechnet sich aus dem Verhältnis des Aktienkurses zum ge- } \\
\text { schätzten Gewinn je Aktie. Beträgt z. B. der aktuelle Aktienkurs 100 EUR, } \\
\text { so ergibt sich bei einer voraussichtlichen Dividende für das laufende Jahr } \\
\text { von 2 EUR ein KGV von 50. Je höher das KGV ist, desto teurer erscheint } \\
\text { die Aktie. Im Beispiel müsste der Gewinn des Unternehmens in 50 Folge- } \\
\text { jahren verdient werden, um den hohen Kurs zu rechtfertigen. KGV- } \\
\text { Analysen sind nur bedingt zur Bewertung von Aktien geeignet, da die } \\
\text { Gewinnprognosen für die Zukunft schwierig sind. Das KGV ist ein Maß- } \\
\text { stab für die Vergleichbarkeit von Unternehmen einer Branche. }\end{array}$ \\
\hline $\begin{array}{l}\text { Dividenden- } \\
\text { rendite }\end{array}$ & $\begin{array}{l}\text { Sie gibt die Verzinsung des Aktienkurses an. Zur Ermittlung der Dividen- } \\
\text { denrendite wird die erwartete Dividende ins Verhältnis zum Börsenkurs } \\
\text { der Aktie gesetzt. }\end{array}$ \\
\hline
\end{tabular}

\section{Investmentanteile}

\begin{tabular}{|l|l|}
\hline $\begin{array}{l}\text { Allgemeine } \\
\text { Kennzeichnung }\end{array}$ & $\begin{array}{l}\text { Es handelt sich um ein in Wertpapieren oder Grundstücken angelegtes } \\
\text { Sondervermögen einer Kapitalanlagegesellschaft. Fonds bündeln die } \\
\text { Gelder vieler Anleger und investieren sie in Aktien, Anleihen und andere } \\
\text { Anlageformen. Die Anteilsinhaber investieren mit einem geringen Betrag } \\
\text { gleichzeitig in verschiedene Anlagen und streuen damit ihr Risiko. In- } \\
\text { vestmentfonds werden von Investmentgesellschaften verwaltet. Das } \\
\text { Fondsvermögen wird bei einer Depotbank verwahrt und bildet ein Son- } \\
\text { dervermögen, das von dem eigenen Vermögen der Gesellschaft getrennt } \\
\text { gehalten wird. Das Fondsvermögen haftet nicht für Verbindlichkeiten der } \\
\text { Gesellschaften. }\end{array}$ \\
\hline $\begin{array}{l}\text { Rechte von } \\
\text { Anteilinhabern }\end{array}$ & $\begin{array}{l}\text { - Miteigentum nach Bruchteilen am Sondervermögen } \\
\text { - Anspruch auf Beteiligung am Fondsertrag } \\
\text { - Anspruch auf Rückgabe der Anteile an die Kapitalanlagegesellschaft } \\
\text { - regelmäßige Erstellung eines Jahresberichts }\end{array}$ \\
\hline $\begin{array}{l}\text { Kauf und Verkauf } \\
\text { von Investmen- } \\
\text { tanteilen }\end{array}$ & $\begin{array}{l}\text { Der Kauf oder Verkauf von Investmentanteilen ist bei der jeweiligen } \\
\text { Investmentgesellschaft oder an der Börse möglich. Fondsanteile wer- } \\
\text { den mit einem Ausgabeaufschlag zur Deckung der Vertriebskosten } \\
\text { ausgegeben; dieser Ausgabeaufschlag entfällt im Börsenhandel. }\end{array}$ \\
\hline Erträge & $\begin{array}{l}\text { Die Erträge aus Dividenden oder Zinsen schüttet die Investmentgesell- } \\
\text { schaft an die Anteilseigner aus oder legt sie wieder an (thesaurierende } \\
\text { Fonds). }\end{array}$ \\
\hline $\begin{array}{l}\text { Errechnung des } \\
\text { Wertes eines } \\
\text { Anteils }\end{array}$ & $\begin{array}{l}\text { Der Wert eines Fondsanteils wird errechnet, indem das Fondsvermö- } \\
\text { gen durch die Anzahl der umlaufenden Anteilsscheine dividiert wird. } \\
\text { Steigt der Wert der im Fondsvermögen enthaltenen Anlagen, erhöht } \\
\text { sich das Fondsvermögen bzw. der Wert des Anteilsscheins. } \\
\text { Beispiel: Fondsvermögen: 150.000.000,00 EUR, Umlaufende Anteile: } \\
\text { 4.500.000, Anteilwert: 33,33 EUR }\end{array}$ \\
\hline
\end{tabular}




\begin{tabular}{|c|c|c|c|}
\hline \begin{tabular}{|l|} 
Arten von \\
Investmentfonds
\end{tabular} & \multicolumn{3}{|c|}{$\begin{array}{l}\text { - Rentenfonds: Der Investmentfonds investiert in nationale und interna- } \\
\text { tionale Rentenwerte. } \\
\text { - Spezialfonds } \\
\text { - Offene Investmentfonds } \\
\text { - Geschlossene Investmentfonds: Anlagesumme ist begrenzt. } \\
\text { - Ausschüttende Fonds: Die Fondserträge werden an die Anleger z. B. } \\
\text { einmal jährlich ausgeschüttet. } \\
\text { - Thesaurierende Fonds: Die Erträge werden wieder in Fondswerte } \\
\text { angelegt. } \\
\text { - Dachfonds: Als Dachfonds werden Investmentfonds bezeichnet, die } \\
\text { das Geld der Anteilseigner wiederum in Anteilen von Investmentfonds } \\
\text { anlegen. } \\
\text { - Aktiv verwaltete Fonds: Das Management verfolgt eine eigene Strate- } \\
\text { gie und versucht mit dieser, die zuvor festgelegte Benchmark zu } \\
\text { schlagen. } \\
\text { - Passiv verwaltete Fonds oder Indexfonds sind an die Wertentwicklung } \\
\text { eines Index gekoppelt. } \\
\text { Vorteil eines Indexfonds gegenüber einem aktiv gemanagten Fonds: } \\
\text { Indexfonds sind bei Erwerb kostengünstiger. } \\
\text { Nachteil gegenüber einem aktiv gemanagten Fonds: } \\
\text { Indexfonds können keine bessere aber auch keine schlechtere Perfor- } \\
\text { mance erreichen als der zugrunde liegende Index. }\end{array}$} \\
\hline Fondse & $\begin{array}{l}\text { - Zinsen } \\
\text { - Dividenden } \\
\text { - Bezugsrechtserlöse } \\
\text { - Kursgewinne }\end{array}$ & & \\
\hline $\begin{array}{l}\text { Allgemeine } \\
\text { Vorteile }\end{array}$ & $\begin{array}{l}\text { - Anlage durch Exper } \\
\text { verwaltet den Fond } \\
\text { - Risikobegrenzung: } \\
\text { Rahmen der Fonds } \\
\text { - Risikomischung: De } \\
\text { gen, das in verschie } \\
\text { - Der Anleger hat die } \\
\text { Beträgen und kann }\end{array}$ & $\begin{array}{l}\text { ten: Management } \\
\text { und analysiert de } \\
\text { Management inves } \\
\text { pedingungen bzw. } \\
\text { r Anleger erwirbt } \\
\text { denen Anlageform } \\
\text { Möglichkeit der W } \\
\text { den Cost-Average }\end{array}$ & $\begin{array}{l}\text { Kapitalanlagegesellschaft } \\
\text { rkt. } \\
\text { mittels Risikostreuung im } \\
\text { Investmentgesetzes. } \\
\text { entum am Sondervermö- } \\
\text { Ivestiert wird. } \\
\text { pieranlage in kleineren } \\
\text { kt nutzen. }\end{array}$ \\
\hline
\end{tabular}




\section{Optionsschuldverschreibungen}

\subsection{Optionsanleihe}

\begin{tabular}{|c|c|}
\hline $\begin{array}{l}\text { Allgemeine } \\
\text { Kennzeichnung }\end{array}$ & $\begin{array}{l}\text { Eine Optionsanleihe ist eine festverzinsliche Schuldverschreibung mit } \\
\text { zusätzlichen Optionsscheinen. Optionsanleihen unterscheiden sich von } \\
\text { normalen Anleihen durch die Zugabe von Optionsscheinen. Diese be- } \\
\text { rechtigen den Inhaber, Aktien oder Anleihen des Emittenten in der Re- } \\
\text { gel nach einer bestimmten Frist zu einem festgelegten Kurs zu bezie- } \\
\text { hen. Mit Beginn der Optionsfrist kann der Anleger über die Options- } \\
\text { scheine getrennt verfügen und diese an der Börse verkaufen. Die An- } \\
\text { leihen notieren anschließend mit dem Kurszusatz „ex“. Nicht getrennte } \\
\text { Anleihen werden „cum“, also mit Anleihe genannt. Mit der Ausübung } \\
\text { der Option erlischt der Anspruch auf Rückzahlung des Nominalbetrages } \\
\text { der Anleihe nicht. }\end{array}$ \\
\hline $\begin{array}{l}\text { Rechte des } \\
\text { Anlegers }\end{array}$ & $\begin{array}{l}\text { - Zinsanspruch } \\
\text { - Rückzahlungsanspruch } \\
\text { - Ausübung des Optionsrechts }\end{array}$ \\
\hline $\begin{array}{l}\text { Vorteile für den } \\
\text { Anleger }\end{array}$ & $\begin{array}{l}\text { Der Anleger erhält eine regelmäßig garantierte Zinszahlung. Die Rück- } \\
\text { zahlung zum Nennwert am Ende der Laufzeit ist ebenfalls garantiert. Das } \\
\text { Kursrisiko ist begrenzt. Mit steigendem Aktienkurs des Unternehmens } \\
\text { steigt auch der Kurs der Optionsanleihe. Bei fallendem Aktienkurs sinkt } \\
\text { der Kurs der Optionsanleihe höchstens auf den Wert der Anleihe ex. }\end{array}$ \\
\hline $\begin{array}{l}\text { Vorteile für das } \\
\text { emittierende } \\
\text { Unternehmen }\end{array}$ & $\begin{array}{l}\text { Durch die Ausgabe einer Optionsanleihe beschafft sich eine AG zu- } \\
\text { nächst Fremdkapital (Anleihe). Zusätzlich hat sie die Möglichkeit zur } \\
\text { Erhöhung des Eigenkapitals durch Emission von Aktien bei Ausübung } \\
\text { der Optionsscheinrechte. }\end{array}$ \\
\hline Arten & $\begin{array}{l}\text { Man unterscheidet das Aufgeld- und das Abgeldmodell bei Optionsan- } \\
\text { leihen. } \\
\text { - Beim Aufgeldmodell ist die Verzinsung marktgerecht und der Aufpreis } \\
\text { für den Optionsschein beträgt } 30 \% \text { bis } 40 \% \text { des Nominalwertes der } \\
\text { - Anleihe. } \\
\text { - Beim Abgeldmodell liegt die Verzinsung unterhalb des Marktzinsni- } \\
\text { veaus als Ausgleich für den Bezug des Optionsscheins. } \\
\text { An der Börse werden } 3 \text { Varianten von Rechten gehandelt: } \\
\text { - Anleihen mit Optionsschein, volle Stücke im Rentenhandel } \\
\text { - Anleihe ohne Optionsschein (o. O.) im Rentenhandel } \\
\text { - Optionsschein ohne Anleihe im Optionsscheinhandel }\end{array}$ \\
\hline $\begin{array}{l}\text { Steuerliche } \\
\text { Behandlung }\end{array}$ & $\begin{array}{l}\text { - Zinsen aus Optionsanleihen unterliegen der 25-prozentigen Abgel- } \\
\text { tungsteuer. } \\
\text { - Die Veräußerungsgewinne unterliegen ohne Einhaltung einer Halte- } \\
\text { frist ebenfalls der Abgeltungsteuer. }\end{array}$ \\
\hline
\end{tabular}




\section{Auszug aus dem Bezugsangebot einer Optionsanleihe der ComTech AG}

Aufgrund des Beschlusses der Hauptversammlung vom 25. Juni 2018 emittieren wir eine Optionsanleihe im Gesamtnennbetrag von 32.000.000,00 EUR.

Ein Bankenkonsortium hat die nom. 32.000.000,00 EUR Optionsschuldverschreibungen mit der Verpflichtung übernommen, sie den Aktionären unserer Gesellschaft zum Bezug anzubieten.

Die Aktionäre können die Optionsschuldverschreibungen im nachstehenden Verhältnis beziehen: auf je 400 Stückaktien entfällt eine Optionsschuldverschreibung über nom. 1.000,00 EUR zum Ausgabekurs von $120 \%$. Gemäß den Anleihe- und Optionsbedingungen hat die Optionsanleihe folgende wesentliche Ausstattungsmerkmale:

Stückelung: Die Optionsanleihe ist eingeteilt in unter sich gleichberechtigte, auf den Inhaber lautende Optionsschuldverschreibungen im Nennbetrag von 1.000,00 EUR.

Verzinsung: Die Optionsschuldverschreibungen werden vom 5. Dezember 2018 an mit jährlich 3,25 \% verzinst. Die Zinsen sind nachträglich am 5. Dezember der Jahre 2019 bis 2028 fällig. Die erste Zinszahlung erfolgt am 5. Dezember 2019.

Laufzeit und Rückzahlung: Die Laufzeit der Optionsanleihe beträgt zehn Jahre fest. Die Gesellschaft ist verpflichtet, die Optionsschuldverschreibungen am 5. Dezember 2028 zum Nennbetrag zurückzuzahlen.

Bedingtes Kapital: Zur Gewährung von Optionsrechten besteht ein bedingtes Kapital in Höhe von 2.560.000,00 EUR.

Optionsscheine: Jeder Optionsschuldverschreibung im Nennbetrag von 1.000,00 EUR sind acht Inhaberoptionsscheine mit Berechtigung zum Bezug von je einer Stückaktie unserer Gesellschaft beigefügt.

Optionsrecht: Die Inhaber der Optionsscheine sind berechtigt, die auf den Optionsscheinen angegebene Anzahl von Stückaktien unserer Gesellschaft zum Optionspreis von 80,00 EUR je Stückaktie zu beziehen. Die Aktien sind gewinnanteilberechtigt vom Beginn des Geschäftsjahres an, in dem sie aufgrund der Ausübung von Optionsrechten entstehen.

Optionsfrist: Das Optionsrecht kann vom 10. Mai 2019 bis zum 27. November 2028 einschließlich ausgeübt werden.

Zum Bezug einer Optionsschuldverschreibung im Nennbetrag von 1.000,00 EUR zum Kurs von $120 \%$ berechtigen die Gewinnanteilscheine Nr. 11 von 400 Stückaktien.

Das Bezugsrecht auf die Optionsschuldverschreibungen wird vom 12. November 2018 bis 23. November 2018 einschließlich an allen deutschen Wertpapierbörsen gehandelt und amtlich notiert. Die Bezugsstellen sind bereit, den An- und Verkauf von Bezugsrechten nach Möglichkeit zu vermitteln.

\subsection{Optionsscheine}

\begin{tabular}{|l|l|}
\hline $\begin{array}{l}\text { Allgemeine } \\
\text { Kennzeich- } \\
\text { nung }\end{array}$ & $\begin{array}{l}\text { Der Optionsschein ist ein eigenständiges Wertpapier, das dem Inhaber das } \\
\text { Recht einräumt, beispielsweise eine bestimmte Anzahl von Aktien im ent- } \\
\text { sprechenden Bezugsverhältnis zu einem bestimmten Kurs (Bezugskurs) } \\
\text { innerhalb einer bestimmten Frist (Bezugsfrist) zu erwerben (Aktienoptions- } \\
\text { schein). Der Optionsschein wird losgelöst von der Anleihe an der Börse } \\
\text { gehandelt. Es ist eine spekulative Anlage mit hohem Chancen-Risiko- }\end{array}$ \\
& $\begin{array}{l}\text { Potenzial. Der Handel mit Optionsscheinen ist ein Finanztermingeschäft, d. } \\
\text { h. die Bank muss über die mit solchen Geschäften verbundenen Risiken } \\
\text { den Kunden förmlich aufklären und dies entsprechen dokumentieren. }\end{array}$ \\
\hline
\end{tabular}




\begin{tabular}{|c|c|}
\hline $\begin{array}{l}\text { Ausstat- } \\
\text { tungsmerk- } \\
\text { male }\end{array}$ & $\begin{array}{l}\text { Klassische Optionsscheine haben meist eine Laufzeit von mehreren Jahren. } \\
\text { Der Optionsschein ist wie eine Kaufoption (Call) ausgestattet und berech- } \\
\text { tigt zum Kauf von Aktien der emittierenden AG zu einem bestimmten Ba- } \\
\text { sispreis. Entsprechend der Kontraktgröße bei Optionen ist bei Options- } \\
\text { scheinen ein bestimmtes Bezugsverhältnis festgelegt. Ein Bezugsverhält- } \\
\text { nis von } 1: 5 \text { bedeutet, dass mit einem Optionsschein } 5 \text { Aktien bezogen } \\
\text { werden können. Um Chancen und Risiken des Optionsscheins zu beurtei- } \\
\text { len, sind die Optionsbedingungen wie Optionsverhältnis, Bezugsfrist, Be- } \\
\text { zugspreis und Optionsprämie zu beachten. }\end{array}$ \\
\hline Hebe & $\begin{array}{l}\text { Die Hebelwirkung beruht darauf, dass für den Erwerb des Optionsscheins } \\
\text { ein geringerer Kapitaleinsatz erforderlich ist als für den Erwerb der Aktie, } \\
\text { sodass der Optionsschein auf Kursänderungen der Aktie überproportional } \\
\text { reagiert. } \\
\text { Der Hebel gibt an, um wie viel Prozent sich der Kurs des Optionsscheins } \\
\text { verändert, wenn der Kurs der Aktie um } 1 \% \text { steigt oder fällt. } \\
\text { Beispiel eines Call-Optionsscheins: } \\
\text { Kurs des Optionsscheins } 0,50 \text { EUR } \\
\text { Kurs der Aktie (Basiswert) } 32,00 \text { EUR } \\
\text { Basispreis (Bezugspreis) } 34,00 \text { EUR } \\
\text { Bezugsverhältnis } 10: 1 \\
\text { Restlaufzeit } 2 \text { Jahre } \\
\text { Ermittlung des Aufgeldes: } \\
\text { Aufgeld = (Basispreis }+ \text { (Kurs des Optionsscheins : Bezugsverhältnis) - } \\
\text { Aktienkurs) : Aktienkurs x } 100 \\
\text { Aufgeld = (34,00 + 0,05 - 32,00) : } 32,00 \times 100=6,41 \% \\
\text { Bei Verteilung des Aufgeldes auf die zwei Jahre Restlaufzeit ergibt sich pro } \\
\text { Jahr ein Aufgeld von } 3,205 \% \text {. } \\
\text { Ermittlung des Hebels: } \\
\text { Hebel = Kurs der Aktie : (Kurs des Optionsscheins x Bezugsverhältnis) } \\
\text { Hebel = } 32:(0,50 \times 10)=6,4\end{array}$ \\
\hline $\begin{array}{l}\text { Motive für den } \\
\text { Erwerb von } \\
\text { Optionsschei- } \\
\text { nen } \\
\end{array}$ & $\begin{array}{l}\text { - Kurssicherung } \\
\text { - Spekulation }\end{array}$ \\
\hline $\begin{array}{l}\text { Steuerliche } \\
\text { Behandlung }\end{array}$ & $\begin{array}{l}\text { Grundsätzlich ist die Differenz zwischen Verkaufs- und Kaufpreis für die } \\
\text { Besteuerung maßgeblich. Stillhalterprämien unterliegen der Abgeltung- } \\
\text { steuer. Gewinne aus dem Verkauf von Optionsscheinen sind ebenfalls } \\
\text { abgeltungsteuerpflichtig. Bei einem Verlust liegen negative Einkünfte aus } \\
\text { Kapitalvermögen vor, die mit anderen Einnahmen wie Zinsen oder Divi- } \\
\text { dendenerträgen verrechnet werden können. }\end{array}$ \\
\hline $\begin{array}{l}\text { Beispiel für } \\
\text { einen } \\
\text { Optionsschein }\end{array}$ & $\begin{array}{l}\text { Die Aktie der Chemie AG wird nach einem langen Kursanstieg zu einem } \\
\text { Kurs von } 52,00 \text { EUR an der Börse gehandelt. Der Depotkunde Jürgen } \\
\text { Schneider besitzt } 100 \text { Aktien und möchte sich seine erzielten Kursgewinne } \\
\text { sichern, ohne aber auf einen möglichen weiteren Kursanstieg der Chemie } \\
\text { AG-Aktie zu verzichten. Herr Schneider sichert sich sein Depot durch einen } \\
\text { Optionsschein ab. }\end{array}$ \\
\hline
\end{tabular}




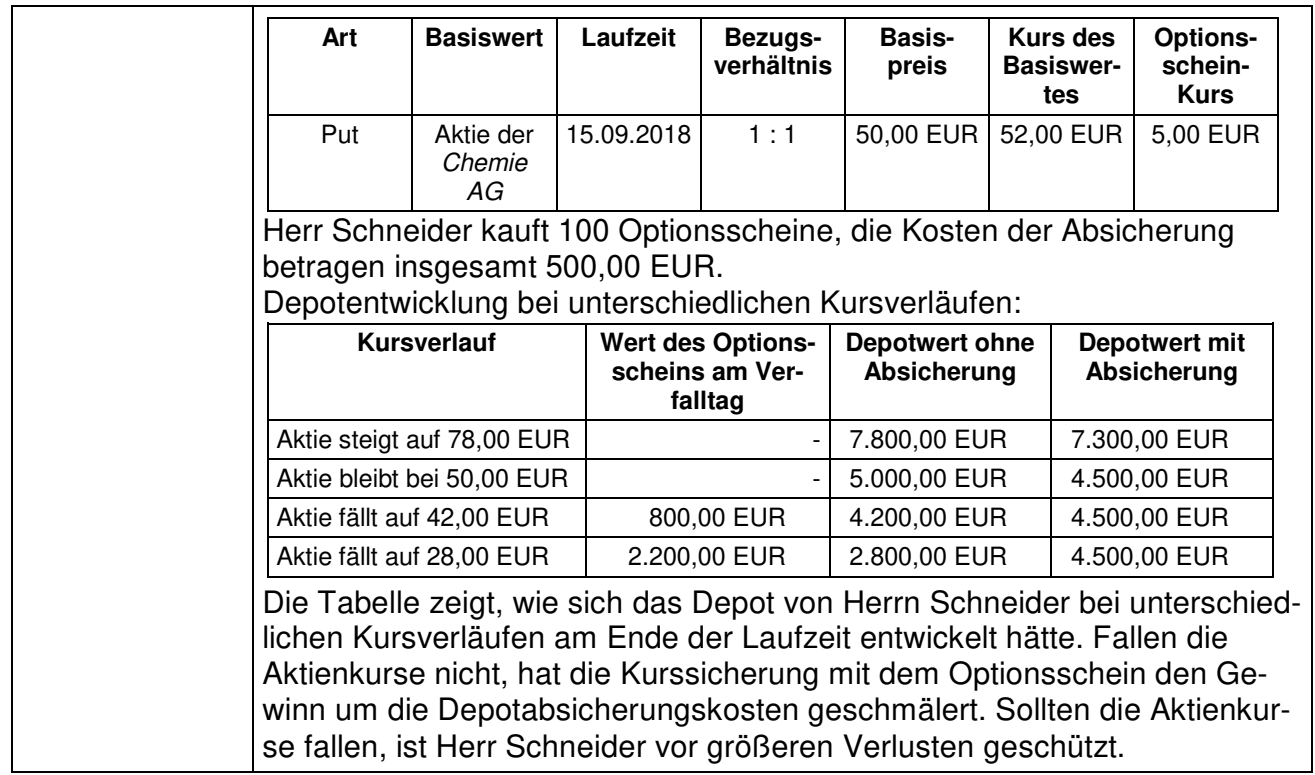

\subsection{Optionen}

\begin{tabular}{|l|l|}
\hline $\begin{array}{l}\text { Allgemeine } \\
\text { Kennzeich- } \\
\text { nung von } \\
\text { Optionen }\end{array}$ & $\begin{array}{l}\text { Optionen sind standardisierte, börsenmäßig gehandelte Vereinbarungen, } \\
\text { die dem Käufer das Recht, aber nicht die Verpflichtung gegeben, } \\
\text { • eine bestimmte Menge eines bestimmten Basiswertes } \\
\text { - innerhalb eines festgelegten Zeitraums (Optionsfrist) } \\
\text { - oder zu einem festgesetzten Zeitpunkt (Optionstermin) } \\
\text { - zu einem bei Vertragsabschluss festgelegten Preis (Basispreis) } \\
\text { - zu kaufen (Call) } \\
\text { - oder zu verkaufen (Put). }\end{array}$ \\
\hline $\begin{array}{l}\text { Put (Verkaufs- } \\
\text { option) }\end{array}$ & $\begin{array}{l}\text { Option, die den Käufer berechtigt, einen bestimmten Basiswert in einer } \\
\text { bestimmten Menge zu einem im Voraus festgelegten Ausübungspreis bis } \\
\text { oder zu einem bestimmten Termin zu verkaufen. Käufer eines Puts erwar- } \\
\text { ten, dass der Preis des Basiswertes während der Laufzeit der Option fällt. }\end{array}$ \\
\hline $\begin{array}{l}\text { Call } \\
\text { (Kaufoption) }\end{array}$ & $\begin{array}{l}\text { Standardisiertes, an einer Terminbörse gehandeltes Kaufrecht auf einen } \\
\text { Basiswert. Ein Call ist ein verbrieftes Recht, aber nicht die Pflicht, eine } \\
\text { bestimmte Menge eines Basiswertes zu einem vereinbarten Preis (Basis- } \\
\text { preis) innerhalb eines festgelegten Zeitraums zu erwerben. }\end{array}$ \\
\hline $\begin{array}{l}\text { Zeitwert eines } \\
\text { Puts }\end{array}$ & $\begin{array}{l}\text { Differenz zwischen aktuellem Kurs eines Basiswertes und dem Basispreis } \\
\text { abzüglich des Optionspreises. Beispiel: } \\
\text { Optionstyp: Put } \\
\text { Basispreis: 45,00 EUR } \\
\text { Optionspreis: 3,00 EUR } \\
\text { aktueller Börsenkurs des Basiswertes: 42,50 EUR } \\
\text { Zeitwert: 0,50 EUR }\end{array}$ \\
\hline
\end{tabular}




\begin{tabular}{|c|c|c|}
\hline Innerer Wert & \multicolumn{2}{|c|}{$\begin{array}{l}\text { Er ist der Wert einer Option, die sich „im Geld“ befindet. Der innere Wert } \\
\text { gibt denjenigen Optionspreis an, bei dem ein Erwerb der Aktie über die } \\
\text { Börse genauso günstig ist wie der Erwerb über die Option. } \\
\text { Beispiel: } \\
\text { Kaufoption über X-Aktien, Basispreis } 95 \text { EUR. Bei einem aktuellen Kurs } \\
\text { der X-Aktie von } 100 \text { EUR und einem Optionsverhältnis von } 1: 1 \text { ist der } \\
\text { innere Wert } 5 \text { EUR. Der Erwerb über die Option }(95+5=100) \text { entspricht } \\
\text { dem aktuellen Börsenkurs. } \\
\text { Der innere Wert einer Option liegt i. d. R. unter dem tatsächlichen Options- } \\
\text { preis an der Börse, da der tatsächliche Preis die Spekulationserwartung } \\
\text { der Anleger widerspiegelt, die umso höher ist, je länger die Restlaufzeit der } \\
\text { Option und die Volatilität des Basiswertes ist. } \\
\text { Der innere Wert der Option (Call oder Put) ist u. a. abhängig von der Volatilität } \\
\text { des Börsenkurses des Basiswertes. Der Optionspreis wird am Verfalltag dem } \\
\text { inneren Wert der Option entsprechen, da der Zeitwert dann null ist. }\end{array}$} \\
\hline \multirow[t]{8}{*}{$\begin{array}{l}\text { Einfluss- } \\
\text { faktoren }\end{array}$} & \multicolumn{2}{|c|}{$\begin{array}{l}\text { Es gibt } 5 \text { Haupteinflussfaktoren, die den Preis einer Option bestimmen. Die } \\
\text { einzelnen Faktoren haben eine unterschiedliche Einflussstärke, die sich } \\
\text { während der Laufzeit der Option verändert. Die Faktoren sind: Innerer } \\
\text { Wert, Basispreis, Laufzeit der Option, Volatilität und Zinsniveau. } \\
\text { Innerer Wert: Die Differenz vom Kurs des Basiswerts zum Basispreis der } \\
\text { Option bestimmt den Inneren Wert einer Option. Der Innere Wert kann } \\
\text { grundsätzlich nicht unter Null sinken. } \\
\text { Bei Calls gilt: Je höher der Kurs oder Preis des Basiswertes, desto höher } \\
\text { ist der Wert der Option. Der Call auf die X-Aktie mit einem Basispreis von } \\
100,00 \text { EUR und einem Aktienkurs von 150,00 EUR hätte einen Wert von } \\
\text { mindestens } 50,00 \text { EUR. Würde der Aktienkurs auf } 170,00 \text { EUR steigen, so } \\
\text { wäre die Option mindestens } 70,00 \text { EUR wert. } \\
\text { Bei Puts verhält es sich gegenläufig. Je niedriger der Kurs oder Preis der } \\
\text { Aktie, desto höher ist der Wert des Puts. Der Put auf die X-Aktie mit einem } \\
\text { Basispreis von } 100,00 \text { EUR und einem Aktienkurs von } 80,00 \text { EUR hätte } \\
\text { einen Wert von } 20 \text { EUR. Bei der Ausübung des Puts kann die Aktie zu } \\
100,00 \text { EUR (Basispreis) angedient werden, obwohl der Marktwert der } \\
\text { Aktie nur bei } 80,00 \text { EUR liegt. Würde der Aktienkurs um weitere } 20 \text { Punkte } \\
\text { auf } 60,00 \text { EUR fallen, würde der Innere Wert des Puts um } 20,00 \text { EUR auf } \\
40,00 \text { EUR steigen. } \\
\text { Zeitwert: Die Differenz zwischen dem Optionswert (Prämie) und dem Inne- } \\
\text { ren Wert wird als Zeitwert bezeichnet. Die Optionsprämie wird mit Hilfe } \\
\text { mathematischer Modelle errechnet. }\end{array}$} \\
\hline & \multicolumn{2}{|c|}{$\begin{array}{l}\text { Beispiel für die Ermittlung des Inneren Wertes bei einem Optionsschein und } \\
\text { einer Option }\end{array}$} \\
\hline & Kurs der Option & 81,00 EUR \\
\hline & Kurs des Optionsscheins & 1,00 EUR \\
\hline & Kontraktgröße Option & 100 Aktien \\
\hline & Bezugsverhältnis Option & $100: 1$ \\
\hline & Basispreis & 300,00 EUR \\
\hline & Kurs des Basistitels & 380,00 EUR \\
\hline
\end{tabular}




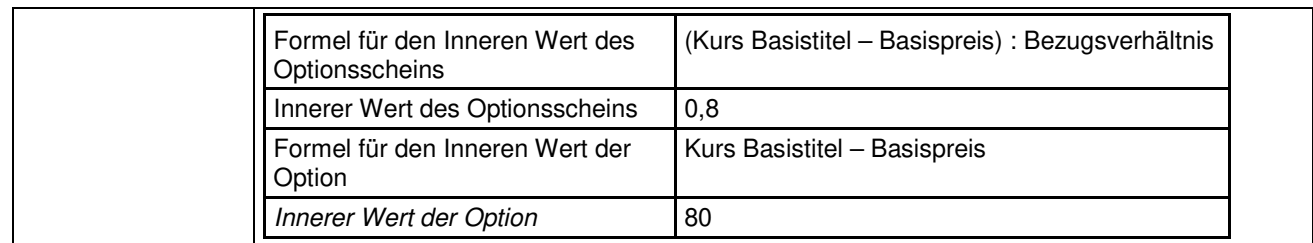

\subsection{Futures}

\begin{tabular}{|c|c|}
\hline $\begin{array}{l}\text { Allgemeine } \\
\text { Kennzeichnung }\end{array}$ & $\begin{array}{l}\text { Futures sind standardisierte, börsenmäßig gehandelte Terminkontrakte } \\
\text { auf Finanzinstrumente mit der vertraglichen Verpflichtung, } \\
\text { - eine bestimmte Menge eines Basiswertes (Kontraktgegenstand) } \\
\text { - zu einem bei Vertragsabschluss festgelegten Preis (Future-Preis) } \\
\text { - zu einem bei Vertragsabschluss vereinbarten späteren Zeitpunkt (Er- } \\
\text { füllungstag) } \\
\text { - zu liefern (Short Position) } \\
\text { • oder abzunehmen (Long Position). } \\
\text { Finanztermingeschäfte sind Festgeschäfte, d. h. Käufer und Verkäufer } \\
\text { gehen eine bindende Liefer- oder Abnahmeverpflichtung ein. In der } \\
\text { Praxis werden die Finanztermingeschäfte nicht erfüllt, sondern vor Fäl- } \\
\text { ligkeit durch Gegengeschäfte glatt gestellt: Gekaufte Kontrakte werden } \\
\text { durch entsprechende Verkäufe, verkaufte Kontrakte durch entspre- } \\
\text { chende Käufe gleicher Kontrakte glatt gestellt. } \\
\text { Der Gewinn oder Verlust ergibt sich aus dem Unterschied zwischen } \\
\text { dem Eröffnungspreis und dem Preis des Glattstellungsgeschäfts. }\end{array}$ \\
\hline Arten & $\begin{array}{l}\text { - Zinsfutures } \\
\text { - Aktienindexfutures } \\
\text { - Devisenfutures }\end{array}$ \\
\hline $\begin{array}{l}\text { Motive für den } \\
\text { Kauf oder Ver- } \\
\text { kauf von Futures }\end{array}$ & $\begin{array}{l}\text { - Kurssicherung: } \\
\text { a) Verkauf eines Wertpapierbestandes auf Termin. } \\
\text { Vorteil: Kurssicherheit } \\
\text { Nachteil: Anleger profitiert nicht von steigenden Marktpreisen. } \\
\text { b) Kauf von Wertpapieren auf Termin mit der Absicht, die Wertpapiere } \\
\text { zu halten. } \\
\text { Vorteil: Kurssicherheit } \\
\text { Nachteil: Auch bei sinkenden Marktpreisen müssen die Wertpapiere } \\
\text { zum höheren Kurs abgenommen werden. } \\
\text { - geringer Liquiditätseinsatz } \\
\text { - hohe Gewinn- aber auch hohe Verlustrisiken }\end{array}$ \\
\hline $\begin{array}{l}\text { Sicherheitsstel- } \\
\text { lung (Margin) }\end{array}$ & $\begin{array}{l}\text { Käufer und Verkäufer eines Futures haben zur Gewährleistung ihrer } \\
\text { Kontraktverpflichtungen Sicherheiten in Geld oder Wertpapieren zu } \\
\text { hinterlegen. Die EUREX berechnet die Höhe der erforderlichen Sicher- } \\
\text { heit börsentäglich auf Grund der Differenz zwischen dem vereinbarten } \\
\text { Future-Preis und dem aktuellen Kassakurs. }\end{array}$ \\
\hline
\end{tabular}




\section{Wandelanleihen}

\begin{tabular}{|c|c|}
\hline $\begin{array}{l}\text { Allgemeine } \\
\text { Kennzeichnung }\end{array}$ & $\begin{array}{l}\text { Die Wandelanleihe verbindet Elemente der Anleihe mit Elementen der } \\
\text { Aktie. Wandelanleihen verbriefen ein Wandlungsrecht: Eine Wandelan- } \\
\text { leihe ist eine Unternehmensanleihe, die innerhalb einer vorher festge- } \\
\text { legten Frist zu einem vorab festgelegten Kurs in Aktien des Unterneh- } \\
\text { mens umgetauscht werden kann. Eine Wandelanleihe ist demnach eine } \\
\text { Anleihe mit einer Kaufoption auf Aktien. } \\
\text { Anleger haben auch die Möglichkeit, die Wandelanleihe - wie bei einer } \\
\text { klassischen Anleihe-bis zur Endfälligkeit zu halten. In diesem Fall erhal- } \\
\text { ten sie jährliche Zinszahlungen vom Schuldner, der am Ende der Laufzeit } \\
\text { die Anleihe zurückzahlt. Der Anleiheninhaber wird also vom Gläubiger } \\
\text { zum Unternehmensteilhaber. Aufgrund dieses Rechts hat eine Wandel- } \\
\text { anleihe eine niedrigere Verzinsung als andere Anleihen. Die Hauptver- } \\
\text { sammlung muss der Begebung einer Wandelanleihe und der damit ver- } \\
\text { bundenen Kapitalerhöhung mit einer Dreiviertel-Mehrheit zustimmen. } \\
\text { Wandelanleihen können sich in verschiedenen Details unterscheiden, } \\
\text { z. B. vorzeitige Kündigungsrechte des Schuldners oder Einschränkun- } \\
\text { gen für Anleger bei der Möglichkeit, die Anleihe in Aktien zu tauschen. }\end{array}$ \\
\hline $\begin{array}{l}\text { Rechte des } \\
\text { Anlegers }\end{array}$ & $\begin{array}{l}\text { - Anspruch auf Rückzahlung zum Nennwert falls keine Wandlung } \\
\text { - Zinsanspruch } \\
\text { - Umtauschrecht in Wertpapieren }\end{array}$ \\
\hline $\begin{array}{l}\text { Gründe für die } \\
\text { Begebung von } \\
\text { Wandelanleihen }\end{array}$ & $\begin{array}{l}\text { Unternehmen können sich durch die Ausgabe von Wandelanleihen } \\
\text { billig verschulden. Da die Wandelanleihe im Vergleich zur normalen } \\
\text { Anleihe mit einem zusätzlichen Recht auf Umtausch in Aktien ausge- } \\
\text { stattet ist, liegt ihr Zinskupon unter jenem normaler Anleihen. } \\
\text { Wandelanleihen: Attraktiv für Emittenten und Anleger } \\
\text { Immer mehr Unternehmen entdecken die Vorzüge einer Finanzierung } \\
\text { mittels Wandelanleihen - und davon können auch Anleger profitieren. } \\
\text { Denn immer mehr Fondsgesellschaften entdecken die Wandelanleihen- } \\
\text { fonds und emittieren kräftig solche Produkte. } \\
\text { Wandelanleihen oder Convertible Bonds bieten einen Zinsvorteil gegen- } \\
\text { über herkömmlichen Anleihen. Außerdem können Firmen über dieses } \\
\text { hybride Kapitalmarktprodukt, das Elemente aus Aktien und Schuldver- } \\
\text { schreibungen in sich vereint, die Basis der Kapitalgeber diversifizieren. } \\
\text { Die Wandelanleihe ermöglicht eine Finanzierung zu attraktiven Konditio- } \\
\text { nen. } \\
\text { Börsenanalysten geben den Refinanzierungsvorteil für einen Triple-B- } \\
\text { Emittenten bei einer 5-jährigen Wandelanleihe mit einer Ersparnis von } \\
\text { 2,5 bis 3,5 Prozentpunkten im Vergleich zu einer herkömmlichen Unter- } \\
\text { nehmensanleihe an. Dieser Vorteil ergibt sich aus dem Optionsrecht zur } \\
\text { Wandlung der Anleihe in Aktien. } \\
\text { Attraktiv ist das Instrument aber auch für Anleger. Wandelanleihen ha- } \\
\text { ben einen Renditevorteil gegenüber Aktien, wenn der Kupon über der } \\
\text { Dividendenrendite liegt. Wandelanleihen haben zudem eine niedrigere } \\
\text { Volatilität als Aktien. Aktienportfolien können so diversifiziert werden. In } \\
\text { Anleiheportfolios sorgen sie hingegen für eine zusätzliche Rendite in- } \\
\text { folge der Aktienkursanstiege. Wandelanleihen haben vor allem aber }\end{array}$ \\
\hline
\end{tabular}




\begin{tabular}{|l|l|}
\hline & $\begin{array}{l}\text { einen großen Vorteil, der sie von allen anderen Finanzmarktinstrumen- } \\
\text { ten unterscheidet: Anleger können von dem Aufwärtspotenzial einer } \\
\text { Aktie profitieren und genießen gleichzeitig den Schutz einer Anleihe bei } \\
\text { fallenden Aktienkursen. Als Faustformel gilt: Wandelanleihen machen } \\
\text { die Aufwärtsbewegung einer Aktie zu etwa zwei Dritteln mit; bei einem } \\
\text { Kursrückgang beträgt die Partizipation nur rund ein Drittel. }\end{array}$ \\
\hline $\begin{array}{l}\text { Vorteile für } \\
\text { Anleger }\end{array}$ & $\begin{array}{l}\text { Der Preis einer Wandelanleihe wird vom Aktienkurs des Unternehmens, } \\
\text { dem Zinsniveau sowie der Bonität des Unternehmens beeinflusst. Er- } \\
\text { fahrungen mit der Anlage in Wandelanleihen zeigen, dass der Kurs } \\
\text { einer Wandelanleihe tendenziell rund zwei Drittel der Hausse eines } \\
\text { Aktienkurses mitmacht, aber nur ein Drittel der Baisse eines Aktienkur- } \\
\text { ses. Wandelanleihen bieten dem Anleger die Möglichkeit einer kontrol- } \\
\text { lierten Spekulation. }\end{array}$ \\
\hline $\begin{array}{l}\text { Risiken einer } \\
\text { Wandelanleihe }\end{array}$ & $\begin{array}{l}\text { Das größte Risiko liegt in der Möglichkeit der Insolvenz des Schuld- } \\
\text { ners. Außerdem sind die Märkte für Wandelanleihen i. d. R. nicht so } \\
\text { liquide wie die Aktienmärkte. Der Kurs der Wandelanleihe kann daher } \\
\text { sehr volatil sein. Daneben müssen die Anleger wie auch bei Anleihen } \\
\text { mit dem Zinsänderungsrisiko rechnen. }\end{array}$ \\
\hline Marktvolumen & $\begin{array}{l}\text { Das Volumen beträgt der am Markt befindlichen Wandelanleihen ca. } \\
\text { 600 Milliarden US-Dollar. Davon entfallen auf europäische Wandelan- } \\
\text { leihen ca. 32 \%. In Deutschland ist die Wandelanleihe kaum verbreitet. }\end{array}$ \\
\hline $\begin{array}{l}\text { Käufer und } \\
\text { Anleger von } \\
\text { Wandelanleihen }\end{array}$ & $\begin{array}{l}\text { Wandelanleihen können sich für Privatanleger eignen. Da das Produkt } \\
\text { kompliziert ist, bietet sich als Alternative zur Direktanlage eine Anlage in } \\
\text { Anteilen an einem auf diese Papiere spezialisierten Fonds an. Über- } \\
\text { wiegend werden Wandelanleihen von Großanlegern, wie Versicherun- } \\
\text { gen und Investmentgesellschaften sowie von Hedgefonds erworben. }\end{array}$ \\
\hline $\begin{array}{l}\text { Steuerliche } \\
\text { Behandlung }\end{array}$ & $\begin{array}{l}\text { Zinsen aus Wandelanleihen und Stückzinsen unterliegen der 25 \%igen } \\
\text { Abgeltungsteuer. Die Veräußerungsgewinne unterliegen ohne Einhal- } \\
\text { tung einer Haltefrist ebenfalls der Abgeltungsteuer. }\end{array}$ \\
\hline
\end{tabular}

\section{Bezugsangebot Wandelanleihe der Chemie AG}

\begin{tabular}{|l|l|}
\hline $2,85 \%$ Wandelschuldverschreibung 2018/2024 \\
\hline Gesamtnennbetrag & $400.000 .000,00$ EUR \\
\hline Bezugsfrist & 14.05 .2018 bis 18.05.2018 \\
\hline Bezugsverhältnis & $\begin{array}{l}\text { Jeweils } 30 \text { Aktien berechtigen zum Bezug einer Wandelschuldver- } \\
\text { schreibung im Nennwert von 500,00 EUR. }\end{array}$ \\
\hline Ausgabekurs & $100 \%$ \\
\hline Kleinste Stückelung & 500,00 EUR \\
\hline Verzinsung & $2,85 \%$ p. a., zahlbar am 1. Juni jeden Jahres \\
\hline Rückzahlung & 1. Juni 2024, sofern nicht gewandelt wurde \\
\hline Wandlungsfrist & 1. Juni 2022 bis 31. März 2024 \\
\hline Wandlungsrecht & $\begin{array}{l}\text { Eine Teilschuldverschreibung im Nennwert von 500,00 EUR kann in } \\
10 \text { Aktien der Chemie AG unter Zuzahlung von 5,00 EUR je Aktie } \\
\text { umgetauscht werden. }\end{array}$ \\
\hline
\end{tabular}


Es können 8 Millionen Aktien aus der Emission von Wandelanleihen ausgegeben werden.

Berechnung: 10 x 400 Mio. : $500=8$ Millionen Aktien

Die Stückaktien der Chemie AG haben einen rechnerischen Anteil am Grundkapital von 2,00 EUR. Zur Sicherung der Umtauschrechte muss die Hauptversammlung eine bedingte Kapitalerhöhung über 16 Millionen EUR beschließen.

Berechnung: 8 Millionen Aktien x 2 EUR = 16 Millionen EUR Kapitalerhöhung

Ein Depotkunde möchte 5.000 EUR Nennwert Wandelanleihen der Chemie AG beziehen. Er benötigt 300 Bezugsrechte.

Berechnung: $30 \times 5.000$ EUR : $500=300$ Bezugsrechte

Die Ausübung des Wandlungsrechts lohnt sich, wenn der Wandlungspreis niedriger ist als der Aktienkurs. Aus dem Wandlungsverhältnis und der Zuzahlung von 5,00 EUR ergibt sich ein Wandlungspreis von 55,00 EUR. Eine Ausübung der Wandlung ist sinnvoll, wenn der Aktienkurs über 55,00 EUR liegt.

Berechnung: 500 EUR Nennwert : 10 Aktien $=50,00$ EUR

50 EUR + 5 EUR Zuzahlung = 55 EUR

Wenn alle Anleger während der Wandlungsfrist von ihrem Wandlungsrecht Gebrauch machen, wandelt sich bei der Chemie AG Fremdkapital von 400 Millionen EUR in Eigenkapital um. Zudem erhält die Chemie $A G$ einen Zuzahlungsbetrag von 40 Millionen EUR. Das Eigenkapital erhöht sich dann insgesamt um 440 Millionen EUR.

Das Grundkapital der Gesellschaft erhöht sich um 16 Millionen EUR, der Restbetrag von 424 Millionen EUR wird der Kapitalrücklage zugeführt.

\section{Genussscheine}

\begin{tabular}{|l|l|}
\hline Allgemeine & Genussscheine sind Wertpapiere, die Genussrechte verbriefen. Darun- \\
ter versteht man das Recht, dem Inhaber einen Anteil am Reingewinn \\
der betreffenden Unternehmung zufließen zu lassen, meistens verbun- \\
den mit dem Recht auf eine Mindestverzinsung (Basisrendite). Der In- \\
haber der Genussrechte hat kein Recht auf einen festen Ertrag und \\
keine Stimmberechtigung auf einer Hauptversammlung. Die Kursent- \\
wicklung der Genussscheine entspricht je nach Ausstattung mehr den \\
Aktien oder mehr den Schuldverschreibungen. Für Kreditinstitute ist die \\
Ausgabe von Genussrechten interessant, da diese z. T. als haftendes \\
Eigenkapital anerkannt werden. \\
Genussscheine sind weniger risikobehaftet als Aktien und viele Deri- \\
vate. Genüsse nehmen eine Zwitterstellung zwischen Aktie und Anleihe \\
ein. Wie festverzinsliche Wertpapiere verbriefen sie die Rückzahlung \\
des eingesetzten Kapitals zum Ende der Laufzeit sowie regelmäßige \\
Ausschüttungen. \\
Die Zinshöhe hängt allerdings vom Bilanzgewinn des Unternehmens \\
ab. Steigende Gewinne können die Ausschüttungen erhöhen, Verluste \\
können die Zinszahlungen senken. Auch ein Totalausfall ist möglich. \\
Hinzu kommen die Kursrisiken. In der Regel müssen Genussscheinin- \\
haber Unternehmensverluste, Kapitalschnitte oder einen Konkurs in \\
voller Höhe mittragen. Die Rückzahlungsansprüche und die Kurse von \\
Genussscheinen verhalten sich entsprechend. \\
Das größere Risiko gegenüber Anleihen gleichen die Emittenten mit \\
höheren Zinszahlungen aus. Der Renditeabstand richtet sich nach der
\end{tabular}




\begin{tabular}{|c|c|}
\hline & $\begin{array}{l}\text { Bonität des Schuldners. Finanzschwache Unternehmen müssen hohe } \\
\text { Zinsen bieten, damit steigt aber auch das Risiko für den Anleger und } \\
\text { umgekehrt. Eine allgemein gültige Regel zur Berechnung von Genuss- } \\
\text { scheinrenditen gibt es nicht. }\end{array}$ \\
\hline $\begin{array}{l}\text { Arten von } \\
\text { Genussrechten }\end{array}$ & $\begin{array}{l}\text { - Genussscheine, die eine Beteiligung am Gewinn und Liquidationser- } \\
\text { lös beinhalten. } \\
\text { - Genussrechte, die eine feste oder variable Verzinsung ohne Beteili- } \\
\text { gung am Liquidationserlös beinhalten. }\end{array}$ \\
\hline $\begin{array}{l}\text { Vorteile von } \\
\text { Genussscheinen } \\
\text { für Anleger }\end{array}$ & $\begin{array}{l}\text { - Genussscheine sind weniger risikobehaftet als Aktien und viele } \\
\text { Derivate. } \\
\text { - Die jährlichen Zinszahlungen (Ausschüttungen) liegen i. d. R. um ein } \\
\text { viertel Prozent höher als bei festverzinslichen Wertpapieren mit glei- } \\
\text { cher Laufzeit. }\end{array}$ \\
\hline $\begin{array}{l}\text { Nachteile von } \\
\text { Genussscheinen } \\
\text { für Emittenten } \\
\text { und Anleger }\end{array}$ & $\begin{array}{l}\text { Das Genussscheinkapital steht den Gläubigern nur für eine begrenzte } \\
\text { Zeit zur Verfügung. } \\
\text { Bei Unternehmensverlusten können die jährlichen Zinszahlungen aus- } \\
\text { fallen, bei Kapitalherabsetzungen sinken die Rückzahlungsansprüche } \\
\text { der Anleger entsprechend. } \\
\text { Das Genussrechtskapital ist ein Zwitter zwischen Eigen- und Fremdka- } \\
\text { pital. Dass es nur bis zum Ende der Laufzeit der Genussscheine und } \\
\text { damit nicht dauerhaft einer AG, z. B. einer Bank zur Verfügung steht, } \\
\text { macht es fremdkapitalähnlich. Der jährliche Zins auf die Genussscheine } \\
\text { kann aber ausfallen, wenn eine Bank Verlust macht. Und im Extremfall } \\
\text { kann Genussrechtskapital eben auch im Nennwert herabgesetzt wer- } \\
\text { den, wenn damit Verluste abzudecken sind. Das macht es zu einem } \\
\text { eigenkapitalähnlichen Instrument. } \\
\text { In den vergangenen Jahren haben aber Banken, die einen Jahresver- } \\
\text { lust erlitten haben, in der Regel ihre Rücklagen und Sonderposten in } \\
\text { der Bilanz aufgelöst, um ihren Genussschein-Inhabern die zugesagten } \\
\text { Zinsen zu zahlen. Die ehemalige Gewerkschaftsbank AHBR war vor } \\
\text { der Finanzkrise lange Zeit die einzige Bank, die zur Kapitalherabset- } \\
\text { zung griff. Die EU-Kommission hat dagegen zum Jahresende } 2008 \\
\text { durchgesetzt, dass alle Banken, die Staatshilfe in der Finanzkrise erhal- } \\
\text { ten, so lange keine Zinsen auf ihr Genussscheinkapital zahlen dürfen, } \\
\text { solange sie in einem Jahr Verlust machen. Der Praxis, Rücklagen und } \\
\text { Sonderposten für die Ausschüttung zu mobilisieren, schob sie somit } \\
\text { einen Riegel vor. }\end{array}$ \\
\hline
\end{tabular}

Beispiel für wesentliche Angaben aus einem Bezugsangebot für Genussscheine

\begin{tabular}{|l|l|}
\hline Emittent: & Reisebank $A G$ \\
\hline Verkaufskurs & $101 \%$ \\
\hline Laufzeitbeginn & 14. Mai 2018 \\
\hline Rückzahlung & 14. Mai 2026 zum Nennwert \\
\hline $\begin{array}{l}\text { Mindestzeich- } \\
\text { nungssumme }\end{array}$ & 1.000 EUR und ein Vielfaches \\
\hline
\end{tabular}




\begin{tabular}{|l|l|}
\hline Ausschüttung & $\begin{array}{l}\text { 4\% p.a. vom Nennwert; jeweils zahlbar am 14. Mai eines Jahres, erstmals } \\
\text { zahlbar am 14. Mai 2019; die Ausschüttung entfällt, soweit sie zu einem } \\
\text { Bilanzverlust führt. }\end{array}$ \\
\hline Nachrangigkeit & $\begin{array}{l}\text { Genussrechtskapital kann im Falle der Insolvenz der Bank erst nach Be- } \\
\text { friedigung der nicht nachrangigen Gläubiger der Bank zurückgefordert } \\
\text { werden. }\end{array}$ \\
\hline $\begin{array}{l}\text { Teilnahme am } \\
\text { Verlust }\end{array}$ & $\begin{array}{l}\text { Genussrechtskapital nimmt während der Dauer der Laufzeit bis zur vollen } \\
\text { Höhe am Bilanzverlust der Bank teil. }\end{array}$ \\
\hline
\end{tabular}

\section{Aktienanleihe}

Die Aktienanleihe ist ein Wertpapier, das Elemente von Aktien und Anleihen aufweist. Aktienanleihen sind Schuldverschreibungen mit einer festen Laufzeit. Die Prämie wird in Form einer Zinszahlung am Ende der Laufzeit in einer Summe gezahlt. Die Zinsen unterliegen der pauschalen Abgeltungsteuer in Höhe von 25 Prozent zuzüglich dem Solidaritätszuschlag und ggf. Kirchensteuer.

Die Art der Rückzahlung des eingesetzten Kapitals hängt davon ab, ob der der Anleihe zugrunde liegende Basiswert, eine Einzelaktie oder ein Index, an einem zuvor festgelegten Stichtag einen bestimmten Kurs (Basispreis) erreicht hat. D. h. bei Aktienanleihen besteht neben dem Emittentenrisiko ein Aktienkursrisiko.

Notiert die Aktie am Stichtag zum Basispreis oder über dem festgelegten Basispreis, wird die Anleihe zum Nennbetrag getilgt. Notiert der Basiswert unter dem Basispreis, erhält der Anleger eine bestimmte Anzahl von Aktien zum Basispreis.

Geht ein Anleger das Risiko von Aktienanleihen ein, sollten solide auf Einzelaktien basierte Aktienwerte ausgesucht werden, möglichst mit einem Basispreis unterhalb des Aktienkurses, wobei der Kurs der Anleihe nicht weit über dem Nennwert von 100 liegen sollte. Steigen die Aktienkurse nur leicht, sind höhere Renditen eher möglich als mit der getrennten Anlage in Aktien und Anleihen.

Aktienanleihen sind dann empfehlenswert, wenn man auf hohe, garantierte laufende Zinseinnahmen eines Emittenten mit mindestens guter Bonität abzielen und davon ausgeht, dass sich der Basiswert mittelfristig eher seitwärts bewegt oder keine stärkeren Kurssteigerungen eintreten.

Beispiel einer Aktienanleihe

\begin{tabular}{|l|l|}
\hline Emittentin & Handelsbank AG \\
\hline Stückelung & $1.000,00$ EUR Nennwert \\
\hline Ausgabetag & 16.10 .2018 \\
\hline Zinssatz & $4,65 \%$ \\
\hline Zinstermin & 16.10. \\
\hline Fälligkeit & 16.10 .2020 \\
\hline Basiswert & Immobilien AG-Aktien \\
\hline Feststellungstag & 09.10 .2020 \\
\hline Tilgung & Nennwert oder 33 Aktien je 1.000,00 EUR \\
& Nennwert \\
\hline Basispreis & 30,30 EUR \\
\hline
\end{tabular}

Angenommen die Immobilien AG-Aktie notiert am Fälligkeitstag der Bankschuldverschreibung im Xetra-Handel bei 21,45 EUR. Die Aktienanleihe wird zum Nennwert zurückgezahlt, wenn 
der Kurs der Immobilien AG-Aktie am Feststellungstag den Basispreis von 30,30 EUR nicht unterschreitet.

Unterschreitet der Kurs der Immobilien AG-Aktie am Feststellungstag den Basispreis, wird die Aktienanleihe je 1.000,00 EUR Nennwert durch Lieferung von 33 Stück Immobilien AG-Aktien zurückgezahlt.

Der höhere Zinssatz der Aktienanleihe stellt einen Risikoaufschlag für den Fall dar, dass die Aktienanleihe nicht zum Nennwert zurückgezahlt wird, sondern in Aktien, deren Gegenwert unter dem Nennwert der Aktienanleihe liegt.

Steigt das Zinsniveau am Kapitalmarkt, wird diese Aktienanleihe für Kapitalanleger unattraktiv.

Sinkt der Kurs der Immobilien AG-Aktie, erhöht sich das Risiko der Rückzahlung in Aktien. Sinkt die Bonität der Handelsbank AG, erhöht sich das Risiko des Totalverlusts.

\section{Börse}

\subsection{Marktsegmente an der Effektenbörse}

\begin{tabular}{|c|c|c|}
\hline Aspekte & Regulierter Markt & Open Market (Freiverkehr) \\
\hline $\begin{array}{l}\text { Allgemeine } \\
\text { Kennzeichnung }\end{array}$ & $\begin{array}{l}\text { Er entstand durch die Zusammen- } \\
\text { legung des amtlichen und des } \\
\text { geregelten Marktes. Er ist ein or- } \\
\text { ganisierter Kapitalmarkt mit stren- } \\
\text { gen Publizitäts- und Transparenz- } \\
\text { pflichten: } \\
\text { - Ad-hoc-Publizität } \\
\text { - Haftung bei Unterlassung unver- } \\
\text { züglicher Veröffentlichung } \\
\text { - Pflicht zur Veröffentlichung von } \\
\text { Director's Dealings und zur Füh- } \\
\text { rung von Insiderverzeichnissen } \\
\text { - Pflicht zur Veröffentlichung be- } \\
\text { stimmter Beteiligungsverhältnisse } \\
\text { - Pflicht einer AG zur Abgabe ei- } \\
\text { ner Entsprechenserklärung zum } \\
\text { Corporate Governance Kodex, d. } \\
\text { h. Regelwerk für eine verantwor- } \\
\text { tungsvolle Unternehmensführung } \\
\text { - Pflicht zur Beachtung der Rege- } \\
\text { lungen zum Mindestpreis bei } \\
\text { Übernahmeangeboten } \\
\text { - Pflicht zur Konzernrechnungs- } \\
\text { legung nach IFRS }\end{array}$ & $\begin{array}{l}\text { Kein organisierter Kapitalmarkt. } \\
\text { Die Publizitäts- und Transparenz- } \\
\text { pflichten wie im regulierten Markt } \\
\text { finden keine Anwendung. } \\
\text { Vorteile für das Unternehmen: } \\
\text { - geringere Kosten für die Börsen- } \\
\text { notierung } \\
\text { - Reduktion der Haftungsrisiken } \\
\text { für Emittenten }\end{array}$ \\
\hline $\begin{array}{l}\text { Zulassungs- } \\
\text { voraussetzungen }\end{array}$ & $\begin{array}{l}\text { - Antrag durch Emittenten und } \\
\text { Finanzdienstleistungsunterneh- } \\
\text { men } \\
\text { - Emissionsprospekt mit Unter- } \\
\text { nehmens- und Emissionsbe- } \\
\text { schreibung }\end{array}$ & $\begin{array}{l}\text { - Antrag auf Zulassung von Fi- } \\
\text { nanzdienstleistungsunternehmen } \\
\text { - Jedes Unternehmen muss über } \\
\text { einen Wertpapierprospekt verfü- } \\
\text { gen oder } \\
\text { - über ein Grundkapital von min- }\end{array}$ \\
\hline
\end{tabular}




\begin{tabular}{|c|c|c|}
\hline Aspekte & Regulierter Markt & Open Market (Freiverkehr) \\
\hline & $\begin{array}{l}\text { - Zulassung zum Handel durch die } \\
\text { Geschäftsführung der Börse } \\
\text { - Prospekthaftung des Emittenten } \\
\text { und des Finanzdienstleistungs- } \\
\text { unternehmens für die Richtigkeit } \\
\text { der Angaben }\end{array}$ & $\begin{array}{l}\text { destens 500.000,00 EUR, das in } \\
\text { Aktien mit einem Mindestnomi- } \\
\text { nalwert von 0,10 EUR eingeteilt } \\
\text { ist. } \\
\text { - Eine direkte Rechtsbeziehung } \\
\text { zwischen der AG und der Börse } \\
\text { besteht nicht. } \\
\text { - Ein Unternehmen, das eine No- } \\
\text { tierung anstrebt, muss einen } \\
\text { Handelsteilnehmer (i. d. R. eine } \\
\text { Wertpapierhandelsbank) beauf- } \\
\text { tragen, einen Antrag auf Einbe- } \\
\text { ziehung seiner Aktien in den } \\
\text { Open Market zu stellen. Dieser } \\
\text { unterliegt den AGB und hat auf- } \\
\text { grund seiner Zulassung als } \\
\text { Händler eine Rechtsbeziehung } \\
\text { zur Deutsche Börse AG. } \\
\text { - Bestätigung des Grundkapitals } \\
\text { durch Wirtschaftsprüfer }\end{array}$ \\
\hline Handel & $\begin{array}{l}\text { Reglementierung des Handels } \\
\text { durch die Bestimmungen des Bör- } \\
\text { sengesetzes } \\
\text { Die Geschäftsführung kann die } \\
\text { Zulassung zum Handel widerrufen, } \\
\text { wenn ein ordnungsgemäßer Bör- } \\
\text { senhandel auf Dauer nicht mehr } \\
\text { gewährleistet ist. }\end{array}$ & $\begin{array}{l}\text { Geschäftsführung der Börse er- } \\
\text { lässt Handelsrichtlinien. }\end{array}$ \\
\hline $\begin{array}{l}\text { Publizitäts- } \\
\text { vorschriften }\end{array}$ & $\begin{array}{l}\text { Die Geschäftsführung kann ver- } \\
\text { langen, dass der Emittent Auskünf- } \\
\text { te veröffentlicht, wenn dies zum } \\
\text { Schutz des Publikums oder für } \\
\text { einen ordnungsgemäßen Börsen- } \\
\text { handel erforderlich ist. }\end{array}$ & $\begin{array}{l}\text { Es sind keine gesetzlichen Publizi- } \\
\text { tätsvorschriften vorgesehen. }\end{array}$ \\
\hline $\begin{array}{l}\text { Teilbereiche des } \\
\text { Marktsegments }\end{array}$ & $\begin{array}{l}\text { Prime Standard: Die in diesem } \\
\text { Segment gelisteten Unternehmen } \\
\text { verpflichten sich zu hoher Transpa- } \\
\text { renz, die internationalen Anforde- } \\
\text { rungen entspricht (Quartalsberich- } \\
\text { te, Jahresabschluss nach IFRS } \\
\text { oder US-GAAP, Analystenkonfe- } \\
\text { renzen mindestens einmal im Jahr, } \\
\text { Unternehmenskalender, Ad-hoc- } \\
\text { Mitteilungen). Die Zulassung im } \\
\text { Prime Standard ist Voraussetzung } \\
\text { für die Aufnahme eines Unterneh- }\end{array}$ & $\begin{array}{l}\text { Entry Standard ist die Bezeich- } \\
\text { nung des sog. qualifizierten Frei- } \\
\text { verkehrs an der Frankfurter Wert- } \\
\text { papierbörse, in dem die Aktien und } \\
\text { Anleihen insbesondere kleiner und } \\
\text { mittlerer Unternehmen einbezogen } \\
\text { sind. Im Entry Standard gelten } \\
\text { etwas strengere Vorschriften als im } \\
\text { Open Market. Die testierten Jah- } \\
\text { resabschlüsse müssen veröffent- } \\
\text { licht werden und kursbewegende } \\
\text { Nachrichten müssen unverzüglich }\end{array}$ \\
\hline
\end{tabular}




\begin{tabular}{|l|l|l|}
\hline Aspekte & \multicolumn{1}{|c|}{ Regulierter Markt } & \multicolumn{1}{|c|}{ Open Market (Freiverkehr) } \\
\hline & mens in die Aktienindizes, z. B. & im Internet veröffentlicht werden. \\
& DAX oder MDAX und TecDAX. & Der Entry Standard soll kleineren \\
& General Standard: Marktsegment & Unternehmen eine kostengünstige \\
des regulierten Marktes an der & Börsennotierung ermöglichen. \\
& $\begin{array}{l}\text { Frankfurter Wertpapierbörse. Es } \\
\text { gelten die gesetzlichen Mindestan- } \\
\text { forderungen (Jahres- }\end{array}$ & \\
& /Halbjahresbericht; Ad-hoc- & \\
& Mitteilungen in deutscher Sprache & \\
& usw.). Relativ niedrige Kosten in & \\
& diesem Marktsegment. & \\
\hline
\end{tabular}

8.2 Xetra

\begin{tabular}{|l|l|}
\hline Kllgemeine & Xetra ist ein von der Deutsche Börse AG entwickeltes elektronisches \\
Handelssystem (Exchange Electronic Trading) für den Kassamarkt, in \\
dem Aktien, Optionsscheine und Rentenwerte gehandelt werden. Mit \\
den Zentralrechnern des Xetra-Systems können sich Client-Rechner \\
weltweit über das Internet oder Standleitungen verbinden. \\
Xetra bietet marktgerechte Ausführungspreise, geringe Transaktions- \\
kosten, Gleichberechtigung, Standortunabhängigkeit und Anonymität \\
der Handelspartner. Herausforderungen für ein elektronisches Han- \\
delssystem wie Xetra betreffen vor allem Stabilität, Verfügbarkeit, Ska- \\
lierbarkeit und Latenz sowie eine langfristig steigende Marktaktivität.
\end{tabular}




\begin{tabular}{|l|l|}
\hline & Die Teilnahme am Handel über Xetra sowie am Parketthandel benötigt \\
keine separate Zulassung, sondern neu gelistete Wertpapiere werden \\
automatisch für den Handel auf beiden Handelsystemen freigeschaltet. \\
Die Deutsche Börse betreibt heute am Standort Frankfurt mehrere In- \\
stanzen des Xetra-Systems: \\
- Xetra Frankfurt 1 ist die Plattform für den deutschen Aktienmarkt. \\
- Xetra Frankfurt 2 ist die Plattform der auf Xetra migrierten Derivate- \\
börse Scoach.
\end{tabular}

\section{Besteuerung von Wertpapiererträgen}

\subsection{Besteuerung von Zinsen und Dividenden}

Kapitalerträge unterliegen einer pauschalen $25 \%$-igen Abgeltungsteuer. Kreditinstitute halten von den Kapitalerträgen die $25 \%$-ige Abgeltungsteuer zuzüglich 5,5\% Solidaritätszuschlag (SolZ) auf die Abgeltungsteuer und ggf. Kirchensteuer (KiSt) auf die Abgeltungsteuer ein und führen die Steuern an das Finanzamt ab. Damit ist die Steuerpflicht des Anlegers abgegolten.

Sparer-Pauschbetrag und Werbungskosten

Es gilt ein Sparer-Pauschbetrag von 801 Euro (Ehegatten 1.602 Euro). Mit dem Sparer-Pauschbetrag sind alle tatsächlich angefallenen Werbungskosten (z. B. Depotgebühren, Vermögensverwaltungsgebühren, Reisekosten für Fahrten zur Hauptversammlung) abgegolten und werden damit nicht gesondert berücksichtigt.

Freistellungsaufträge sind nur wirksam, wenn bei Erteilung des Freistellungsauftrags die Steueridentifikationsnummer angegeben wurde. Bei gemeinsamen Freistellungsaufträgen sind die Steueridentifikationsnummern beider Ehegatten anzugeben.

\section{Beispiel für Zinserträge ohne Freistellungsauftrag}

\begin{tabular}{|l|r|}
\hline \multicolumn{1}{|c|}{$5,75 \%$ von $22.500,00$ EUR } & $1.293,75$ EUR \\
\hline$/ .25,00 \%$ Abgeltungsteuer & 323,43 EUR \\
\hline$/ .5,5 \%$ SolZ & 17,78 EUR \\
\hline Nettozinsertrag & $\mathbf{9 5 2 , 5 4 ~ E U R ~}$ \\
\hline
\end{tabular}

Beispiel für Zinserträge mit Freistellungsauftrag (FSA) von 225,50 EUR

\begin{tabular}{|l|r|}
\hline $5,75 \%$ von 22.500,00 EUR & $1.293,75$ EUR \\
\hline.$/$ FSA & 225,50 EUR \\
\hline$=$ Zwischensumme & $1.068,25$ EUR \\
\hline.$/ .25 \%$ Abgeltungsteuer & 267,06 EUR \\
\hline$. / .5,5 \%$ SolZ & 14,68 EUR \\
\hline$=$ Zwischensumme & 786,51 EUR \\
\hline
\end{tabular}




\begin{tabular}{|l|r|}
\hline+ FSA & 225,50 EUR \\
\hline = Nettozinsertrag & $\mathbf{1 . 0 1 2 , 0 1 ~ E U R ~}$ \\
\hline
\end{tabular}

Beispiel für Dividendenerträge ohne Freistellungsauftrag, 400 Aktien, Dividende 0,80 EUR je Aktie

\begin{tabular}{|c|c|}
\hline Bardividende 0,80 EUR je Aktie $\times 400$ & 320,00 EUR \\
\hline.$/ .25 \%$ Abgeltungsteuer & 80,00 EUR \\
\hline$. / .5,5 \%$ SolZ & 4,40 EUR \\
\hline$=$ Gutschriftsbetrag & 235,60 EUR \\
\hline
\end{tabular}

Beispiel für Dividendenerträge mit Freistellungsauftrag über 100,00 EUR, 400 Aktien, Dividende 0,80 EUR je Aktie

\begin{tabular}{|l|r|}
\hline Bardividende 0,80 EUR je Aktie $x 400$ & 320,00 EUR \\
\hline I. FSA & 100,00 EUR \\
\hline$=$ Zwischensumme & 220,00 EUR \\
\hline I. $25 \%$ Abgeltungsteuer & 55,00 EUR \\
\hline I. $5,5 \%$ SolZ & 3,02 EUR \\
\hline = Zwischensumme & $\mathbf{1 6 1 , 9 8 ~ E U R ~}$ \\
\hline + FSA & 100,00 EUR \\
\hline = Nettozinsertrag & $\mathbf{2 6 1 , 9 8 ~ E U R ~}$ \\
\hline
\end{tabular}

Besteuerung von Veräußerungsgewinnen

Veräußerungsgewinne bei Wertpapierverkäufen zählen zu den Einkünften aus Kapitalvermögen und unterliegen der Abgeltungsteuer. Ein Veräußerungsgewinn ist die Differenz zwischen dem bei dem Erwerb gezahlten Kaufpreis und dem bei der Veräußerung erzielten Verkaufserlös unter Berücksichtigung der An- und Verkaufskosten.

Beispiel für die Besteuerung eines Veräußerungsgewinns

mit einem Freistellungsauftrag von 100,00 EUR

\begin{tabular}{|l|r|}
\hline Kaufpreis & $4.267,33$ EUR \\
\hline Verkaufspreis & $6.378,69$ EUR \\
\hline Veräußerungsgewinn & $2.111,36$ EUR \\
\hline I. FSA & 100,00 EUR \\
\hline = Zwischensumme & $\mathbf{2 . 0 1 1 , 3 6 ~ E U R ~}$ \\
\hline I. $25 \%$ Abgeltungsteuer & 502,84 EUR \\
\hline I. $5,5 \%$ SolZ & 27,65 EUR \\
\hline Z Zwischensumme & $\mathbf{1 . 4 8 0 , 8 7 ~ E U R ~}$ \\
\hline+ FSA & 100,00 EUR \\
\hline = Nettoveräußerungsgewinn & $\mathbf{1 . 5 8 0 , 8 7}$ EUR \\
\hline
\end{tabular}

\section{Das automatische Kirchensteuerabzugsverfahren}

Es ist nicht mehr erforderlich, einen Antrag auf Einbehalt von Kirchensteuer auf abgeltend besteuerte Kapitalerträge zu stellen. Der Einbehalt für und die Weiterleitung an die steuererhebende Religionsgemeinschaft erfolgt jetzt automatisch. Das bedeutet, dass die Mitglieder einer steuererhebenden Religionsgemeinschaft nichts weiter veranlassen müssen, um ihren kirchensteuerrechtlichen Pflichten im Zusammenhang mit der Abgeltungsteuer nachzukommen.

Alle zum Steuerabzug vom Kapitalertrag verpflichteten Stellen, z. B. Kreditinstitute und Versicherungen, fragen zur Vorbereitung des automatischen Abzugs der Kirchensteuer auf Abgeltungsteuer einmal jährlich beim Bundeszentralamt für Steuern (BZSt) die Religionszugehörig- 
keit aller Kunden ab. Um den Kirchensteuerabzug vornehmen zu können, ist die Bank gesetzlich verpflichtet, die Religionszugehörigkeit ihrer Kunden in Form eines verschlüsselten Kennzeichens beim BZSt abzufragen. Das sog. Kirchensteuerabzugsmerkmal gibt Auskunft über die Zugehörigkeit eines Kunden zu einer steuererhebenden Religionsgemeinschaft und den geltenden Kirchensteuersatz. Die Abfrage erfolgt einmal jährlich zwischen dem 1. September und dem 31. Oktober. Damit ist die Kirchensteuerpflicht des Kunden für Kapitaleinkünfte vollständig abgegolten. Weitere Angaben in der Steuererklärung entfallen.

Wenn der Kunde nicht möchte, dass das BZSt seine Kirchensteuerdaten verschlüsselt übermittelt, kann der Kunde der Datenweitergabe bis zum 30. Juni eines Jahres widersprechen. Der Widerspruch muss direkt an das BZSt gerichtet werden. Das BZSt sperrt dann die Übermittlung des Kirchensteuerabzugsmerkmals und meldet den Widerspruch dem Finanzamt des Kunden. Kirchenmitglieder werden vom Finanzamt zur Abgabe einer Steuererklärung für die Erhebung der Kirchensteuer auf Abgeltungsteuer aufgefordert.

\section{Kirchensteuer auf Abgeltungsteuer}

Wenn man einer Religionsgemeinschaft angehört, die Kirchensteuer verlangt, ist die Kirchensteuer eine Pflichtsteuer, die zusätzlich zur Abgeltungsteuer gezahlt werden muss. Die Kirchensteuer beträgt $8 \%$ in Bayern und Baden-Württemberg. In allen anderen Bundesländern $9 \%$, prozentual berechnet von der Höhe der Abgeltungsteuer. Da man allerdings die Kirchensteuer als Sonderausgabe absetzen kann, ist die genaue Berechnungsgrundlage der Kirchensteuer nicht $9 \%$ von $25 \%$, sondern die $25 \%$ Abgeltungsteuer abzüglich des möglichen Sonderausgabenabzuges. Da die Kirchensteuer bei der Einkommensteuer als Sonderausgabe abzugsfähig ist, errechnet sich die Abgeltungsteuer nach folgender Formel:

Abgeltungsteuer $=$ Kapitalerträge $:(4+($ Kirchensteuersatz $: 100))$

Bei $9 \%$ Kirchensteuer ergibt dies die Berechnungsgrundlage von 24,45\%.

Bei $8 \%$ Kirchensteuer ist die Berechnungsgrundlage 24,51\%.

Falls man zu den Steuerpflichtigen gehört, die $9 \%$ Kirchensteuer zu zahlen haben, ergibt sich dann folgende zu zahlende Gesamtsumme bei schon abgezogenen Sonderausgaben: Für 100,00 EUR Zinsen, Dividenden oder Kursgewinne 24,45 EUR Abgeltungsteuer, 1,34 EUR Solidaritätszuschlag und 2,20 EUR Kirchensteuer, also insgesamt 27,98 EUR.

Falls man zu den Steuerpflichtigen gehört, die 8 \% Kirchensteuer zu zahlen haben, ergibt sich dann folgende zu zahlende Gesamtsumme (bei schon abgezogenen Sonderausgaben): Für 100,00 EUR Zinsen, Dividenden oder Kursgewinne 24,51 EUR Abgeltungsteuer, 1,34 EUR Solidaritätszuschlag (berechnet von 24,51 EUR) und 1,960 EUR Kirchensteuer, also insgesamt 27,81 EUR.

Beispiel eines Zinsertrags unter Berücksichtigung von $9 \%$ Kirchensteuer

\begin{tabular}{|l|r|}
\hline $4 \%$ Zinsen auf 10.000 EUR für 1 Jahr & 400,00 EUR \\
\hline$. / .24,45 \%$ Abgeltungsteuer & 97,80 EUR \\
\hline$. / .5,5 \%$ Solidaritätszuschlag auf die Abgeltungsteuer von 97,80 EUR & 5,37 EUR \\
\hline.$/ .9 \%$ Kirchensteuer auf die Abgeltungsteuer von 97,80 EUR & 8,80 EUR \\
\hline$=$ Gutschriftsbetrag & $\mathbf{2 8 8 , 0 3}$ EUR \\
\hline
\end{tabular}

\section{Verlustverrechnungstöpfe}

Veräußerungsverluste können als negative Kapitalerträge mit positiven Kapitalerträgen verrechnet werden. Negative Kapitalerträge begründen einen Steuererstattungsanspruch an das Finanzamt, der auf drei Wegen geltend gemacht werden kann:

- rückwirkende Steuererstattung durch die Bank innerhalb eines Kalenderjahres 
- Ausstellung einer Verlustbescheinigung durch die Bank und Geltendmachung des Verlustes in der Einkommensteuererklärung

- Einstellung des Verlustes in ein Verlustverrechnungskonto, wenn keine sofortige Steuerverrechnung möglich ist.

Veräußerungsverluste aus Aktiengeschäften dürfen nur mit Gewinnen aus Aktiengeschäften verrechnet werden. Veräußerungsgewinne aus Aktiengeschäften können hingegen mit allen anderen negativen Kapitalerträgen verrechnet werden. Andere negative Kapitalerträge (z. B. Veräußerungsverluste bei Zertifikaten oder Investmentanteilen, gezahlte Stückzinsen beim Erwerb von Anleihen können mit allen positiven Kapitalerträgen (z. B. Zinserträgen, Dividenden, Veräußerungsgewinnen bei Aktien oder Zertifikaten) verrechnet werden. Die Bank muss daher aufgrund der unterschiedlichen Verrechnungsregelungen zwei unterschiedliche Verlustverrechnungstöpfe führen:

- Aktienverlustverrechnungstopf: Erfassung der Veräußerungsverluste aus Aktiengeschäften; Verrechnung nur mit späteren Gewinnen aus Aktiengeschäften

- Allgemeiner Verlustverrechnungstopf: Erfassung aller anderen negativen Kapitalerträge; Verrechnung mit allen späteren positiven Kapitalerträgen einschl. der Gewinne aus Aktiengeschäften

\section{Veräußerungsgewinne und Verlustverrechnungstöpfe}

Veräußerungsgewinne bei Aktien sind als positive Kapitalerträge steuerpflichtig. Ein Veräußerungsgewinn ist die positive Differenz zwischen dem beim Erwerb gezahlten Kaufpreis und dem bei der Veräußerung erzielten Verkaufserlös unter Berücksichtigung der An- und Verkaufskosten. Veräußerungsverluste können als negative Kapitalerträge mit positiven Kapitalerträgen verrechnet werden. Negative Kapitalerträge begründen einen Steuererstattungsanspruch an das Finanzamt. Veräußerungsverluste aus Aktiengeschäften dürfen nur mit Gewinnen aus Aktiengeschäften verrechnet werden. Veräußerungsgewinne aus Aktiengeschäften können mit allen anderen negativen Kapitalerträgen verrechnet werden. Aufgrund dieser Regelung muss die Bank einen Aktienverlustverrechnungstopf und einen allgemeinen Verlustverrechnungstopf führen. Die Verlustverrechnung hat Vorrang vor der Belastung des Freistellungsauftrags (FSA).

Beispiel: Ein Kunde hat noch einen FSA von 801,00 EUR

\begin{tabular}{|l|r|}
\hline Veräußerungsgewinn & $1.600,00$ EUR \\
\hline /. Veräußerungsverlust & $1.100,00$ EUR \\
\hline /. Bestand im Verlustverrechnungstopf des Kunden & 0,00 EUR \\
\hline = verbleibender Veräußerungsgewinn & 500,00 EUR \\
\hline Noch verbleibender FSA & $\mathbf{3 0 1 , 0 0 ~ E U R ~}$ \\
\hline
\end{tabular}

\section{Beispiel: Wiederaufleben eines FSA}

Ein Depotkunde hat einen FSA in Höhe von 801,00 EUR erteilt.

Folgende Kapitalerträge bzw. -verluste werden erzielt:

\begin{tabular}{|l|l|r|}
\hline & $\begin{array}{c}\text { Allgemeiner } \\
\text { Verlustverrechnungstopf }\end{array}$ & Verbleibender FSA \\
\hline 14.03. & $\begin{array}{l}\text { Veräußerungsge- } \\
\text { winn bei Bundesan- } \\
\text { leihen 400,00 EUR }\end{array}$ & 401,00 EUR \\
\hline 15.06. & $\begin{array}{l}\text { Zinsen auf Anleihen } \\
150,00 \text { EUR }\end{array}$ & 251,00 EUR \\
\hline
\end{tabular}




\begin{tabular}{|l|l|l|}
\hline $\begin{array}{l}\text { 12.10. } \begin{array}{l}\text { Verlust bei Optionen } \\
\text { 850,00 EUR }\end{array} \\
\end{array}$ & $\begin{array}{l}\text { In den allgemeinen Verlustver- } \\
\text { rechnungstopf wird der Betrag } \\
\text { von 300,00 EUR eingestellt } \\
(850,00-400,00-150,00)\end{array}$ & $\begin{array}{l}\text { Die am 14.3. und 15.6. er- } \\
\text { folgten Belastungen des } \\
\text { Freistellungsvolumens wer- } \\
\text { den rückgängig gemacht. } \\
\text { Neuer FSA 801,00 EUR }\end{array}$ \\
\hline Jahresende & $\begin{array}{l}\text { Der Bestand des Verlustver- } \\
\text { rechnungstopfes von } \\
\text { 300,00 EUR wird auf das } \\
\text { nächste Jahr übertragen. }\end{array}$ & $\begin{array}{l}\text { Das Freistellungsvolumen } \\
\text { von 801,00 EUR verfällt am } \\
\text { Jahresende. }\end{array}$ \\
\hline
\end{tabular}

\section{Nichtveranlagungs-Bescheinigung (NV-Bescheinigung)}

Bei Vorlage einer NV-Bescheinigung zahlt das Kreditinstitut die Kapitalerträge ohne Steuerabzug aus. Eine NV-Bescheinigung stellt das Finanzamt auf Antrag des Steuerpflichtigen aus, wenn seine Kapitalerträge voraussichtlich nicht einkommensteuerpflichtig sind. Die betraglich nicht begrenzte NV-Bescheinigung gilt für maximal drei Jahre und muss nach Fristablauf neu beim Finanzamt beantragt werden. Eine NV-Bescheinigung ist für Personen interessant, die nicht zur Einkommensteuer veranlagt werden und Kapitalerträge über den Sparer-Pauschbetrag hinaus erzielen.

\section{Stückzinsen und allgemeiner Verlustverrechnungstopf}

\section{Beispiel 1}

Die Nordbank AG führt am 23.11. (Dienstag) für den Depotkunden Rainer Bittermann den folgenden Kaufauftrag aus:

- 50.000,00 EUR Nennwert 4,0 \% Internet AG-Inhaberschuldverschreibungen

- Zinstermin: 13. September, ganzjährig

Der Auftrag wird zum Kurs von 100,75 \% ausgeführt. Weder der von der Nordbank AG für Herrn Bittermann geführte allgemeine Verlustverrechnungstopf noch das Steuerverrechnungskonto (Steuerverrechnungstopf) weisen einen Bestand auf. Zurzeit liegt weder ein Freistellungsauftrag noch eine Kirchensteuerpflicht vor.

Herr Bittermann muss für diesen Kaufauftrag für 73 Zinstage 400,00 EUR Stückzinsen an den Veräußerer zahlen. Da es sich bei den zu zahlenden Stückzinsen für Herrn Bittermann um einen Aufwand handelt, erhöhen diese Stückzinsen den Saldo seines allgemeinen Verlustverrechnungstopfs.

\section{Beispiel 2}

Herr Jens Müller ist Depotkunde der Nordbank AG. Ein Freistellungsauftrag von 500,00 EUR liegt der Nordbank AG für dieses Depot für 2018 vor. Herr Müller hatte im März 2018 bereits eine Zinsgutschrift in Höhe von 200,00 EUR erhalten, die auf den Freistellungsbetrag angerechnet wurde.

Am 4. Mai 2018 hatte Herr Müller eine Unternehmensanleihe im Nennwert von 30.000,00 EUR erworben. Für diesen Kauf waren Herrn Müller Stückzinsen in Höhe von 1.052,88 EUR berechnet worden, die in seinem Allgemeinen Verlustverrechnungstopf eingestellt wurden.

Die laufende Zinsgutschrift in Höhe von brutto 2.100,00 EUR aus dieser Unternehmensanleihe hatte Herr Müller am 5. November 2018 erhalten.

Die Zinsgutschrift für diese Unternehmensanleihe wird unter der Annahme ermittelt, dass Herr Müller keine weiteren Zinsgutschriften im laufenden Jahr erhalten hatte. 
Ermittlung der Zinsgutschrift:

\begin{tabular}{|c|c|}
\hline Bruttozinsen & 2.100,00 EUR \\
\hline Bestand im Allgemeinen Verlustverrechnungstopf & 1.052,88 EUR \\
\hline ./. freigestellte Zinsgutschrift vom März 2018 & 200,00 EUR \\
\hline verbleibende Stückzinsen aus dem Allgemeinen Verlustverrechnungstopf & 852,88 EUR \\
\hline+ Freistellungsauftrag & 500,00 EUR \\
\hline aktuelles Freistellungsvolumen & 1.352,88 EUR \\
\hline$=$ steuerpflichtiger Zinsertrag $(2.100,00-1.352,88)$ & 747,12 EUR \\
\hline.$/ .25 \%$ Abgeltungsteuer & 186,78 EUR \\
\hline$. / .5,5 \%$ SolZ auf Abgeltungsteuer & 10,27 EUR \\
\hline \multicolumn{2}{|l|}{ Gutschrift: } \\
\hline Bruttozinsen & 2.100,00 EUR \\
\hline ./. Abgeltungsteuer & 186,78 EUR \\
\hline ./. SolZ auf Abgeltungsteuer & 10,27 EUR \\
\hline Zinsgutschrift & 1.902,95 EUR \\
\hline
\end{tabular}

\subsection{Besteuerung von Investmentfonds und Investmenterträgen}

Die Investmentsteuerreform ist mit Wirkung zum 1. Januar 2018 in Kraft getreten. Dadurch ergaben sich zahlreiche Neuerungen bei der Besteuerung von Erträgen aus Investmentfonds. Diese Reform bezieht sich unter anderem auf Aktienfonds, Mischfonds sowie Immobilienfonds.

Die Erträge der Investmentfonds stellen nach deutschem Recht „Einkünfte aus Kapitalvermögen" dar, die separat von anderen Einkünften besteuert werden (sog. Abgeltungsteuer). Sie unterliegen grundsätzlich einer 25\%igen Kapitalertragsteuer, die sich um den Solidaritätszuschlag und ggf. um die Kirchensteuer erhöht.

Dabei gilt derjenige als unbeschränkt steuerpflichtig, der in Deutschland seinen Wohnsitz oder gewöhnlichen Aufenthalt hat und mit seinen Einkünften der deutschen Einkommensteuerpflicht unterliegt.. Ausländische Privatanleger, die weder ihren Wohnsitz noch ihren gewöhnlichen Aufenthalt in Deutschland haben, unterliegen nicht dem Kapitalertragsteuerabzug in Deutschland.

Zahlung von Körperschaftsteuer aus dem Fondvermögen

Seit der Investmentsteuerreform müssen deutsche Fonds Körperschaftsteuer auf bestimmte inländische Erträge in Höhe von 15 \% aus dem Fondsvermögen zahlen. Inländische Dividenden und Immobilienerträge werden also bereits auf Fondsebene mit einer Körperschaftsteuer von $15 \%$ (bei Immobilienerträgen. zzgl. SolZ) belastet. Damit behandelt der Gesetzgeber deutsche und ausländische Fonds im Hinblick auf deren Einkünfte aus Deutschland steuerlich gleich. Die Fonds zahlen Anlegern somit geringere Kapitalbeträge aus. Als Ausgleich bekommen Anleger je nach Fondsart eine Teilfreistellung für Dividenden und Verkaufsgewinne.

Teilfreistellung von der Abgeltungssteuer

Um die Vorbelastung mit Körperschaftsteuer und die mangelnde Anrechnungsfähigkeit ausländischer Quellensteuer zu kompensieren, gewährt der Gesetzgeber je nach Fondsart eine sogenannte Teilfreistellung von der Abgeltungsteuer.

Die Anleger von Publikumsfonds unterliegen jetzt einer pauschalen Besteuerung von Investmenterträgen. Dazu zählen Ausschüttungen, die sogenannte Vorabpauschale sowie Gewinne 
aus der Rückgabe bzw. Veräußerung von Fondsanteilen.

\begin{tabular}{|l|c|}
\hline Teilfreistellung von Investmentfonds & Freistellungsquote \\
\hline Aktienfonds (mind. 51\% Aktien) & $30 \%$ \\
\hline Mischfonds (mind. 25\% Aktien) & $15 \%$ \\
\hline Immobilienfonds (mind. 51 \% Immobilien/ Immobiliengesellschaften) & $60 \%$ \\
\hline $\begin{array}{l}\text { Immobilienfonds mit Schwerpunkt im Ausland } \\
\text { (mind. 51\% ausländische Immobilien / Immobiliengesellschaften) }\end{array}$ & $80 \%$ \\
\hline
\end{tabular}

Die Fondsanleger müssen selbst die Mittel zur Zahlung der Steuer bereitstellen. Daher darf die depotführende Stelle die erforderlichen Beträge zur Abführung der Steuer auf die Vorabpauschale direkt vom Girokonto oder von einem anderen Referenzkonto des Anlegers einziehen - auch ohne dessen Einwilligung.

Vorabpauschale

Mit der Vorabpauschale soll sichergestellt werden, dass ein bestimmter Mindestbetrag versteuert wird, auch dann, wenn ein Fonds keine oder eine zu geringe Ausschüttung vornimmt. Diese sogenannte Vorabpauschale wird jährlich ermittelt und bezieht sich immer auf das Vorjahr. Die Vorabpauschale ist eine vorweggenommene Besteuerung zukünftiger Wertsteigerungen. Daher wird die Vorabpauschale beim Verkauf der Fondsanteile auch vom tatsächlichen Veräußerungsgewinn abgezogen. Basis für die Berechnung bildet die langfristig erzielbare Rendite öffentlicher Anleihen. Der Basiszins orientiert sich am Zinssatz, den die Deutsche Bundesbank jeweils auf den ersten Börsentag des Jahres errechnet.

Auf die Vorabpauschale wird am Anfang des folgenden Kalenderjahres von der depotführenden Stelle Abgeltungsteuer einbehalten. Um eine Doppelbesteuerung zu vermeiden, kann auf die Vorabpauschale die einbehaltene Steuer später von den tatsächlichen Veräußerungsgewinnen beim Verkauf der Fondsanteile wieder abgezogen werden.

Die Vorabpauschale ist die Differenz zwischen dem sogenannten Basisertrag des Fonds und der Ausschüttung. Hierzu wird zunächst zu Beginn eines Kalenderjahres für das vorangegangene Kalenderjahr der Basisertrag nach der Formel berechnet: Basisertrag $=70 \%$ des jährl. Basiszinses x Rücknahmepreis der Fondsanteile zum Jahresbeginn des vorangegangenen Kalenderjahres (z. B. 1.1.2018). Dann wird vom Basisertrag die Ausschüttung des letzten Kalenderjahres (z. B. in 2018) abgezogen: Vorabpauschale = Basisertrag - Ausschüttung des letzten Kalenderjahres.

Die Vorabpauschale kann niemals negativ werden. Der Basisertrag kann nicht höher sein als der Mehrbetrag, der sich aus dem zwischen dem ersten und dem letzten im Kalenderjahr festgesetzten Rücknahmepreis zuzüglich der Ausschüttungen innerhalb des Kalenderjahres ergibt.

Beispiel für die Vorabpauschale:

Gegeben sind folgende Daten:

- Fondspreis zum 2. Januar 2019: 100 EUR

- Fondspreis zum 30. Dezember 2019: 120 EUR

- Basiszins (angenommen): $1 \%$

- Ausschüttung für das Geschäftsjahr: 0,50 EUR je Anteil

Der Anleger besitzt 500 Fondsanteile eines Aktienfonds.

Der Basisertrag beträgt ( $70 \%$ von $1 \%$ ) 0,7 \% x 100 EUR = 0,70 EUR. Die Vorabpauschale beträgt somit 0,70 EUR - 0,50 EUR $=0,20$ EUR je Anteil.

Die Erträge aus dem Fonds für das Geschäftsjahr 2019 umfassen die Ausschüttung in Höhe 
von 0,50 EUR je Anteil und die Vorabpauschale in Höhe von 0,20 EUR je Anteil, insgesamt also 0,70 EUR je Anteil. Davon sind nur $70 \%$ steuerpflichtig (Teilfreistellung $30 \%$ ) = 0,49 EUR je Anteil bzw. bei 500 Anteilen insgesamt 245 EUR. Diese werden auf den Freistellungsauftrag angerechnet.

Für thesaurierende Fonds und Fonds mit Teilausschüttungen ergeben sich unterschiedliche Ergebnisse, die sich auf den Zeitpunkt der Steuerpflicht auswirken:

Einbehalt der Steuer

Die Abgeltungsteuer ist ein Abzug der Steuer direkt an der Quelle. In den meisten Fällen wird daher die Abgeltungsteuer durch deutsche Kreditinstitute einbehalten.

Das gilt auch für die Kirchensteuer, die seit 2015 automatisch einbehalten wird und über das Betriebsstätten-Finanzamt der Kreditinstitute an die Religionsgemeinschaften weitergeleitet wird. Zu diesem Zweck fragen die Banken einmal jährlich im Zeitraum vom 1. September bis 31. Oktober beim Bundeszentralamt für Steuern die Religionszugehörigkeit ihrer Kunden zum Stichtag 31. August des Jahres ab.

Anleger können dem automatischen Datenabruf beim Bundeszentralamt für Steuern schriftlich widersprechen, indem sie einen Sperrvermerk einlegen. Der Sperrvermerk entbindet nicht von der Kirchensteuerpflicht. Sie müssen dann die Kirchensteuer auf die Abgeltungsteuer über die Steuererklärung ans Finanzamt abführen. Das Bundeszentralamt für Steuern ist gesetzlich verpflichtet, das zuständige Finanzamt über die Sperre zu informieren.

Verlustverrechnung

Für in einem Depot verwahrte Fondsanteile führt das inländische Kreditinstitut u. a. einen allgemeinen Verlustverrechnungstopf' um fortlaufend eine Verrechnung von Erträgen und Veräußerungsgewinnen mit Veräußerungsverlusten und anderen negativen Kapitalerträgen vorzunehmen.

Auch die Teilfreistellung ist auf Verluste aus der Veräußerung der Fondsanteile anwendbar.

\section{Verwahrung und Verwaltung von Wertpapieren}

\subsection{Girosammelverwahrung}

\begin{tabular}{|l|l|}
\hline $\begin{array}{l}\text { Allgemeine } \\
\text { Kennzeichnung }\end{array}$ & $\begin{array}{l}\text { Unter der Girosammelverwahrung bezeichnet man die Verwahrung } \\
\text { von Wertpapieren bei einer Bank in einem sogenannten Girosammel- } \\
\text { depot. Dabei werden alle Effekten derselben Gattung gemeinsam } \\
\text { verwahrt. Der so verwahrte Bestand steht im Eigentum nach Bruchtei- } \\
\text { len aller Einlieferer. Jeder hat einen Herausgabeanspruch an Stücken } \\
\text { der beschriebenen Wertpapiergattung, die als Gattungssache unterei- } \\
\text { nander austauschbar sind. }\end{array}$ \\
\hline Eigentumserwerb & $\begin{array}{l}\text { Das Eigentum wird durch Buchung auf dem Depotkonto erworben, } \\
\text { wenn der Verwahrer zugleich den Kauf vermittelt. Bei der Einlieferung } \\
\text { effektiver Stücke geht das Einzeleigentum an den Papieren unter. } \\
\text { Regelmäßig wird ein Sammelbestand nur von einer Wertpapiersam- } \\
\text { melbank gebildet. Diese kann innerhalb des Sammelbestands prob- } \\
\text { lemlos den Effektengiroverkehr durchführen. } \\
\text { Gemeinsame Aufbewahrung der von verschiedenen Kunden hinter- } \\
\text { legten Effekten derselben Gattung, wobei die einlegenden Kunden } \\
\text { Eigentumsrecht nicht an eingelieferten Effekten, sondern bruchteiliges } \\
\text { Miteigentum am Sammeldepotbestand erhalten. }\end{array}$ \\
\hline
\end{tabular}




\begin{tabular}{|c|c|}
\hline $\begin{array}{l}\text { Verwaltungs- } \\
\text { arbeiten }\end{array}$ & $\begin{array}{l}\text { Folgende Verwaltungsarbeiten werden von der Wertpapiersammel- } \\
\text { bank übernommen: } \\
\text { - Zins- und Dividendenscheineinlösung } \\
\text { - buchtechnische Abwicklung von Kapitalerhöhungen und -herabset- } \\
\text { zungen } \\
\text { - Durchführung der Verwaltungsaufgaben bei Auslosungen } \\
\text { - Kündigungen } \\
\text { Die Wertpapiersammelbank ist nicht berechtigt, Depotstimmrechte } \\
\text { auszuüben. }\end{array}$ \\
\hline
\end{tabular}

10.2 Sonderverwahrung

\begin{tabular}{|l|l|}
\hline $\begin{array}{l}\text { Allgemeine } \\
\text { Kennzeichnung }\end{array}$ & $\begin{array}{l}\text { Eine Streifbandverwahrung oder auch Sonderverwahrung genannt ist } \\
\text { eine Form des offenen Depots, das dazu dient, Wertpapiere zu ver- } \\
\text { wahren und zu verwalten. Es ist ein Bankgeschäft und obliegt einer } \\
\text { Depotbank. Der Anleger hat bei einer Sonderverwahrung Eigentum an } \\
\text { den verwahrten Wertpapierurkunden. Die Aufbewahrung dieser Stü- } \\
\text { cke wird gesondert vorgenommen. Die Wertpapiere erhalten eine } \\
\text { Kennzeichnung, die über den Hinterleger Auskunft gibt. }\end{array}$ \\
\hline $\begin{array}{l}\text { Gründe für die } \\
\text { Sonderverwahrung }\end{array}$ & $\begin{array}{l}\text { Eine Sonderverwahrung kommt nur in Frage, wenn Wertpapiere nicht } \\
\text { sammelverwahrfähig sind oder wenn der Anleger ausdrücklich } \\
\text { wünscht, dass die Wertpapiere gesondert verwahrt werden sollen. }\end{array}$ \\
\hline $\begin{array}{l}\text { Trennung von } \\
\text { pierbentänden }\end{array}$ & $\begin{array}{l}\text { Bei einer Streifbandverwahrung muss die Bank darauf achten, dass } \\
\text { die Wertpapiere der Kunden auch getrennt von bankeigenen Wertpa- } \\
\text { pierbeständen und den Wertpapieren dritter Personen aufbewahrt } \\
\text { werden. Eine Streifbandverwahrung liegt dann vor, wenn Wertpapiere } \\
\text { in sogenannten Streifbändern oder Mappen aufbewahrt werden. Die } \\
\text { Kennzeichnung der Streifbänder beinhaltet Angaben zur Person, wel- } \\
\text { che die Wertpapiere hinterlegt hat, und beispielsweise die Wertpa- } \\
\text { pierkennnummer ISIN und die Art des Wertpapiers. Außerdem dürfen } \\
\text { Mäntel und Bögen nicht zusammen verwahrt werden. }\end{array}$ \\
\hline Kosten & $\begin{array}{l}\text { Die Wertpapiere werden bei einer Streifbandverwahrung zum Beispiel } \\
\text { im Safe der Bank verwahrt. Der Anleger muss damit rechnen, dass er } \\
\text { die Kosten für die Verwaltung seiner Wertpapiere zu tragen hat. }\end{array}$ \\
\hline Eigentumserwerb & $\begin{array}{l}\text { Werden vom Bankkunden Wertpapiere käuflich erworben, erhält die- } \\
\text { ser ein sogenanntes Stückeverzeichnis. Dieses Stückeverzeichnis } \\
\text { dient dem Anleger als Beweis dafür, dass er Eigentum an den Stü- } \\
\text { cken besitzt. In einem Stückeverzeichnis werden alle erworbenen } \\
\text { Stücke mit der jeweiligen Stücknummer für den Käufer aufgelistet. }\end{array}$ \\
\hline
\end{tabular}




\section{Anlageberatung}

\begin{tabular}{|c|c|}
\hline Grundlagen & $\begin{array}{l}\text { - Provisionsbasierte Anlageberatung: Bei einem Geschäftsab- } \\
\text { - Honorarä-Anlageberatung: Das Kreditinstitut erhält eine Vergütung } \\
\text { vom Kunden, deren Höhe von der Dauer und Komplexität der An- } \\
\text { lageberatung abhängig ist. } \\
\text { Vor Beginn der Beratung und vor Abschluss des Beratungsvertrages } \\
\text { ist der Kunde in verständlicher Form darüber zu informieren, ob die } \\
\text { Anlageberatung als unabhängige Honorar-Anlageberatung erbracht } \\
\text { wird oder nicht. } \\
\text { Direktbanken: Sie erbringen ihre Leistungen ohne jede Beratungsleis- } \\
\text { tung an. Die Bankgeschäfte können demnach zu sehr günstigen Kon- } \\
\text { ditionen abgeschlossen werden. Die Anlageentscheidung wird vom } \\
\text { Kunden in Eigenverantwortung ohne Beratungsleistung der Bank ge- } \\
\text { troffen. }\end{array}$ \\
\hline $\begin{array}{l}\text { Sachkundenach- } \\
\text { weis für Anlagebe- } \\
\text { rater/-innen }\end{array}$ & $\begin{array}{l}\text { Anlageberater/-innen müssen die für eine qualifizierte Beratung erfor- } \\
\text { derliche Sachkunde besitzen. Dazu gehören Kenntnisse in den Berei- } \\
\text { chen Kundenberatung, Rechtsgrundlagen, Fachkenntnisse. }\end{array}$ \\
\hline Kundengruppen & $\begin{array}{l}\text { - Privatkunden: Zu einem Vermögensaufbau werden dem Kunden in } \\
\text { erster Linie standardisierte Produkte in den Geschäftsstellen der } \\
\text { Bank angeboten. Die Produkte sind auf die Bedürfnisse der unter- } \\
\text { schiedlichen Kundengruppen zugeschnitten und so gestaltet, dass } \\
\text { sie dem Kunden ohne aufwendigen Beratungsbedarf erläutert wer- } \\
\text { den können. } \\
\text { - Vermögende Privatkunden: Kriterien für die Zuordnung zu dieser } \\
\text { Kundengruppe sind das Jahreseinkommen und das Vermögen der } \\
\text { Kunden. Die Kunden werden aktiv von besonderen Beratern in spe- } \\
\text { ziellen Beratungszentren betreut und beraten. } \\
\text { - Firmenkunden: Bei dieser Kundengruppe werden komplexe Finan- } \\
\text { zierungsfragen, z. B. Zahlungsverkehrsleistungen, Unternehmens- } \\
\text { beteiligungen und -übernahmen, Kreditgewährungen, Devisenge- } \\
\text { schäfte und -absicherungen, Anlagemöglichkeiten gelöst. }\end{array}$ \\
\hline $\begin{array}{l}\text { Verhaltensregeln } \\
\text { nach dem Wertpa- } \\
\text { pier-handelsgesetz } \\
\text { (WpHG) }\end{array}$ & $\begin{array}{l}\text { Das WpHG unterscheidet professionelle Kunden und Privatkunden. } \\
\text { - Professionelle Kunden sind Kunden, die über ausreichende Erfah- } \\
\text { rungen, Kenntnisse und Sachverstand verfügen, um ihre Anlageent- } \\
\text { scheidungen zu treffen und die damit verbundenen Risiken ange- } \\
\text { messen beurteilen zu können. Die Informations- und Aufklärungs- } \\
\text { pflichten gegenüber diesen Kunden sind gering. } \\
\text { - Privatkunden sind vor dem Abschluss von Finanzdienstleistungsge- } \\
\text { schäften umfangreich über die Art des Geschäftes und die damit } \\
\text { verbundenen Risiken aufzuklären. } \\
\text { Allgemeine Regel: Ein Wertpapierdienstleistungsunternehmen muss } \\
\text { alle Leistungen ehrlich, redlich und professionell im bestmöglichen } \\
\text { Interesse seiner Kunden erbringen. Außerdem muss das Unterneh- } \\
\text { men angemessene organisatorische Maßnahmen treffen, um Interes- }\end{array}$ \\
\hline
\end{tabular}




\begin{tabular}{|c|c|}
\hline & $\begin{array}{l}\text { senskonflikte zu vermeiden. Über trotzdem bestehende Interessens- } \\
\text { konflikte ist der Kunde vor einem Geschäftsabschluss zu informieren. } \\
\text { Das Unternehmen darf keine Anreize für Mitarbeiter schaffen, nicht im } \\
\text { bestmöglichen Interesse ihrer Kunden zu handeln. Insbesondere dür- } \\
\text { fen Mitarbeiter nicht durch Vergütungsvereinbarungen oder Verkaufs- } \\
\text { ziele Anreize erhalten, einem Privatkunden bestimmte Produkte zu } \\
\text { empfehlen, obwohl ein anderes Finanzinstrument eigentlich geeigneter } \\
\text { für ihn ist. Das Unternehmen muss Finanzinstrumente so ausgestal- } \\
\text { ten, dass sie den Bedürfnissen eines bestimmten Zielmarktes entspre- } \\
\text { chen. } \\
\text { Das WpHG verbietet, anderen unter Ausnutzung ihrer Unerfahrenheit } \\
\text { zu Börsenspekulationsgeschäften zu verleiten. Das sind insbesondere } \\
\text { Termin- und Optionsgeschäfte, die darauf gerichtet sind, aus dem } \\
\text { Unterschied zwischen dem für die Lieferzeit festgelegten Preis und } \\
\text { dem zur Lieferzeit vorhandenen Börsen- oder Marktpreis einen Ge- } \\
\text { winn zu erzielen. }\end{array}$ \\
\hline $\begin{array}{l}\text { Bearbeitung von } \\
\text { Kundenaufträgen }\end{array}$ & $\begin{array}{l}\text { Ein Wertpapierdienstleister muss geeignete Vorkehrungen treffen, um } \\
\text { - Kundenaufträge unverzüglich auszuführen, } \\
\text { - Vergleichbare Kundenaufträge nach der Reihenfolge ihres Eingangs } \\
\text { auszuführen. }\end{array}$ \\
\hline $\begin{array}{l}\text { Aufzeichnungs- } \\
\text { und Aufbewah- } \\
\text { rungspflicht }\end{array}$ & $\begin{array}{l}\text { Ein Wertpapierdienstleister muss Aufzeichnungen erstellen über die } \\
\text { von ihm erbrachten Wertpapierdienstleistungen sowie die von ihm } \\
\text { getätigten Geschäften und über Vereinbarungen mit Kunden, die die } \\
\text { Rechte und Pflichten der Vertragsparteien festlegen. } \\
\text { Die Aufzeichnungen sind mindestens fünf Jahre ab dem Zeitpunkt der } \\
\text { Erteilung aufzubewahren. }\end{array}$ \\
\hline Anlageberatung & $\begin{array}{l}\text { Anlageberatung ist die Abgabe von persönlichen Empfehlungen an } \\
\text { Kunden, die sich auf Geschäfte mit bestimmten Finanzinstrumenten } \\
\text { beziehen, sofern die Empfehlung auf eine Prüfung der persönlichen } \\
\text { Umstände des Anlegers gestützt oder als für inn geeignet dargestellt } \\
\text { wird. } \\
\text { Vor einer Anlageberatung ist der Kunde darüber zu informieren, ob } \\
\text { - die Anlageberatung als unabhängige Honorar-Anlageberatung er- } \\
\text { bracht wird oder nicht. Kreditinstitute erbringen die Anlageberatung } \\
\text { i. d. R. nicht als unabhängige Honorar-Anlageberatung. Sie stellen } \\
\text { dem Kunden kein zeitabhängiges Honorar für die Anlageberatung in } \\
\text { Rechnung, sondern berechnen Provisionen und erhalten oft Zuwen- } \\
\text { dungen von Vertriebspartnern. } \\
\text { - Sich die Anlageberatung auf eine umfangreiche Analyse verschie- } \\
\text { dener Finanzinstrumente von mehreren Emittenten stützt oder auf } \\
\text { eine eher beschränkte Auswahl bezieht. } \\
\text { - Der Wertpapierdienstleister dem Kunden regelmäßig eine Beurtei- } \\
\text { lung der Geeignetheit der empfohlenen Finanzinstrumente zur Ver- } \\
\text { fügung stellt. }\end{array}$ \\
\hline
\end{tabular}




\begin{tabular}{|c|c|}
\hline $\begin{array}{l}\text { Ablauf einer Anla- } \\
\text { geberatung }\end{array}$ & $\begin{array}{l}\text { Eine Anlageberatung vollzieht sich in folgenden Stufen: } \\
\text { - Einholung der erforderlichen Kundeninformationen } \\
\text { - Analyse der Kundendaten und Ermittlung geeigneter Finanzinstru- } \\
\text { mente } \\
\text { - Information des Kunden über alle wesentlichen Aspekte der Geldan- } \\
\text { lage } \\
\text { - Vertragsabschluss } \\
\text { Die geführten Beratungsgespräche müssen aufgezeichnet und für } \\
\text { mindestens fünf Jahre gespeichert werden. Der Kunde ist vorab über } \\
\text { die Aufzeichnung des Gesprächs zu informieren. Wenn der Kunde der } \\
\text { Aufzeichnung widerspricht, darf die Bank keine Wertpapierdienstleis- } \\
\text { tungen erbringen. }\end{array}$ \\
\hline $\begin{array}{l}\text { Schadensersatz } \\
\text { bei Falschberatung }\end{array}$ & $\begin{array}{l}\text { Bei einer fehlerhaften Beratung hat der Kunde einen Anspruch auf } \\
\text { Schadensersatz. Im Streitfall ist die Geeignetheitserklärung ein wichti- } \\
\text { ges Beweismittel und sollte deshalb sorgfältig ausgefüllt werden. Es ist } \\
\text { üblich, dass der Berater am Schluss der Beratung noch einmal mit } \\
\text { dem Kunden die Geeignetheitserklärung durchgeht und sich die Rich- } \\
\text { tigkeit der Dokumentation vom Kunden unterzeichnen lässt. Scha- } \\
\text { densersatzansprüche verjähren nach drei Jahren. }\end{array}$ \\
\hline $\begin{array}{l}\text { Regeln für Verhal- } \\
\text { tensweisen bei } \\
\text { Anlegern }\end{array}$ & $\begin{array}{l}\text { Bei der Informationsflut, die über die Anleger tagtäglich hereinbricht, } \\
\text { bereitet es vielen Anlegern Schwierigkeiten, neue Nachrichten rational } \\
\text { zu analysieren und zu bewerten. Soll man abwarten oder handeln } \\
\text { lautet für viele Privatanleger oft die entscheidende Frage. Aus prakti- } \\
\text { schen Gründen wird oftmals zunächst abgewartet und erst dann rea- } \\
\text { giert, wenn sich eine Neuigkeit bereits stark ausgewirkt hat und Anle- } \\
\text { ger wie z.B. im Fall eines Aktienkursabsturzes zum Handeln zwingt. } \\
\text { Oder der Anleger reagiert nur deshalb, weil die Nachricht durch die } \\
\text { Medien besonders stark verbreitet wird. In beiden Fällen kommt die } \\
\text { Reaktion des Anlegers erst, wenn viele andere Marktteilnehmer bereits } \\
\text { gehandelt haben. Dies ist für den Anleger nachteilig. Denn man kauft } \\
\text { oder verkauft immer zu einem Kurs, der die neuen Informationen be- } \\
\text { reits verarbeitet hat oder vielleicht sogar bereits überreagiert hat. Se- } \\
\text { lektive Wahrnehmung führt deshalb zu einer unbewussten Verzerrung } \\
\text { der Wirklichkeit. } \\
\text { Zudem nimmt der Anleger häufig nur Nachrichten wahr, die mit seiner } \\
\text { Grundeinstellung zu einer Aktie vereinbar sind. Ist der Anleger einem } \\
\text { Unternehmen gegenüber positiv gestimmt, so wird er mit Freude und } \\
\text { Genugtuung auf gute Nachrichten reagieren und sich selbst bestätigt } \\
\text { fühlen, getreu dem Motto: „Ich hab's ja gewusst!“ Informationen, die } \\
\text { auf negative Entwicklungen hindeuten, werden dagegen einfach über- } \\
\text { lesen oder relativiert. Mit diesem Verhalten der selektiven Wahrneh- } \\
\text { mung rechtfertigt der Anleger unbewusst seine Entscheidung z.B. eine } \\
\text { bestimmte Aktie gekauft zu haben. } \\
\text { Ein Börsenexperte bringt es auf den Punkt: „Viele Anleger verdienen } \\
\text { an der Börse kein Geld, weil sie Gefangene ihrer selektiven Wahr- } \\
\text { nehmung sind.“ } \\
\text { Selbst wenn schlechte Nachrichten den Kurs einer Aktie einbrechen }\end{array}$ \\
\hline
\end{tabular}




\begin{abstract}
lassen, klammern sich viele Anleger z.B. an die optimistischen Aussagen des Vorstands. Dabei ist es sein Job, sich und sein Unternehmen gut zu verkaufen und schlechte Entwicklungen herunterzuspielen um sich „nichts zu verbauen“ und nicht zu Letzt auch um seinen Job zu behalten. Unabhängig davon ob sich z.B. Vorwürfe aus den Medien als wahr oder falsch erweisen: Man wird kaum einen Vorstand finden, der die Zukunft seines Unternehmens als düster bezeichnet oder Betrugsvorwürfe nicht abwehrt. Das ist nur dann nicht mehr möglich, wenn Polizeiermittlungen das Gegenteil beweisen oder ein Unternehmen gerade Insolvenz angemeldet hat. Auch in Diskussionsforen und Blogs im Internet wird jede Meinung vertreten sein. Sucht man eine bestätigende positive Einschätzung, so wird sich diese im Internet sehr leicht finden lassen. Genau wie Pessimisten natürlich auch ihre Bestätigung finden. Es gilt wie immer: Nur die Börse hat recht - und die kann ihre Meinung auch ändern.

Um sich eine Meinung zu bilden, sollte der Anleger daher bewusst auf charttechnische Entwicklungen, Signale und Bestätigungen achten. Das ist auch für Neuanleger machbar.

Ist der Anleger durch einen Bericht oder eine Unternehmensmeldung skeptisch geworden, so ist es zweckmäßig, auf eine mögliche charttechnische Schwäche zu achten. Das könnte z.B. das Unterschreiten einer Unterstützungslinie sein, d.h. wenn ein Kursbereich unterschritten wird, welcher der Aktie zuvor mehrmals Rückhalt geboten hatte. Gibt es hingegen bei einer vermeintlich negativen Meldung nur einen kurzen Rücksetzer von dem sich die Aktie rasch erholt, so war die Meldung offensichtlich falscher Alarm. Gleiches gilt dann, wenn eine Aktie z.B. nach positiven Quartalszahlen kurz stark anspringt und dann deutlich ins Minus dreht. Auch dann sollte man hinterfragen ob die weiteren Aussichten für die Aktie wirklich so gut sind wie dargestellt. Informationen können auch „Ruination“ bedeuten insbesondere dann, wenn der Anleger auf jede Kleinigkeit reagiert. Eine alte Börsenwahrheit lautet: „Viel Hin und Her macht die Taschen leer“.
\end{abstract}

\title{
12. Rating
}

\begin{tabular}{|l|l|}
\hline $\begin{array}{l}\text { Allgemeine } \\
\text { Kennzeich- } \\
\text { nung }\end{array}$ & $\begin{array}{l}\text { Es handelt sich um eine standardisierte Bonitätsbeurteilung von handelbaren } \\
\text { Finanzpapieren (z. B. Anleihen oder Geldmarktpapiere, die Forderungsrechte } \\
\text { verbriefen) und ihren Emittenten durch Kreditbewertungsagenturen (Ratinga- } \\
\text { genturen). Dabei geht es um eine bonitätsmäßige Einstufung von Kreditneh- } \\
\text { mern und Anleiheschuldnern (Credit Rating, Unternehmensrating) nach ein- } \\
\text { heitlichen, konsistenten Verfahren. Das Rating gibt internationalen Investoren } \\
\text { gültige Maßstäbe als Grundlagen für Investitionsentscheidungen an die Hand. } \\
\text { Damit werden Transparenz und Effizienz des Kapitalmarktes gesteigert. }\end{array}$ \\
\hline Funktionen & $\begin{array}{l}\text { Das Rating soll einem Käufer langfristiger Anleihen (Bonds) oder kurzfristiger } \\
\text { Geldmarktpapiere (Commercial Papers, Certificates of Deposit) den Grad des } \\
\text { Risikos eines Investments verdeutlichen. Die Rating-Agenturen verwenden für } \\
\text { die Einstufung von Anleihen andere Symbole als für die Einstufung von Geld- } \\
\text { marktpapieren und ähnlichen kurzfristigen Verbindlichkeiten, z. B. Banker's }\end{array}$ \\
\hline
\end{tabular}




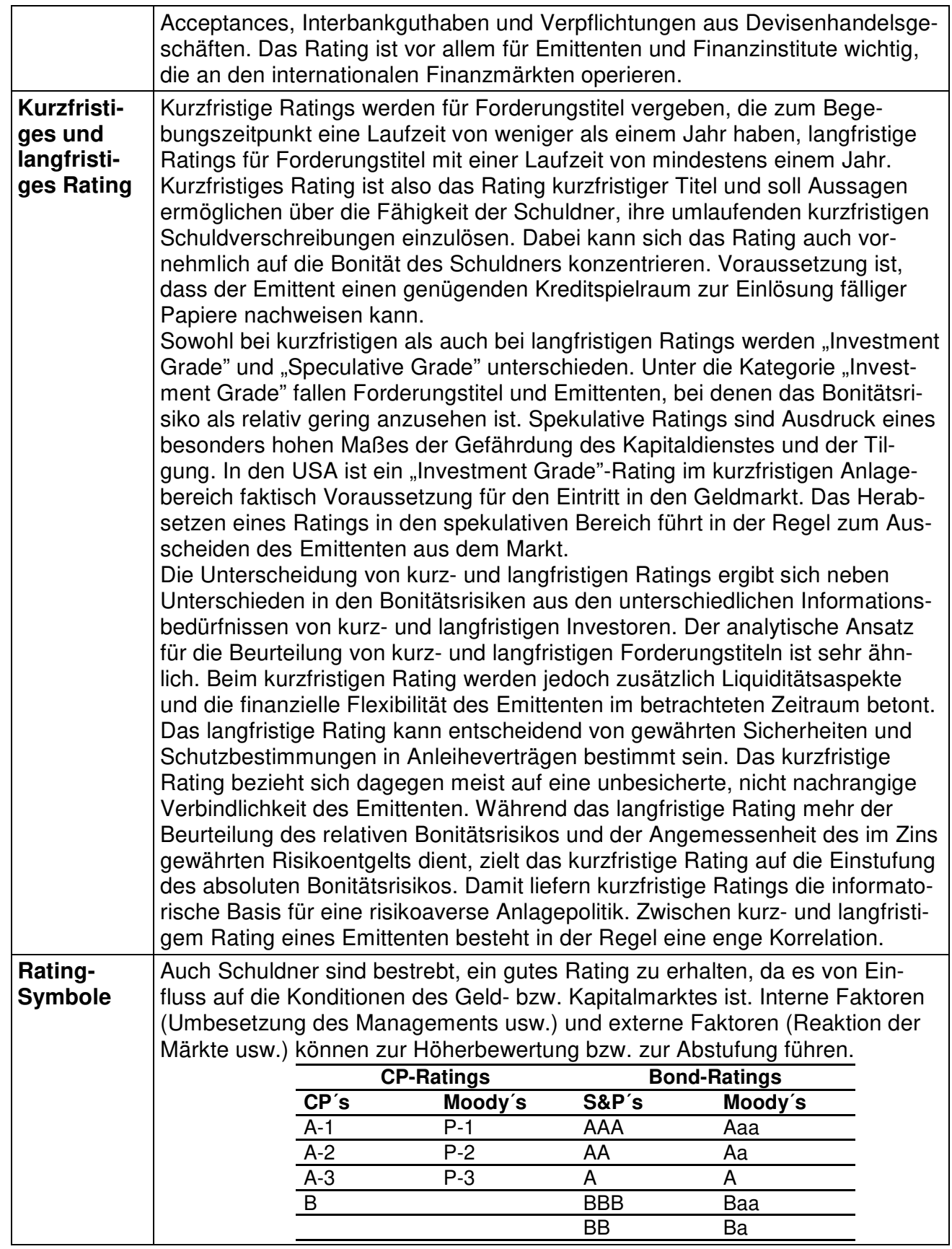




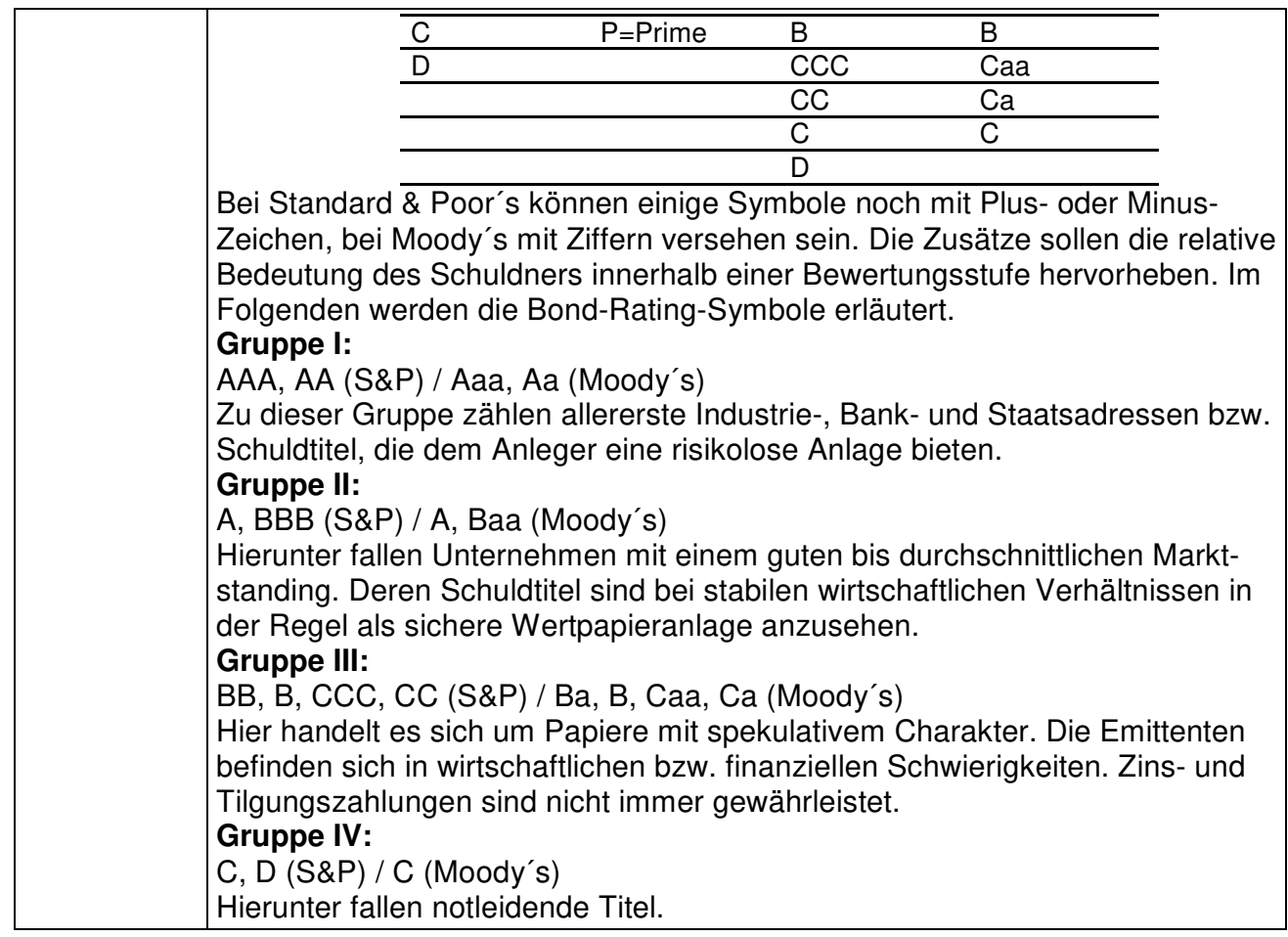

